\title{
A MIXED METHODS EXPLORATORY STUDY OF DIGITAL LITERACIES IN HIGHER EDUCATION
}

\section{by}

Susan K. Shannon

\author{
A dissertation \\ submitted in partial fulfillment \\ of the requirements for the degree of \\ Doctor of Education in Educational Technology \\ Boise State University
}

December 2017 
(C) 2017

Susan K. Shannon

ALL RIGHTS RESERVED 


\title{
BOISE STATE UNIVERSITY GRADUATE COLLEGE
}

\section{DEFENSE COMMITTEE AND FINAL READING APPROVALS}

\author{
of the dissertation submitted by
}

\author{
Susan K. Shannon
}

Dissertation Title: A Mixed Methods Exploratory Study of Digital Literacies in Higher Education

Date of Final Oral Examination: $\quad 27$ September 2017

The following individuals read and discussed the dissertation submitted by student Susan K. Shannon, and they evaluated her presentation and response to questions during the final oral examination. They found that the student passed the final oral examination.

Chareen Lee Snelson, Ed.D. Chair, Supervisory Committee

Dazhi Yang, Ph.D. Member, Supervisory Committee

Maude S. Yacapsin, Ed.D. Member, Supervisory Committee

Chris Haskell, Ed.D. Member, Supervisory Committee

The final reading approval of the dissertation was granted by Chareen Lee Snelson, Ed.D, Chair of the Supervisory Committee. The dissertation was approved by the Graduate College. 


\section{DEDICATION}

In dedication to my husband, Brian, for your unwavering and endless support through this journey. 


\section{ACKNOWLEDGEMENTS}

I would like to acknowledge Chareen Snelson, chair of my supervisory committee, for her time, encouragement, and straight forward guidance. She was always timely with her support as she led me through this study. From the beginning, she grounded me, driving me to better focus my proposal. She helped me conceptualize, write, and navigate all stages and processes involved. Dr. Snelson also helped me form a strong committee. I am fortunate to have had such a wonderful Chair!

I would also like to acknowledge my committee members, Dazhi Yang, Maude Yacapsin, and Chris Haskell for their interest in the study. They offered knowledgeable insights for ways to improve my proposal, guided me through revisions to the screening and cleaning processes, and were with me for a final review of the dissertation.

I will always be grateful to Bill Strausbaugh for pushing me to pursue my doctoral degree. His confidence in me was ever present. He periodically checked in with me over the last nine years asking me how I was doing, and assuring me I could do it with phrases like, "you got this" and "you can do it!" His encouragement kept me going.

Additional members of the Messiah College community I would like to thank are Robin Lauermann, Assistant Dean of General Education and Common Learning and Advising, and James LaGrand, Chair of the CCC Steering Committee. They supported my efforts to get approval from the CCC Steering Committee to engage with all Created and Called for Community (CCC) courses in an attempt to recruit first year students, the target population for this study. With their support I was able to engage with faculty 
members and present recruitment materials in class and within the learning management course site.

In addition, this study would not exist without the support from Gila Kurtz and Yehuda Peled. They allowed me to use their digital literacy framework and assessment instrument in my research. I cannot thank them enough. Gila's continued interest and encouragement was always reassuring and encouraging. Thank you Gila and Yehuda!

Finally, I would like to acknowledge my Mom and Dad for supporting and encouraging me to go, do, and be whatever I wanted. 


\begin{abstract}
This exploratory study examines the assessment of digital literacy in higher education using Kurtz and Peled's (2016) digital literacy framework and assessment instrument. As information and communications technologies have grown over the last part of the $20^{\text {th }}$ century and the first part of the $21^{\text {st }}$ century, so has the socio-cultural environment (Kurtz \& Peled, 2016; Roxin \& Rusitoru, 2016). Literacy has grown from a simple concept involving the ability to read and write to a complex concept that includes many more competencies. A review of the literature shows the emergence of many new literacies (Šorgo, Bartol, Dolničar, \& Podgornik, 2016). While much is written about new literacies in general, little is written specifically on the assessment of digital literacy (Ainley, Schulz, \& Fraillon, 2016; Literat, 2014; \& Mills, 2010). At the same time, institutions of higher education are attempting to align their educational objectives with the ever evolving digital landscape. The two questions driving this research are:

(1) Based on Kurtz and Peled's (2016) digital learning domains, how digitally literate are Messiah College's first year undergraduate students? and

(2) How do supporting digital files and text reflections and explanations extend Kurtz and Peled's (2016) instrument assessing digital literacy?

Using an embedded mixed methods approach, participants of this study are Messiah College's first year students who completed a survey instrument with quantitative and qualitative data collection components. Analysis included descriptive statistics calculations of the quantitative data, and qualitative content analysis (QCA) of the
\end{abstract}


qualitative data. Results indicated Messiah College's first year undergraduate students in the 2016-2017 academic year were digitally literate with a majority of students responding positively to six of seven of Kurtz and Peled's (2016) digital learning domains (DLDs). One of the seven DLDs, information management, received an unacceptable reliability score of $\alpha=0.53$. The qualitative data: (a) added a layer of supporting evidence for all but one of the DLDs, information validation; (b) demonstrated digital literacies complexity; and (c) presented an additional relevant category, emotion; extending Kurtz and Peled's quantitative assessment. A synthesis of the quantitative and qualitative components extended the independent results providing a detailed assessment of first year students' digital literacy. This detailed assessment supported a prioritization of the DLDs informing Messiah College of areas where additional programing may help support and improve students' digital literacies. 


\section{TABLE OF CONTENTS}

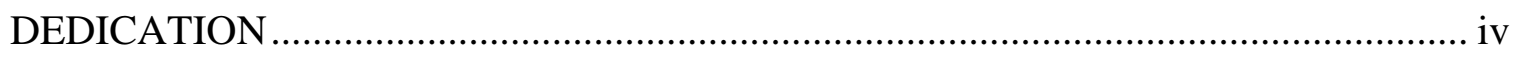

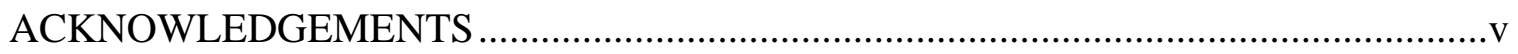

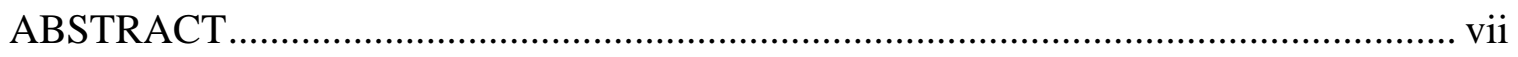

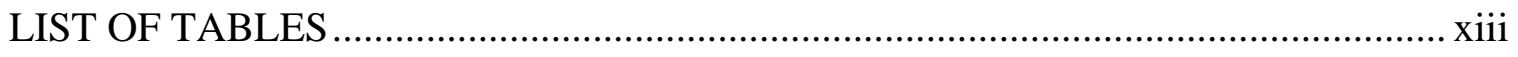

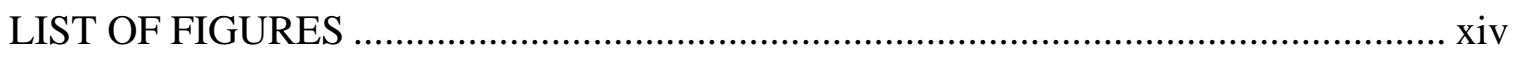

LIST OF ABBREVIATIONS ............................................................................

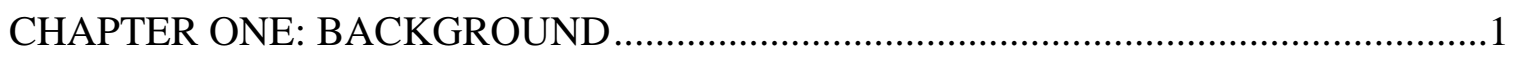

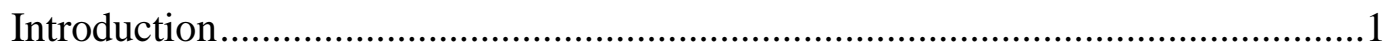

Purpose

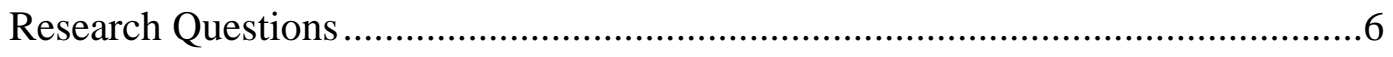

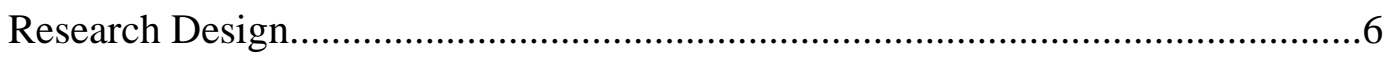

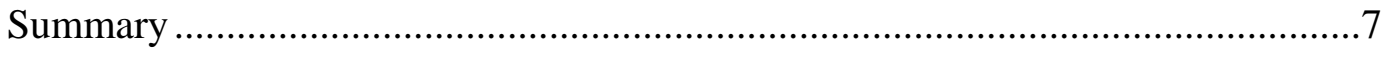

CHAPTER TWO: LITERATURE REVIEW …………….......................................

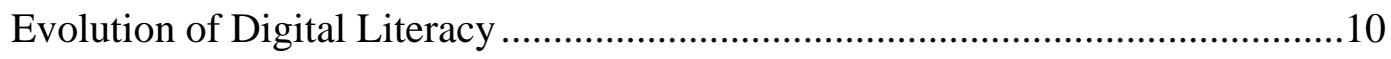

Information and Communications Technologies (ICTs) ............................10

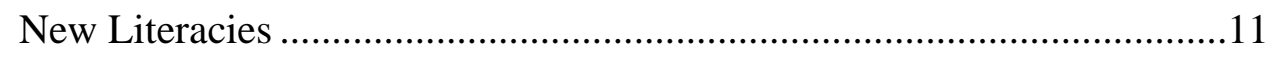

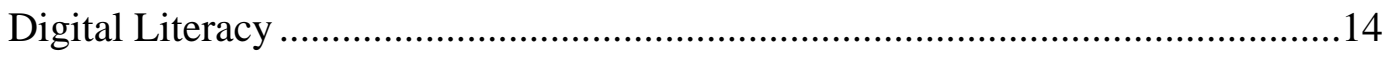

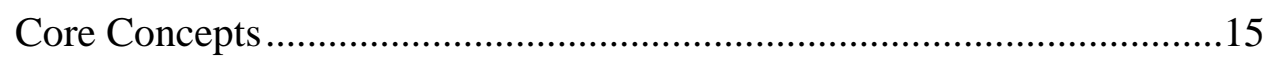

A Digital Literacy Framework................................................................17 
Assessment Instruments

Information Literacy (IL) Instruments ...............................................24

Media Literacy Instrument........................................................26

Digital Literacy Instrument............................................................22

Summary of Assessment Instruments .............................................28

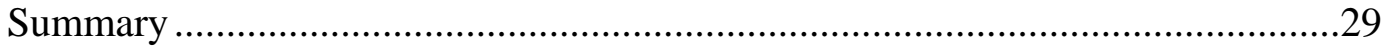

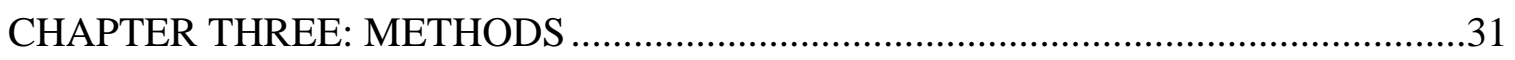

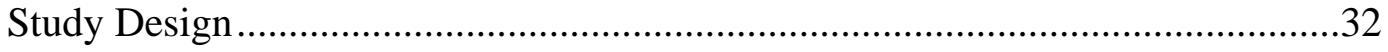

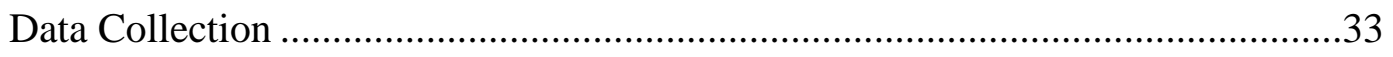

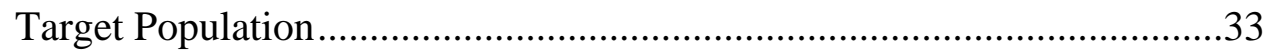

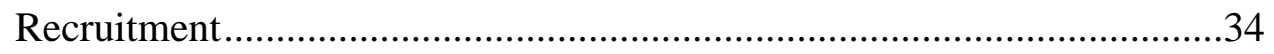

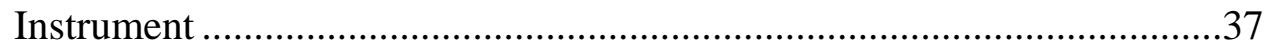

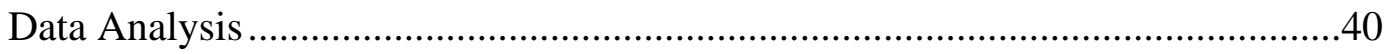

Screening and Cleaning Quantitative Date ..........................................4

Quantitative Analysis...................................................................44

Qualitative Analysis................................................................45

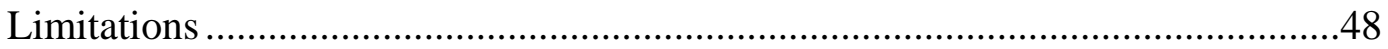

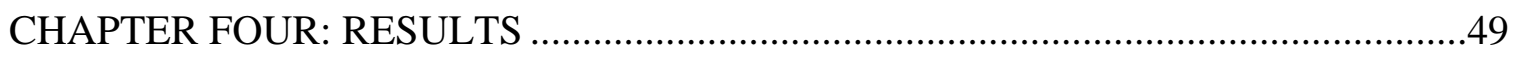

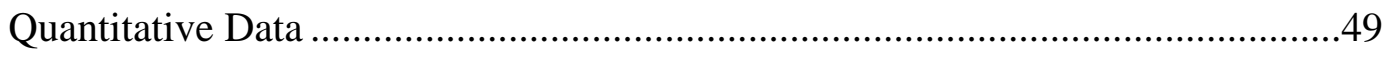

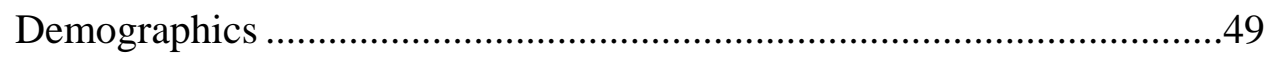

Digital Learning Domains’ Descriptive Statistics ................................50

Quantitative Summary ..............................................................65

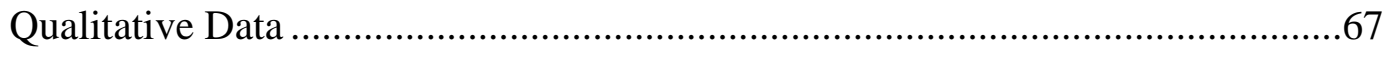


Data Driven Analysis .............................................................................

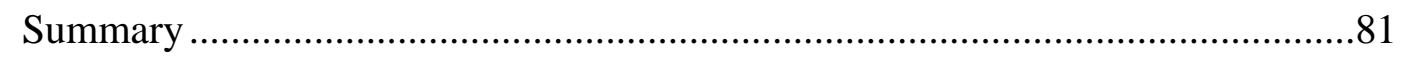

CHAPTER FIVE: SYNTHESIS, INTERPRETATIONS, AND FINAL THOUGHTS...83

Synthesis of Quantitative and Qualitative Components .......................................84

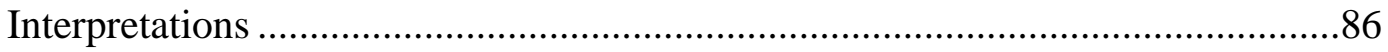

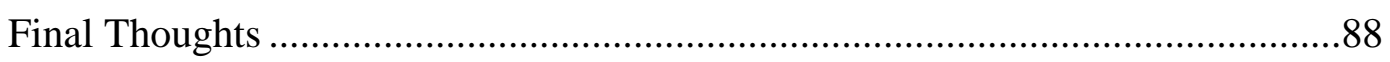

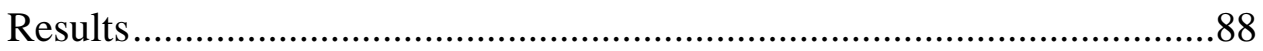

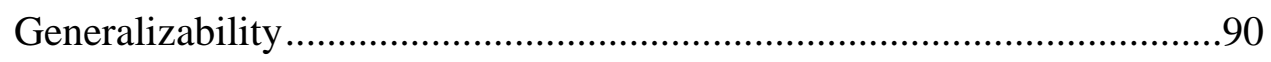

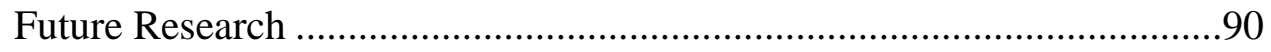

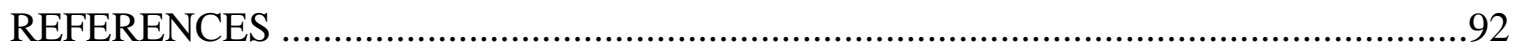

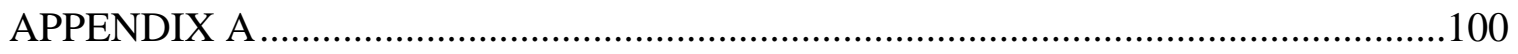

Messiah College Strategic Plan 2016-2020 ............................................................101

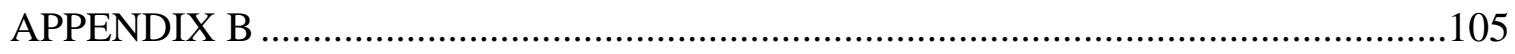

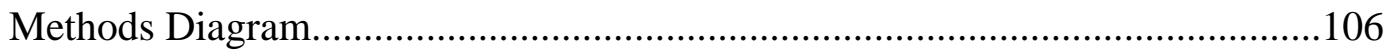

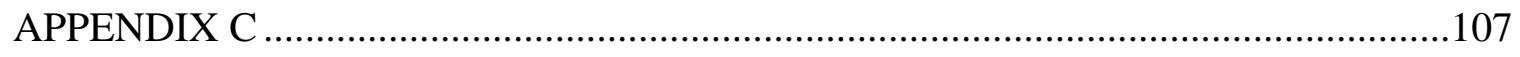

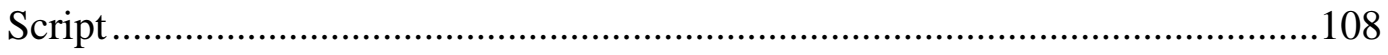

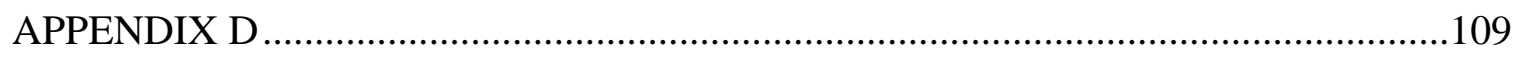

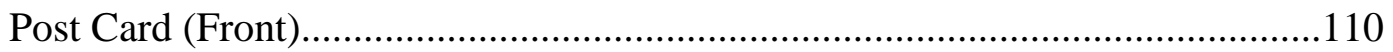

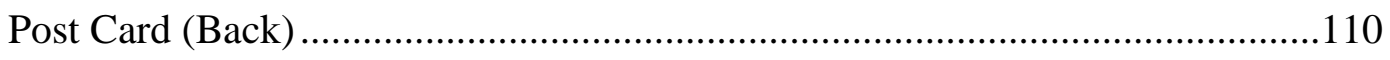

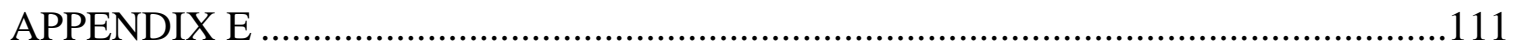

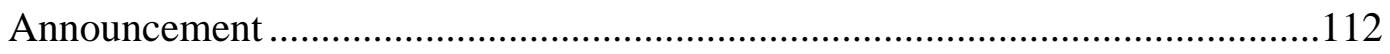

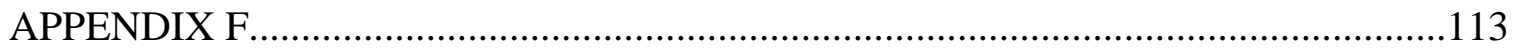




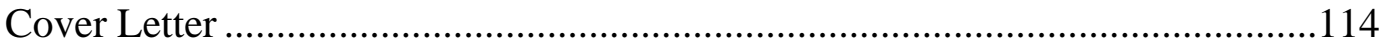

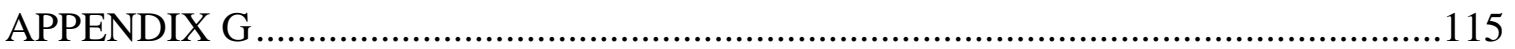

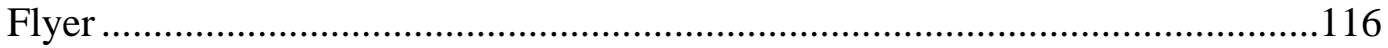

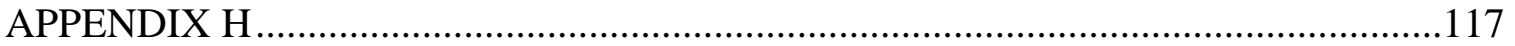

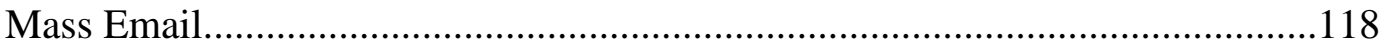

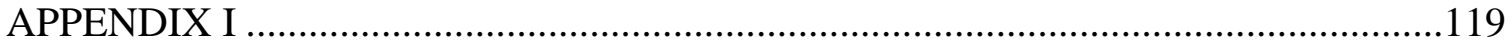

Organized Packet of Materials Delivered to Faculty ........................................120

Sample Email to Faculty Members ..............................................................120

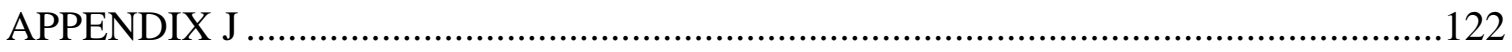

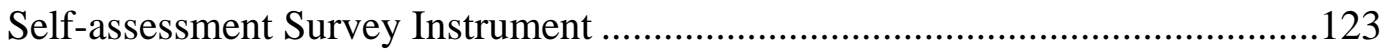

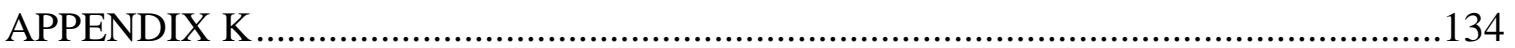

Descriptive Statistics for Page Time Submissions for Each DLD.....................135

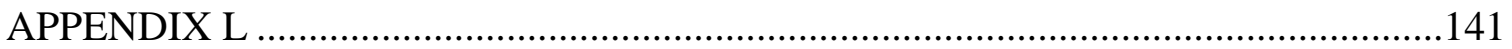

Boxplots of all Performance Statements for each DLD..................................142 


\section{LIST OF TABLES}

Table 2.1 A Comparison of Ideas Related to Information and Media Literacy........ 13

Table 2.2 Instruments Assessing New Literacies ...................................................... 29

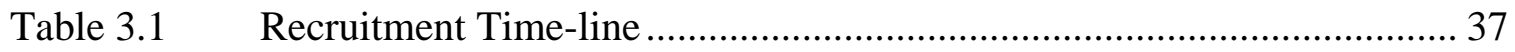

Table 3.2 Digital Learning Domains with Corresponding Performance Statements 38

Table 3.3 Results of Page Submission Time for each DLD ................................ 42

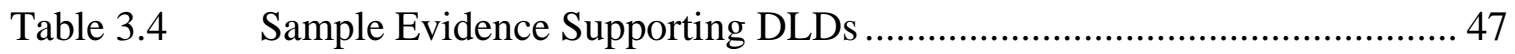

Table 4.1 Descriptive Statistics for each PS in Information Research and Retrieval53

Table 4.2 Descriptive Statistics for each PS for Information Validation................. 55

Table 4.3 Descriptive Statistics for each PS for Information Management............. 57

Table 4.4 Descriptive Statistics for each PS for Processing and Presentation of Information .............................................................................. 59

Table 4.5 Descriptive Statistics for each PS for Team-based Learning in Digital

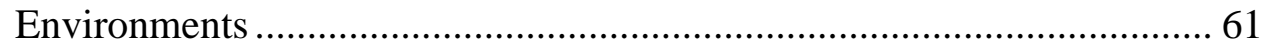

Table 4.6 Descriptive Statistics for each PS for Awareness of Digital Integrity...... 63

Table 4.7 Descriptive Statistics for each PS for Social Responsibility ................... 65

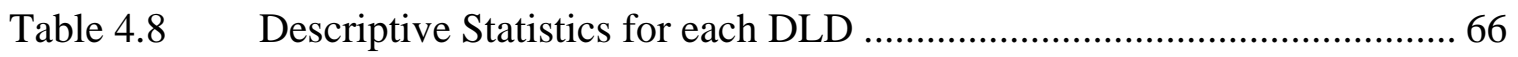

Table 5.1 DLDs Synthesized Assessment Prioritized......................................... 88

Descriptive Statistics of Response Times (sec.) for Each DLD ................................ 135 


\section{LIST OF FIGURES}

Figure 1. DL Competencies: Categorized by Kurtz and Peled's 7 DLDs............... 22

Figure 2. Diagram of study's design ............................................................... 33

Figure 3. Visual highlights seventeen cases with page submission times below 2 sec./PS threshold. Times are in seconds, and ' $x$ ' indicates an unwanted response to at least one self-report indices

Figure 4. Graphical representation of the proportions of categories in sample data for gender, age, and racial/ethnic identity.

Figure 5. Stacked bar chart combining scaled responses for all 12 performance statements to information research and retrieval ................................. 51

Figure 6. Stacked bar chart combining scaled responses for all five performance statements to information validation.

Figure 7. Stacked bar chart combining scaled responses for all three performance statements to information management

Figure 8. Stacked bar chart combining scaled responses for all eight performance statements to processing and presentation of information.

Figure 9. Stacked bar chart combining scaled responses for all eight performance statements to team-based learning in digital environments .

Figure 10. Stacked bar chart combining scaled responses for all 15 performance statements to awareness of digital integrity.....

Figure 11. Stacked bar chart combining scaled responses for all three performance statements to social responsibility

Figure 12. A graphical representation of negative, neutral, and positive responses to

DLDs. Note information management ( $\square=0.53$ ).

Figure 13. A screenshot of nested nodes within NVivo for the Information 
Figure 14. Screenshots of folder structure from one respondent for the Information Management DLD

Figure 15. A screenshot of a public infographic developed as a group project for a class. 72

Figure 16. A screenshot of a video developed as a component of a larger group PowerPoint presentation 72

Figure 17. A screenshot of a public website developed with HTML and CSS for a

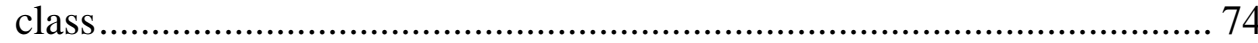

Figure 18. A screenshot of one sheet in an Excel project used to display information 75

Figure 19. Cases with properties overlapping multiple DLDs. Circle size proportional to number of cases ................................................................................ 78

Figure 20. A screenshot of nested nodes within NVivo for emotion .......................... 79

Figure 21. Representation of emotions within respective DLD ................................. 81

Figure 22. Summary of combined quantitative and qualitative results for each DLD. Positive response equals the combined percent for Somewhat-agree and Strongly-agree responses. Emotions are positive except for fear 86

Box plots for page submission times in seconds for 7 DLDs. The most extreme value on the high end for the first, sixth, and seventh DLD were eliminated to produce a clearer presentation of results on low end. 140 


\section{LIST OF ABBREVIATIONS}

ACRL

BSU

$\mathrm{CCC}$

CWEOs

DLDs

GC

ICTs

IRB

NML

QCA

TDC

UNESCO
Association of College and Research Libraries

Boise State University

Created and Called for Community

College Wide Educational Objectives

Digital Learning Domains

Graduate College

Information and Communications Technologies

Institutional Review Board

New Media Literacy

Qualitative Content Analysis

Thesis and Dissertation Coordinator

United Nations Educational, Scientific and Cultural Organization 


\section{CHAPTER ONE: BACKGROUND}

Literacy has expanded from reading and writing print based materials to a fluid concept that includes: (a) active participation in a digital society (Hobbs, 2010; \& Literat, 2014); (b) an understanding of legal, social and ethical issues in digital environments (Kurtz \& Peled, 2016); and (c) social responsibility in digital environments (Kurtz \& Peled, 2016). Digital literacy is just one of the many new literacies discussed in educational literature in the $21^{\text {st }}$ century. Changes in information and communications technologies (ICTs) and the digital landscape have driven the changes in how literacy is defined. Educational institutions must align their goals and objectives with the changing digital landscape. Relevant, guiding principles provide a sound framework by which educators are better able to craft meaningful activities for students growing up in and living in a digital media participatory culture (Johnson et al., 2016). This research explored the digital literacy proficiency of first year undergraduate students at Messiah College, to provide baseline data to the College to support efforts to revise guiding educational principles that are, in part, outdated and irrelevant to the current environment.

\section{Introduction}

Messiah College, founded in 1909, is a private Christian College located in Mechanicsburg, Pennsylvania with 2,788 undergraduate students and 517 graduate students offering over 80 undergraduate majors and 19 graduate-level degree and certificate programs (Messiah College, 2016). The College's Strategic Plan for 20162020 includes language that supports a review of the undergraduate College Wide 
Educational Objectives (CWEOs). Specifically, the Plan states, "Messiah College will prepare educators to cultivate appropriate teaching and learning outcomes that meet the needs of a changing student body" (see Appendix A, Theme 3). This goal includes an action step to "review and revise the College Wide Educational Objectives in light of the changing environment with attention to digital proficiency and intercultural competencies" (Appendix A, Theme 3, Goal 3). The inclusion of digital proficiency competencies in the strategic plan signifies these competencies as a high priority for the College to address in coming years. Meshing mission statements and strategic plans with the socio-cultural environment, and engaging curricula with digital literacies has become "one of the most pressing concerns of higher education today" (emrecaglayan, 2016, Third para.). Johnson et al. (2016) state, "Through the creation of frameworks, higher education leaders are helping students and faculty learn skills for working in a digital society" (p. 25).

A closer look at contemporary society sheds light on why Messiah College chose to prioritize a review of the CWEO's with attention given to digital proficiency. Societies are fluid (Martin, 2006). They evolve by, with, and for the citizens that participate in them. Dewey (1916) referred to a society as "an organic union of individuals" whereby citizens must be ready, able and willing to utilize the tools available to them to "act economically and efficiently" (Article I). An accelerated use of information and communications technologies (ICTs) in society and in education (Greenberg \& Zanetis, 2012; Yousef, Chatti, \& Schroeder, 2014) has helped create a participatory culture mindset increasing collaboration and knowledge sharing beyond local communities (Jenkins, Clinton, Purushotma, Robinson, \& Weigel, 2006). Such active participation in a 
contemporary global society with support from ICTs can increase common values held within a group. However, as Dewey (1916) noted, "social return [must] be demanded from all and ... opportunity for development of distinctive capacities [must] be afforded all" (p. 142). It is therefore, important that education supports student engagement in this participatory culture through the ICTs available in this contemporary digital age.

Literacy, a necessary competency for active participation in society, has expanded from reading and writing of printed text to a skillset that includes many more higher order outcomes. Many terms have been associated with new literacies, including information, media and digital literacy, and these literacies overlap in many ways (Šorgo, et al., 2016).

Information literacy evolved from a need that supports the abilities to (a) recognize a need for information, (b) access, evaluate and use information, and (c) understanding social connections among sources. These skillsets grew from needs associated with the use of library resources (Association of College and Research Libraries, 2016; Chartered Institute of Library and Information Professionals, 2013).

Media literacy focuses on the medium, or tool, used to create and communicate a message (Jolls \& Wilson, 2014). Like information literacy, accessing and evaluating information is valued (Martens, 2010; Rogow, 2011) as is collaboration in a participatory culture (Jenkins et al., 2006). The National Association for Media Literacy Education (2007) supports developing skills that include: (a) inquiry, (b) self-expression, and (c) critical thinking.

Digital literacies, the new literacy that is the focus of this research, includes multiple overlapping competencies similar to information and media literacy. Goodfellow 
(2011) referenced digital literacy as a framework with sociocultural underpinnings, and Tan (2013) sees it as a skillset that includes the act of establishing the authority of material. Kurtz and Peled (2016) make an important distinction for digital literacies, arguing these literacies "are valuable only insofar as they are capable of evolution in light of changing technical, social, economic, cultural, and educational contexts" (p. 147).

While much is written about the need for education to focus on skillsets and competencies associated with these ever evolving new literacies, limited assessment instruments exist (Boh Podgornik, Dolnicar, Šorgo, \& Tomaž, 2015; Kurtz \& Peled, 2016; Literat, 2014; Mills, 2010; Walsh, 2010). Most of the limited emerging instruments consist of self-reports created around different conceptual frameworks. Literat's (2014) instrument on new media literacy (NML) measures individuals" "NML skills, media exposure, digital participation, and civic engagement," (p. 15) and takes into account both online and offline student behaviors.

Kurtz and Peled's (2016) instrument measures students' digital literacies within seven digital learning domains (DLDs) identified as: (a) information research and retrieval, (b) information validation, (c) information management, (d) processing and presentation of information, (e) team-based learning in digital environments, (f) awareness of digital integrity, and (g) social responsibility. Their DLDs, were developed based on a theoretical conceptual framework, and reviewed by "six expert researchers in the educational technology field and seven graduate students of ICT learning at the College of Academic Studies in Israel” (p. 148). 


\section{Purpose}

Society's improving ICTs and growing participatory culture provide the general social context for this research within a higher education institution. Revising the outdated policies and frameworks that guide processes within educational institutions is necessary for maintaining relevance in changing times. From accreditation practices to teaching and learning practices, change is a common theme as Ewell (2015) explains:

As demonstrated by the past ten years, change can happen quickly and become transformational before those who experience it become aware of the fact. After all, tools that are now taken for granted, ranging from Google to GoToMeeting, were only created in the last decade. This makes it all the more imperative that higher education policy leaders quickly but carefully identify the implications behind current trends and to remake quality assurance structures and practices more suited to emerging realities. (p. 9)

The purpose of this research is to support Messiah College in its attempt to revise its College Wide Educational Objectives (CWEOs) with a focus on digital proficiency. The use of an existing scale to measure students' digital literacy proficiency is a first step toward achieving this goal. Use of this scale will guide the College toward determining an acceptable digital proficiency, or level of mastery of the digital age, providing a target the College may strive to achieve.

In addition, by measuring first year students' digital literacy proficiency using Kurtz and Peled's (2016) digital literacy assessment instrument, Messiah College will gain insight on student competencies related to seven DLDs. Assessing the strengths and weaknesses of these students as they relate to each DLD will help identify areas in which incoming students require the most support. This baseline data will be valuable to the College as it works toward building educational outcomes that are in sync with the digital and socio-cultural landscape. Relevant CWEOs provide a supporting framework for 
educators as they develop program and course objectives, and design student learning activities to improve student learning.

Finally, this exploratory embedded mixed-methods study expands the limited research currently available on the assessment of digital literacies. Adding a qualitative component to Kurtz and Peled's (2016) quantitative self-assessment survey instrument provides a descriptive and interpretive analysis that is not possible with quantitative data alone (Creswell \& Plano Clark, 2011). Meaning constructed from these data supports the work aimed toward achieving Messiah College's goal of improving teaching and learning outcomes with a focus on digital proficiency, and increases general knowledge about the assessment of digital literacies.

\section{Research Questions}

This research describes the digital literacy proficiency of students from data collected through a self-assessment instrument, and explores students' digital artifacts and open-ended text reflections and explanations demonstrating their digital literacies. The following questions will guide this research:

(1) Based on Kurtz and Peled's (2016) digital learning domains, how digitally literate are Messiah College's first year undergraduate students? and

(2) How do supporting digital files and text reflections and explanations extend Kurtz and Peled's (2016) instrument assessing digital literacy?

\section{Research Design}

This study follows a mixed-method design, using a survey instrument to collect quantitative and qualitative data from volunteer participants (Creswell \& Plano Clark, 2011). First year students above the age of 18 represent the target population. Participants 
rated themselves on a 5 level Likert-type scale on 54 performance statements and provided a digital file that they believe demonstrates their digital literacy proficiency. In addition, students included reflective statements and explanations as additional qualitative data. Analysis included descriptive statistics (Hatcher, 2013) and qualitative content analysis (Saldaña, 2016; Schreier, 2012).

\section{Summary}

Information and communications technologies (ICTs) are transforming society (Greenberg \& Zanetis, 2012; Yousef et al., 2014). Changing socio-cultural environments are influencing educational institutions, increasing the need for transforming strategic plans, guiding institutional documentation, and educational objectives to maintain practices that are relevant to society (Ewell, 2015). Results from this embedded mixed methods exploratory study will inform members of the Messiah College task force shepherding the Strategic Plan toward completion, providing a better understanding of digital literacies and how first year students assess themselves in seven digital learning domains (DLDs), supporting the alignment of educational objectives to student needs.

In addition, this research extends what knowledge currently exists in the educational community on the assessment of digital literacies. There is a need for further research on new literacies and the assessment of new literacies specifically (Boh Podgornik et al., 2015; Kurtz \& Peled, 2016; Literat, 2014; Mills, 2010; Walsh, 2010). Emerging instruments described further in Chapter two are reported to be reliable. However, further testing and verification of instruments is required as these instruments are not yet verified through multiple studies. Specifically, there are few tools that can assess digital literacy, a literacy for the digital age (Gilster, 1997). While Kurtz and Peled 
(2016) developed a self-assessment instrument that is reported to be reliable, this instrument is in need of further evaluation. Using Kurtz and Peled's (2016) instrument this study supports Messiah College as it works toward improving the CWEOs with a focus on digital proficiency and extends knowledge on the assessment of digital literacies for the educational community.

Chapter two begins with a review of the literature associated with the growth of information and communications technologies (ICTs) over the last part of the $20^{\text {th }}$ century and first part of the $21^{\text {st }}$ century and the effects of the growth of ICTs on the sociocultural landscape leading to multiple new definitions for literacy. A review of digital literacy, specifically, follows. Chapter two concludes with a review of the studies assessing new literacies. 


\section{CHAPTER TWO: LITERATURE REVIEW}

This literature review begins with an historical account of the evolution of digital literacy. This historic account includes the growth of information and communications technologies (ICTs) and the expanding definition of literacy. A synthesis of the literature on new literacies, specifically digital literacy, follows. Many authors articulate the concepts they believe are integral to new literacies as skill sets or competencies. Kurtz and Peled's (2016) seven digital learning domains provide a framework for the synthesis of the many competencies discussed in the literature. Finally, a review of empirical studies involving assessment instruments developed to measure new literacies concludes this Chapter.

Digital literacy includes more than simply the ability to read and write with digital media. It includes awareness of rights, responsibilities, and etiquette required for ethical active participation within a given social context in a digital society (Hobbs, 2010; Janssen et al., 2013; Kurtz \& Peled, 2016; Park, 2016; Ribble, 2016; \& Roxin \& Rusitoru, 2016). Digital literacy highlights information access and the validation of information through critical thinking, analysis and evaluation (Gilster, 1997; Hobbs 2010; Janssen et al., 2013; Kurtz \& Peled, 2016; Rheingold, 2012; \& Ribble, 2016). In addition, having the ability to learn about and navigate the multiple systems and formats from which information is created and presented in this digital age is integral to digital literacy (Gilster, 1997; \& Janssen et al., 2013). Finally, digital literacy includes the ability to collaboratively and creatively produce new content in multiple forms and the ability to 
share new content with other members of society (Kurtz \& Peled, 2016; Mills 2010, Park, 2016; \& Roxin \& Rusitoru, 2016). This abstract literacy originated in the last part of the $20^{\text {th }}$ century alongside information and communications technologies (ICTs).

\section{Evolution of Digital Literacy}

Information and communications technologies (ICTs) have transformed socioeconomic and socio-cultural environments around the globe. Cultures and economies are in many ways defined by their use of ICTs (UNESCO, 2016). This section synthesizes the growth of ICTs and briefly describes emerging new literacies resulting from the evolving ICTs in society. This discussion on transforming ICTs in society and the expanding philosophies surrounding what it means to be literate provides a backdrop for a more thorough discussion on digital literacy, specifically, in the following section. Information and Communications Technologies (ICTs)

The acceleration of information and communications technologies (ICTs) over the last half of the $20^{\text {th }}$ century and initial decades in the $21^{\text {st }}$ century is facilitating a shift in nearly all socio-cultural elements around the globe (Jenkins et al., 2006). Beginning with commercial radio and television broadcasts in the early part of the $20^{\text {th }}$ century ICTs grew to include portable video cameras available to the individual consumer that were capable of recording audio and video (Snelson \& Perkins, 2009). The development of the Internet and an ever growing number of digital ICTs followed (Gilster, 1997). Eighty-three percent of contemporary students in higher education agree that technology will play an important role in their future careers (The Educause Center for Analysis and Research, 2016). Baller, Dutta, and Lanvin (2016) define the digital $\left(3^{\text {rd }}\right)$ revolution as one with increasing "global, digital communications; low-cost processing and high density data 
storage; and an increasingly connected population of active users of digital technologies" (p. 3). Building on the "infrastructure of the digital $\left[3^{\text {rd }}\right]$ revolution" (p. vii), they explain the fourth industrial revolution as a change society, one that is built on the backbone of current ICTs that will transform society in exponential ways. This transformation has spurred new thinking related to the traditional definition of literacy.

\section{$\underline{\text { New Literacies }}$}

New literacies emerged in large part from the transformations in information and communications technologies (ICTs) and expanding knowledge society (Sharma, Fantin, Prabhu, Guan, \& Dattakumar, 2016). While early conversations regarding how literacy should be defined began in the mid-twentieth century, interpretations continue to be fluid.

Many novel literacy concepts have been put forward in response to the new social and technological environments. Some are independent and novel, such as digital literacy and information fluency, whereas others are compound concepts such as multiliteracies, transliteracy and media and information literacy (MIL) (Lee, 2013, p. 4).

"Terms such as digital, media and information literacy are used to describe the recent and future knowledge and skills required to allow an individual to navigate media- and information-rich environments" (Šorgo et al., 2016, p. 2).

As early as the 1960's Debes put forth the need for individuals to actively participate in their interpretation of visuals (Association of American Colleges and Universities, 2002; Blummer, 2015). Debes' idea remains valid and integral to other interpretations, including information and media literacies, two new literacies that align closely with digital literacy. A discussion follows on information and media literacies specifically. 
Conceptually, information literacy (IL) includes the ability of individuals to find the truth in documents, and focus on a document's relevance, reliability, validity, timeliness, accuracy, and completeness (Lau, 2013), and has had a strong association with academic libraries. IL, evolved from skillsets needed in libraries that support information access from books, periodicals, and media archives (Keeffe, 2016). It is explained, more recently, as a literacy that involves knowing when and why to access information, where to find information, and how to evaluate, use, and communicate it in an ethical manner (Chartered Institute of Library and Information Professionals, 2013). The Association of College and Research Libraries (2016) and Kurbanoglu, Akkoyunlu, and Umay (2004) articulate an additional skill set, the ability to recognize the need for information prior to finding or locating the information. The Association of College and Research Libraries (ACRL) also embraces the need for information literate individuals to understand social connections and implications among sources. While Klomsri and Tedre (2016) and Lau (2013) describe the need for IL as an over-arching literacy, Keeffe (2016) presumes other ICTs and digital literacies will remain the focus in this current transforming knowledge economy.

Media literacy focuses more on the messages that are presented through different media (Lau, 2013). Jolls and Wilson (2014) explain each medium, tool, communication outlet, or "form through which a message is conveyed ... has its own technological 'grammar' or bias that shapes and creates a message in a unique way" (p. 69). Jolls and Wilson (2014) further explain how media transform a topic and provide a vehicle by which to represent, symbolize, and package communications. They include the need for an individual to deconstruct and construct meaning from the message and media. 
Additional supporting competencies of media literacy include the ability of an individual to access, analyze, evaluate, create, or produce, and distribute messages within a global society (Hobbs, 2010; Martens, 2010; Rogow, 2011).

Media literacy also includes the ability to form social connections through active, collaboration in a participatory culture (Jenkins et al., 2006) supporting critical investigations and the formation of new knowledge (Jolls \& Wilson, 2014). Media literate individuals, Martens (2010) declares, "take an active rather than a passive role in acquiring new knowledge and skills. In this way, they become fully able to participate as critical consumers and citizens in a media-saturated society" (p. 6). The National Association for Media Literacy Education (2007) states, "the purpose of media literacy education is to help individuals of all ages develop the habits of inquiry and skills of expression that they need to be critical thinkers, effective communicators and active citizens in today's world" (p. 1). Table 2.1 synthesizes the ideas described in this section as they relate to information and media literacy.

\section{Table 2.1 A Comparison of Ideas Related to Information and Media Literacy}

\begin{tabular}{|l|l|l|}
\hline & Information Literacy & Media Literacy \\
\hline Focus & $\begin{array}{l}\text { Relevance, reliability, validity, } \\
\text { timeliness, accuracy, completeness }\end{array}$ & $\begin{array}{l}\text { Message presented through } \\
\text { different media transform topic }\end{array}$ \\
\hline Application & $\begin{array}{l}\text { Ability to apply information for } \\
\text { problem solving }\end{array}$ & $\begin{array}{l}\text { Ability to producing new } \\
\text { knowledge }\end{array}$ \\
\hline Abilities & $\begin{array}{l}\text { Knowing when, why, where, and } \\
\text { how to use ethically; }\end{array}$ & $\begin{array}{l}\text { Deconstructing and constructing } \\
\text { meaning; }\end{array}$ \\
& Critical thinking & Critical thinking \\
\hline $\begin{array}{l}\text { Social } \\
\text { Connections }\end{array}$ & $\begin{array}{l}\text { Understanding social context; } \\
\text { Effective use of information }\end{array}$ & $\begin{array}{l}\text { Collaborative learning; } \\
\text { Sharing; Active citizenship }\end{array}$ \\
\hline
\end{tabular}


New literacies have moved beyond the core skills of reading and writing into a complex constellation of competencies that include the ability to not only find and read resources, but critically analyze each resource, make new meaning, share new knowledge in multiple forms, and actively participate in society. Lankshear and Knobel (2007) contend, new literacies are "ways of generating, communicating and negotiating meaningful content ... [beyond text] ... within contexts of participation” (p. 224). Information and media literacy, regardless of different terminology, are closely linked in the literature and often used interchangeably with digital literacy (Ainley et al., 2016; Hobbs, 2010). Hobbs (2010) makes clear that digital and media literacies provide an expansion of the classic definition of literacy, and do not supplant it, and she makes a case for propelling both digital and media literacies, which she defines as a "constellation of life skills" (p. vii), into the mainstream. Ainley et al. (2016) express a similar point of view affirming digital literacy is required for participation in a knowledge economy and information society. A closer look at digital literacy follows in the next section.

\section{Digital Literacy}

Gilster (1997) introduced digital literacy as a literacy for the digital age, and shares his concern for society as individuals learn how to navigate in this collaborative, interactive, participatory environment that is so different from passive, consumptive practices of the past. Entering the second decade of the $21^{\text {st }}$ century, digital literacy became more frequently referenced in the literature. In her work with new literacy studies, Mills (2010) recognizes the "digital turn," a shift toward digital literacies, and explains "knowledge and literacy practices are primarily seen as constructions of particular social groups, rather than attributed to individual cognition alone" (p. 247). 
This proposal of the interpretation of digital literacy being constructed by different social groups exposes the complexity of digital literacy and the difficulties integral to developing a consistent set of competencies for a more global society.

Even though conceptualizations of digital literacy by the authors included here are complex, they do have overlapping features. After briefly addressing digital literacy's core concepts outlined by multiple authors in the field, Kurtz and Peled's (2016) digital literacy framework synthesizes the overlapping features of digital literacy.

\section{$\underline{\text { Core Concepts }}$}

In her call to action, Hobbs (2010) raises the need for people to have "the ability to access, analyze and engage in critical thinking about the array of messages they receive and send in order to make informed decisions about the everyday issues they face regarding health, work, politics and leisure" (p. vii). Digital and media literacy, Hobbs asserts, improves through deep collaborative engagement with ideas and information in socio-cultural life. Rheingold (2012) explains, digital literacies include the social competency to work effectively and collaboratively with others, and the ability to be mindful of information and representations (media) so as to filter the irrelevant information that is so prevalent. Rheingold $(2012$, p. 3) states,

as people who are trying to get along day to day in a hyperscale, warp-speed civilization that seems so often to be beyond anyone's control, digital literacy is something powerful we can learn as well as exercise for ourselves and each other.

In their attempt to provide clearer insight to digital literacy, Janssen et al. (2013) completed a Delphi study that included idea generation from 95 experts, aggregated through content analysis and refined with further comment from the experts. The following twelve competencies resulted: 
(a) general knowledge and functional skills,

(b) use in everyday life,

(c) specialized and advanced competence for work and creative expression,

(d) technology mediated communication and collaboration,

(e) information processing and management,

(f) privacy and security,

(g) legal and ethical aspects,

(h) balanced attitude towards technology,

(i) understanding and awareness of role of ICT in society,

(j) learning about and with digital technologies,

(k) informed decisions on appropriate digital technologies, and

(1) seamless use demonstrating self-efficacy.

Janssen et al. (2013) describe areas (d, e, f, g, h, and i) as relevant for all uses of digital technologies on a day to day basis; they describe other areas as moving from specific lower order skills (a, b, and c) to more self-directed higher order thinking skills (j, k, and 1). They note, "the digitally competent person demonstrates self-efficacy and seamless use of digital technologies" (p. 478), and they argue for the inclusion of attitudes in addition to knowledge and skills in their list of competencies. More recently, the definition of digital literacy has expanded to include security, concern for an individual's rights, responsibilities, and etiquette (Ribble, 2016), as well as computational thinking (Park, 2016). 


\section{$\underline{\text { A Digital Literacy Framework }}$}

Kurtz and Peled (2016) with the help of six researchers in the field of educational technology and seven graduate students in the field of ICT identified seven digital learning domains (DLDs).

- Information Research and Retrieval

- Information Validation

- Information Management

- Processing and Presentation of Information

- Team-based Learning in Digital Environments

- Awareness of Digital Integrity

- Social Responsibility

These DLDs establish the framework for the self-assessment tool used in this research. The digital competencies and conceptual items described by: Gilster, 1997; Hobbs, 2010; Mills, 2010; Rheingold, 2012; Janssen et al., 2013; Ribble, 2016; Park, 2016; and Roxin, and Rusitoru, 2016 easily map to the DLDs developed by Kurtz and Peled (2016).

Therefore, the organization of competencies and skill sets described in this section follow Kurtz and Peled's seven DLDs.

\section{$\underline{\text { Information Research and Retrieval }}$}

Foundational to most new literacies, is the ability to seek and find information within digital sites (Gilster, 1997; Hobbs, 2010; Kurtz \& Peled, 2016; Ribble, 2016). This most basic skill expands to include initial considerations for actual need for information and know how related to searching digital systems. Kurtz and Peled (2016) address this initial ability to identify and articulate the need of information, a task required prior to a 
search. In addition, Janssen et al. (2013) address the need for informed decisions supporting the use of appropriate digital technologies for researching.

\section{Information Validation}

Information Validation is a digital learning domain that, while foundational, can be a more cognitively demanding skill than Information Research, Retrieval, and Management. Not only do Kurtz and Peled (2016) support the ability to determine a source's credibility, they also include the skill required to determine if the information will meet the intended needs of a given task. Critical thinking is required (Gilster, 1997; Park, 2016; Rheingold, 2012), as is mindful reflection (Gilster, 1997; Rheingold, 2012) and the ability to problem solve (Roxin \& Rusitoru, 2016). A digitally literate individual must be able to analyze, evaluate, understand, and reflect on a given task and the information required to meet the need (Gilster, 1997; Hobbs, 2010).

\section{Information Management}

Kurtz and Peled (2016) describe information management from a very basic level referencing the ability to organize digital files. Like Information Research and Retrieval, this is another foundational skill to many new literacies. However, Gilster (1997) and Janssen et al. (2013) extend this foundational concept a bit further. They speak of the need for self-efficacy of an individual in the ability to seamlessly navigate in a digital environment, while at the same time having the ability to process information received from multiple formats. They also express the need for digitally literate individuals to have the ability to learn about and with digital technologies, an increasing necessity as available technologies are evolving rapidly. 


\section{$\underline{\text { Processing and Presentation of Information }}$}

At its most basic level, processing, managing, and presenting information involves content creation and knowledge assembly (Gilster, 1997; Hobbs, 2010; Park, 2016). Hobbs (2010) explains active participation in digital literacy practices "cultivate[s] an active approach to the process of meaning making” (p. 31). Yet, digital literacy includes more, moving beyond basic representation toward the use of multiple forms of digital media for creative expression (Janssen et al., 2013; Kurtz \& Peled, 2016; Mills, 2010; Roxin \& Rusitoru, 2016). There is, Janssen et al. (2013) note, an intricate relationship between digital technologies and creative expression.

\section{$\underline{\text { Team-based Learning in Digital Environments }}$}

Team-based learning, like social responsibility links to the need of individuals to work collaboratively in this participatory culture. Kurtz and Peled (2016) look closely at individual team-members' awareness of their role and the roles of other team-members and the alignment of individual roles for the work of the group. Concern for collaborative engagement and the ability to construct social groups (Mills, 2010; Rheingold, 2012) as well as having the ability to share individual thoughts with group members (Gilster, 1997; Hobbs, 2010; Kurtz \& Peled, 2016) are noted in the literature as being important competencies of digital literacy. In addition, Janssen et al. (2013) and Park (2016) refer specifically to the abilities of individuals to participate in technology mediated communication and collaboration within a group.

\section{$\underline{\text { Awareness of Digital Integrity }}$}

Digital integrity encompasses the knowledge of common practices and compliance with copyright and the legal and ethical aspects associated with the use of 
digital media including awareness and understanding of Creative Commons licenses and how to provide attribution (Gilster, 1997; Hobbs, 2010; Kurtz \& Peled, 2016). In similar fashion, Janssen et al. (2013) include privacy and security, and legal and ethical aspects as competencies of digital literacy. They state, the following for each respectively,

The digitally competent person has the capacity to protect personal data and take appropriate security measures; [and] the digitally competent person behaves appropriately and in a socially responsible way in digital environments, demonstrating awareness and knowledge of legal and ethical aspects on the use of ICT and digital content. (Janssen et al., 2013, p. 477)

Park (2016) provides details specific to digital literacy and security including: password protection, internet and mobile security related to hacking, scams, and malware detection.

\section{$\underline{\text { Social Responsibility }}$}

Social responsibility is a key component necessary for life in a participatory culture (Jenkins et al., 2006) in this emerging fourth industrial revolution driven by the digital economy (Baller et al., 2016). Kurtz and Peled (2016) describe social responsibility as an awareness of threatening situations and understanding of social consequences related to one's actions as do Ribble (2016) and Roxin \& Rusitoru (2016) who refer to the need for social awareness and concern for individual rights and responsibilities. Social etiquette that is necessary in all social groups, even those that are online, is also considered as standard of conduct (Ribble, 2016) and is comparable to Hobbs' (2010) identified need for making responsible choices with social actions. Park (2016) separates what she refers to as digital emotional intelligence form digital literacy in a broader conversation on digital skills. She refers to the need for an emotional awareness, self-regulation, and empathy for others. It is with an awareness and 
understanding of the role of ICT in society that individuals are able to balance their perceptions of and actions with ICT in society (Janssen et al., 2013).

Navigating this knowledge economy and information society involves many complex abilities. Digital literacy is multifaceted because it involves the use of ICTs which are transforming at an exponential rate and it includes social responsibilities and team-based learning that evolve given the time, place, context and participants involved. Even the learning domains described here overlap when applying them to a particular context. Figure 1 represents the many overlapping points outlined here and provides a visual reference of how the competencies described in the literature align with Kurtz and Peled's (2016) digital learning domains. 


\begin{tabular}{|c|c|c|c|c|c|c|c|c|c|}
\hline $\begin{array}{r}\text { Digital Literacy } \\
\text { Catagorized using Kurtz and Pele }\end{array}$ & & & & & & & & & \\
\hline Information Research and Retrieval & & & & & & & & & $\mathrm{x}$ \\
\hline Articulate need & & & & & & & & & $\mathrm{x}$ \\
\hline Search; Access & $x$ & $\mathrm{x}$ & & & & $\mathrm{x}$ & & & $\mathrm{x}$ \\
\hline Informed decisions on appropriate digital technologies & & & & & $\mathrm{x}$ & & & & \\
\hline General knowledge and functional skills; Aquire & $x$ & & & & $\mathrm{x}$ & & & & \\
\hline Information Validation & & & & & & & & & $\mathrm{x}$ \\
\hline Critical Thinking & $\mathrm{x}$ & & & $\mathrm{x}$ & & & $\mathrm{x}$ & & \\
\hline Computational thinking; Problem solving & & & & & & & $\mathrm{x}$ & $\mathrm{x}$ & \\
\hline Mindful reflection & $\mathrm{x}$ & & & $\mathrm{x}$ & & & & $\mathrm{x}$ & \\
\hline Analyze; Evaluate quality; Understand and reflect & $\mathrm{x}$ & $\mathrm{x}$ & & & & & & & $\mathrm{x}$ \\
\hline Information Management & & & & & & & & & $\mathrm{x}$ \\
\hline Learning about and with digital techologies & & & & & $\mathrm{x}$ & & & & \\
\hline Use information in multuple formats in everyday life & $\mathrm{x}$ & $\mathrm{x}$ & & & $\mathrm{x}$ & & & & \\
\hline Seamless use demonstrating self-efficacy & $\mathrm{x}$ & & & & $\mathrm{x}$ & & & & \\
\hline Information processing and management & & & & & $\mathrm{x}$ & & & & $x$ \\
\hline Processing and Presentation of Information & & & & & & & & & $\mathrm{x}$ \\
\hline Content creation; Knowledge assembley & $\mathrm{x}$ & $\mathrm{x}$ & & & & & $\mathrm{x}$ & & $\mathrm{x}$ \\
\hline Creative production of digital media & & & $\mathrm{x}$ & & & & & $\mathrm{x}$ & \\
\hline Specialized competence for creative expression & & & & & $\mathrm{x}$ & & & & $\mathrm{x}$ \\
\hline Information processing and management & & & & & $\mathrm{x}$ & $\mathrm{x}$ & & & \\
\hline Team-based Learning in Digital Environments & & & & & & & & & $\mathrm{x}$ \\
\hline Collaborative engagement; Social group construction & & & $\mathrm{x}$ & $\mathrm{x}$ & & & & & $\mathrm{x}$ \\
\hline Engage; Sharing; Pooling knowledge & & $\mathrm{x}$ & & & & & & $\mathrm{x}$ & $\mathrm{x}$ \\
\hline Digital co-creator & & & & & & & $\mathrm{x}$ & & \\
\hline Technology mediated communication and collaboration & & & & & $\mathrm{x}$ & & $\mathrm{x}$ & & \\
\hline Awareness of Digital Integrity & & & & & & & & & $\mathrm{x}$ \\
\hline Privacy and security & & & & & $\mathrm{x}$ & & $\mathrm{x}$ & & \\
\hline Legal and ethical aspects & $\mathrm{x}$ & $\mathrm{x}$ & & & $\mathrm{x}$ & & $\mathrm{x}$ & & $\mathrm{x}$ \\
\hline Social Responsibility & & & & & & & & & $\mathrm{x}$ \\
\hline Concern or individual rights, responsibilities, etiquette & & & & & & $\mathrm{x}$ & $\mathrm{x}$ & $\mathrm{x}$ & $\mathrm{x}$ \\
\hline Social action; Responsible choices & & $\mathrm{x}$ & & & & & $\mathrm{x}$ & & \\
\hline Balanced attitude towards technology & & & & & $\mathrm{x}$ & & & & \\
\hline Understanding and awareness of role of ICT in society & & & & & $\mathrm{x}$ & $\mathrm{x}$ & $\mathrm{x}$ & $\mathrm{x}$ & $\mathrm{x}$ \\
\hline
\end{tabular}

Figure 1. DL Competencies: Categorized by Kurtz and Peled's 7 DLDs 


\section{Assessment Instruments}

While active development of a common language defining digital literacy has been under way for the last decade, assessment instruments are only recently emerging (Ainley et al., 2016). The challenges associated with a shift from defining competencies conceptually to measuring competencies empirically abound. This challenge of shifting from conceptual clarity of digital literacy to the assessment of digital literacy is a result of the fluid ICT environment, and is in part due to the many voices and interpretations of new literacies that have led to industry tensions related to literacy's boundaries, pedagogical concerns, and digital practices (Mills, 2010). Ainley et al. (2016) emphasize these challenges in assessment development noting the breadth of skills from basic to advanced ICT usage and the breadth of contexts. These challenges are relevant to global assessment as well as more local assessments.

Regardless, "valid, reliable, practical assessments of $21^{\text {st }}$ century skills are needed" (Dede, 2010, p. 54). Mills (2010) calls for new innovative assessment models for contemporary times. She claims authentic digital literacy practices in social contexts are missing from assessments of conventional literacy, and affirms mixed methods approaches for improving empirical studies, aiding in the transformation of these new literacies.

Mills (2010) is not alone in her call for assessment measures. Walsh (2010) also calls for additional research on assessment criteria related to these new literacies, as do Jocius (2013) and Hung, Chiu, and Yeh (2013). In her qualitative study with high school students Jocius (2013) references the difficulties in assessing multimodal class projects on responding to a book, The Kite Runner; and Hung, Chiu, and Yeh (2013) conclude 
from their research of a formative assessment rubric for students' multimodal projects, "there is an urgent need to develop alternative ways of assessment in support of students' new literacy practices in the digital age" (p. 400).

While some empirical studies exist on the assessment of digital literacy, standardization of these evaluations is challenging (Boh Podgornik et al., 2015). To date there is no final agreement for best assessment method (Boh Podgornik et al., 2015). A sample of the empirical studies associated with information, media and digital literacies assessment instruments in higher education follow. The instruments presented here include an information literacy test and self-assessment instruments for information, media, and digital literacy.

\section{$\underline{\text { Information Literacy (IL) Instruments }}$}

Four instruments used to assess information or ICT literacies are identified here. While each instrument references a different conceptual framework, the scores from these varied instruments are all reported to be reliable, or "stable and consistent," (p. 159) one indication of a good instrument (Creswell, 2012). Calculations of Cronbach's alpha, is "one of the most important and pervasive statistics in research involving test construction and use" (Cortina, 1993, p. 98). Each of the four IL instruments introduced here indicate acceptable values for reliability (Nunnally, 1978).

Kurbanoglu et al. (2004) explain low self-efficacy is a limiting factor to lifelong learning, and express the need for an appropriate self-efficacy scale for the assessment of IL. In their attempt to develop a self-efficacy instrument that measures and individual's IL, Kurbanoglu et al. tested the properties of a scale based on the following seven domains: (a) defining the need for information, (b) initiating the search strategy, (c) 
locating and accessing the resources, (d) assessing and comprehending the information, (e) interpreting synthesizing and using the information, (f) communicating the information, and (g) evaluating the product and process. Their 28 -item self-efficacy scale was given to 374 teachers, and was calculated to be reliable with a Cronbach's alpha = .92.

Focusing on 19 essential competencies of IL, Tondeur et al. (2015) developed a self-report instrument for measuring pre-service teachers' ICT competencies in supporting student use of ICTs and competencies with the integration of ICTs in their pedagogies. A total of 931 pre-service teachers participated in their study. Their instruments, based on 5-point Likert-type scales, were found to be reliable with calculated Cronbach's alpha values for ICT competencies and instructional design equal to .94 and .89 respectively.

In an attempt to serve higher education institutions in developing courses that improve student IL, Boh Podgornick et al. (2015) developed an IL test composed of 40 multiple choice questions, each with one correct answer. The 22 performance indicators of IL as proposed by the ACRL, a division of the American Library Association, (American Library Association, 2000) provided a conceptual framework. Subscales were used to better identify areas of need. Testing occurred before and after participation in an IL-related course. Using 536 students in the first test group and 163 students in the second (posttest group), Boh Podgornik et al. (2015) found a 13.1\% increase in test results with the "most significant improvement ...in advanced search strategies. Understanding the economic, legal, and social issues surrounding the use of information 
improved to a lesser extent" (p. 12). Reliability for their test was calculated to be sufficient, Cronbach's alpha $=.74$.

In an attempt to better understand aspects that influence IL, Šorgo et al. (2016) used the IL test developed by Boh Podgornik et al. (2015) in addition to four scales rating: (a) ICT experiences, (b) ICT-rich courses, (c) Internet confidence, and (d) ICT ownership. Reliability for their test was calculated with a Cronbach's alpha of 0.71 . Results from their study that included 299 student participants indicated increased application use does not improve IL, nor does increased device ownership. However, ownership of devices does impact one's experience and confidence which in turn produces a positive impact on IL. Likewise, "ICT-rich university courses have an impact on ICT experiences and student confidence" (p. 16).

\section{$\underline{\text { Media Literacy Instrument }}$}

In her attempt to develop a "comprehensive assessment tool that could be used to measure new media literacies" (p. 16), Literat (2014) tested the properties of a self-report instrument based on the New Media Consortium's 12 media literacy skills identified by Jenkins et al. (2006): (a) play, (b) performance, (c) simulation, (d) appropriation, (e) multitasking, (f) distributed cognition, (g) collective intelligence, (h) judgement, (i) transmedia navigation, (j) networking negotiation. A convenience sample drawn from a link distributed through social networking sites on the web drew 327 participants. Sixty statements were built around the $12 \mathrm{NML}$ skills. Literat used a 5 point Likert-type scale ranging from strongly disagree to strongly agree. A factor analysis of her questionnaire indicated ten subscales, not twelve, emerged with "adequate reliability" (p. 21). Her results indicated individuals with a higher level of consumption and production 
experience correlated with higher media literacy as did participation in Web 2.0 platforms and an individual's civic engagement. This 80 question assessment took approximately 20 minutes to complete. The questionnaire's length was noted as a limitation to attracting participation. Literat calls for qualitative components to future research "to achieve a fuller and more precise assessment of media literacy" (p. 23) and questions the ability of similar assessments to be useful "for both baseline and endline assessments" (p. 23). The specificity of particular digital platforms in this questionnaire was problematic for some participants, as one user indicated using a particular platform does not make one more or less media literate.

Digital Literacy Instrument

Using a conceptual framework that includes visual literacy, literacies associated with ICT, and digital literacy, Kurtz and Peled (2016) validated a set of digital literacies that originated from prior work completed by Beaudoin, Kurtz, Jung, Suzuki, and Grabowski (2013). The seven digital learning domains (DLDs) identified for their instrument are: (a) information research and retrieval, (b) information validation, (c) information management, (d) processing and presentation of information, (e) team-based learning in digital environments, (f) awareness of digital integrity, and (g) social responsibility.

Six expert researchers in the educational technology field and seven graduate students of ICT learning supplied open-ended responses validating 65 performance statements and the seven DLDs (identified above) used in Kurtz and Peled's (2016) instrument. Results from data collected from 253 students using the revised instrument resulted in a range of reliability for each DLD between Cronbach's alpha $=.717$ and .930 . 
Given their work toward validating an instrument for measuring digital literacies, Kurtz and Peled (2016) declared digital literacies "are valuable only insofar as they are capable of evolution in light of changing technical, social, economic, cultural, and educational contexts" (p. 147). Their instrument is not technology specific and, therefore, has the potential to withstand future ICT changes to socio-cultural environments.

\section{$\underline{\text { Summary of Assessment Instruments }}$}

Some assessment instruments exist for the new literacies described here. Table 2.2 provides a summary of these emerging assessment instruments, and includes the new literacy assessed (information, media, digital), the framework, instrument type, number of participants used to test the instrument, the instrument's reliability, and authors associated with each instrument. 
Table 2.2 Instruments Assessing New Literacies

\begin{tabular}{|c|c|c|c|c|c|}
\hline Literacy & Framework & Instrument & $\begin{array}{l}\text { Participants } \\
\text { in study }\end{array}$ & $\begin{array}{l}\text { Reliability } \\
\text { (Cronbach's } \\
\text { alpha) }\end{array}$ & Authors \\
\hline Information & 7 domains & Self-report & 374 & .91 & $\begin{array}{l}\text { Kurbanoglu et al. } \\
\text { (2004) }\end{array}$ \\
\hline Information & $\begin{array}{l}19 \text { essential } \\
\text { competencies }\end{array}$ & Self-report & 931 & $\begin{array}{l}\mathrm{SU}=.94 \\
\mathrm{ID}=.89\end{array}$ & $\begin{array}{l}\text { Tondeur et al. } \\
\text { (2015) }\end{array}$ \\
\hline Information & $\begin{array}{l}22 \\
\text { performance } \\
\text { indicators }\end{array}$ & Test & $\begin{array}{l}\text { Pretest } 536 \\
\text { Post-test } 163\end{array}$ & .74 & $\begin{array}{l}\text { Boh Podgornik et } \\
\text { al. (2015) }\end{array}$ \\
\hline Information & $\begin{array}{l}\text { Influencing } \\
\text { aspects }\end{array}$ & $\begin{array}{l}\text { Test and } \\
\text { Scales }\end{array}$ & 299 & .71 & Šorgo et al. (2016) \\
\hline Media & $\begin{array}{l}12 \text { media } \\
\text { literacies } \\
\text { skills }\end{array}$ & Self-report & 327 & .90 & Literat (2014) \\
\hline Digital & $\begin{array}{l}7 \text { digital } \\
\text { learning } \\
\text { domains }\end{array}$ & Self-report & 1889 & $.717-.930$ & $\begin{array}{l}\text { Kurtz \& Peled } \\
(2016)\end{array}$ \\
\hline
\end{tabular}

Notes: $\mathrm{SU}=$ student use; ID = instructional design

\section{Summary}

The advent and growth of ICTs in society has and will have a revolutionary effect on socio-cultural environments around the globe (Baller et al., 2016). The shift in ICTs has drastically altered the amount, form, and mode of information available and has altered the way in which individuals search for, retrieve, remix and send communications (Rheingold, 2012). These changes have altered the way in which society defines literacy. Information, media, and digital literacies are some of the new literacies represented in the literature. Common themes for the new literacies identified here include:

(a) the ability to find and access information from all media types, 
(b) the ability to critically evaluate, analyze and interpret all sources,

(c) the ability to deconstruct and construct new meaning,

(d) the ability to present and/or distribute new expressions

(e) the ability to engage in these activities while at the same time being aware of social context and rights, responsibilities and etiquette associated with collaborative engagement.

Digital literacy provides a broad context that includes competencies associated with information and media literacies. Digital literacy has the power to transform a society (Rheingold, 2012). While, Janssen et al. (2013) support the notion that "a common language is needed" (p. 473) in the field of digital competence, defining digital literacy remains a complex process. Digital literacy remains an important and fluid field of study, as educational institutions attempt to define literacy in an information media rich society.

A need exists for further research on new literacies in general and the assessment of digital literacy, specifically. Mills (2010) and Literat (2014) call for mixed methods studies and studies involving qualitative data analysis. Ainley et al. (2016) call for work toward a global assessment when they state, "there is considerable work to be done in building on [existing] work so that measures are appropriate for a wider range of countries" (p.18). Better assessment of digital literacies can improve digital literacies, and can therefore "make the difference between being empowered or manipulated" (Rheingold, 2012, p. 3). As individuals grow in their participation in democratic societies (Martin, 2006), "the international community should learn how to better measure digital literacy skills" (UNESCO, 2016, p. 378). 


\section{CHAPTER THREE: METHODS}

This exploratory study followed an embedded mixed methods design. Mixed methods studies combine "the advantages of both quantitative and qualitative data" (Creswell, 2012, p. 545) and uncover multiple perspectives (Creswell \& Plano Clark, 2011). Creswell and Plano Clark (2011) describe embedded mixed methods, specifically, as having both quantitative and qualitative components within one traditional design. A fixed approach to this study placed quantitative methods first in the design and qualitative methods second. Each component remained independent through the analysis phase. Quantitative and qualitative components were mixed when drawing conclusions at the end of the study.

First year students in the 2016-2017 academic year at Messiah College represented the target population for this study. Recruitment efforts focused on students enrolled in a course taken by most first year students in the spring semester of their first year. The survey instrument used for this research included Kurtz and Peled's (2016) self-assessment instrument used to collect quantitative data, and open ended prompts used to collect qualitative data. Qualitative data included digital media files and text reflections and explanations supplied by the participants at the end of the survey.

Data analysis procedures included calculations of frequencies and percentages of participant demographic data and the quantitative responses to 54 performance statements grouped among the seven DLDs of Kurtz and Peled's (2016) self-assessment. Qualitative content analysis (QCA) supported the analysis of qualitative data collected at the end of 
the survey. This qualitative analysis began with a conceptual organization of data according to Kurtz and Peled's seven DLDs. Then, using the constant comparative approach of grounded theory, final categorizations of qualitative data were determined (Glaser, 2002).

This chapter begins with a detailed look at this study's mixed methods features. The data collection section includes information related to the target population, recruitment efforts, and the research instrument. The data analysis section includes screening techniques, and quantitative and qualitative assessment practices used to answer this study's research questions. The chapter ends with research limitations.

\section{Study Design}

Creswell (2012) explains, an embedded mixed methods design includes the collection and analysis of quantitative and qualitative data with "one form of data play[ing] a supportive role to the other form of data" (p. 544). The supporting data augments, supports, or extends the primary form of data (Creswell, 2012). Collection of the quantitative and qualitative data components can happen simultaneously or sequentially, and each form of data is used to answer a different research question (Creswell, 2012). Creswell also highlights the importance of clarifying the intended purpose of the secondary data set when using this method.

This study's primary orientation is quantitative. Data collected from the selfassessment of seven DLDs aimed to answer the first research question: Based on Kurtz and Peled's (2016) digital learning domains, how digitally literate are Messiah College's first year undergraduate students? Qualitative data collection followed sequentially within the same survey instrument, and aimed to answer the second research question: 
How do supporting digital files and text reflections and explanations extend Kurtz and Peled's (2016) instrument assessing digital literacy? This mixed methods study extends the research available on digital literacy, providing valuable insights on digital literacy assessment that have not been provided by quantitative data alone (Literat, 2014; Mills, 2010). A diagram of this study's design appears in Figure 2 and Appendix B.

\begin{tabular}{|c|c|c|c|c|}
\hline $\begin{array}{l}\text { QUAN } \\
\text { data } \\
\text { collection }\end{array}$ & $\begin{array}{l}\frac{\text { qual }}{\text { data }} \\
\text { collection }\end{array}$ & $\begin{array}{c}\text { QUAN } \\
\text { data } \\
\text { analysis }\end{array}$ & $\begin{array}{c}\begin{array}{c}\text { Qual } \\
\text { data } \\
\text { analysis }\end{array} \\
\end{array}$ & Interpretation \\
\hline $\begin{array}{l}\text { Procedures: } \\
\text { Recruitment through } \\
\text { CCC course to obtain } \\
\text { larges sample possible } \\
\text { Online self-assessment } \\
\text { survey including } \\
\text { demographic questions } \\
\text { and } 5 \text { level Likert-type } \\
\text { scale for } 54 \text { performance } \\
\text { statements rating } 7 \\
\text { digital learning domains }\end{array}$ & $\begin{array}{l}\text { Procedures: } \\
\text { Recruitment through } \\
\text { CCC course to obtain } \\
\text { larges sample possible } \\
\text { Online self-assessment } \\
\text { survey included email } \\
\text { method for submitting of } \\
\text { qualitative artifacts }\end{array}$ & $\begin{array}{l}\text { Procedures: } \\
\text { Descriptive statistics on } \\
\text { demographic data and } \\
\text { each of } 54 \text { performance } \\
\text { statements }(N=125) \\
\text { Reliability of } 7 \text { digital } \\
\text { learning domains }\end{array}$ & $\begin{array}{l}\text { Procedures: } \\
\text { Qualitative content analysis } \\
\text { (QCA) }(\mathrm{N}=27) \\
\text { Conceptual organization } \\
\text { according to } 7 \text { digital learning } \\
\text { domains } \\
\text { Systematic, data-driven analysis } \\
\text { using: grounded theory's open } \\
\text { coding, conceptualization of } \\
\text { properties, and the development } \\
\text { of final categories }\end{array}$ & $\begin{array}{l}\text { Procedures: } \\
\text { Synthesis of independent } \\
\text { assessment of quantitative and } \\
\text { qualitative results } \\
\text { Evidence for construct validity } \\
\begin{array}{l}\text { Consider how mixed methods } \\
\text { provides insights on digital } \\
\text { literacy assessment }\end{array}\end{array}$ \\
\hline $\begin{array}{l}\text { Products: } \\
\text { Numeric data }(N=125)\end{array}$ & $\begin{array}{l}\text { Products: } \\
\text { Digital artifacts, text } \\
\text { reflection/explanations, } \\
\text { and researcher memos ( } N \\
=27 \text { ) }\end{array}$ & $\begin{array}{l}\text { Products: } \\
\text { Frequency, percent, } \\
\text { median, and interquartile } \\
\text { range; Cronbach's alpha } \\
\text { for } 7 \text { digital learning } \\
\text { domains } \\
\text { Bar charts; Data Tables } \\
\text { Box Plots }\end{array}$ & $\begin{array}{l}\text { Products: } \\
\begin{array}{l}\text { Sample quotes and screen shots } \\
\text { of artifacts conceptually } \\
\text { organized according to } 7 \text { DLDs }\end{array} \\
\text { Model representations of } \\
\text { overlapping DLDs; Mindmap of } \\
\text { emotions }\end{array}$ & $\begin{array}{l}\text { Products: } \\
\text { Discussion of: } \\
\text { Final synthesis } \\
\text { Interpretations } \\
\text { Future research }\end{array}$ \\
\hline
\end{tabular}

Figure 2. Diagram of study's design

\section{Data Collection}

The target population for this study was first year students at Messiah College in the 2016-2017 academic year. Recruitment efforts focused on a course in which nearly all first year students were enrolled, Created and Called to Community (CCC). A survey instrument supported the data collection efforts of the quantitative and qualitative elements of this study. This section provides detail on the: (a) target population, (b) recruitment efforts, and (c) survey instrument.

\section{$\underline{\text { Target Population }}$}


First-year students attending Messiah College in the 2016-2017 academic year represented the target population for this study, specifically, first year students, 18 years of age or older. First year students in the fall of 2016 totaled 660, with $39 \%$ male and $61 \%$ female. A large portion, 89\%, began the year as 18 or 19 years old (Messiah College, 2016). Of all undergraduate students for the 2016-2017 academic year, underrepresented racial/ethnic cultural populations accounted for $17.4 \%$ of population, a portion of the total population of undergraduate students that has continued to increase over the past five years (Messiah College, 2016). Students under the age of 18 in the fall semester of 2016 accounted for only $6.5 \%$ of the total first year enrollment (Messiah College, 2016). By the second semester of the first year, when this research took place, this portion of the population under the age of 18 was expected to be even smaller. Therefore, students under the age of 18 were excluded from this research, eliminating the need for parent/guardian informed consent.

Creswell (2012) indicates the importance of selecting, "as large a sample as possible [in survey research] so that the sample will exhibit similar characteristics to the target population" (p. 381), thus reducing sampling error. Given the recruitment procedures that follow, a 95\% chance of sample having similar characteristics to the total population, and a $4 \%$ tolerance for error, the sample size expected for this research was 100 (Fowler, 1988). Recruitment procedures that follow attempted to produce the largest representative sample possible.

\section{$\underline{\text { Recruitment }}$}

In an attempt to reach as large a sample as possible, recruitment efforts focused on a course that nearly all first year students take in the spring semester of their first year, 
Created and Called for Community (CCC). The Assistant Dean of General Education and Common Learning and Advising and the Chair of the CCC Steering Committee consented to providing this research opportunity to students enrolled in CCC. All sections of the CCC course use the learning management system, Canvas, providing a streamlined avenue for storing recruitment materials and sending communications. Recruitment materials modeled by sample documents provided by the Boise State University IRB (Institutional Review Board) included:

- A script read by faculty to their respective CCC courses (see Appendix C).

- A post card (see Appendix D).

- An Announcement generated from each CCC course within the learning management system, Canvas, to students that provides them with links to a video introduction and the survey (see Appendix E).

- A cover letter provided to students in digital form through CCC courses in Canvas (see Appendix F).

- A flyer circulated around campus to spark interest in the study and posted electronically through CCC courses in Canvas (see Appendix G).

- A mass email sent to all first year students with links to a video introduction and the survey (see Appendix H).

Students were able to review digital copies of these recruitment materials from a Module developed within each Canvas course.

Receiving Messiah College's Institutional Review Board (IRB) approval (\#2016008) and a successful defense of this proposed research, the following strategy commenced in an attempt to address Hatcher's (2013) assumptions for independence of 
observation by providing a systematic consistent approach for all participants. Recruitment began with a communication from the Chair of the CCC Steering Committee to all CCC faculty members on January 24,2017 , encouraging them to support recruitment efforts for this study. To improve researcher visibility for the faculty members and students physical copies of the faculty script, postcards for all students, and a flier were organized by section and delivered to each of the 36 sections of the CCC course February 6 to 9,2017. An image of the organized packets of materials and a sample copy of the email sent to faculty members appear in Appendix I.

On February 13, 2017 faculty members received an email communication thanking them for their support and notifying them that an Announcement would be automatically generated to their students through their Canvas course on February 16, 2017. Then, on the week of February 20, 2017 this researcher handed out fliers to first year students. Finally, on March 3, 2017 all first year students received a mass email as a final reminder they had until March 5, 2017 to participate in the research if they desired. Table 3.1 displays a timeline of these recruitment efforts. 
Table $3.1 \quad$ Recruitment Time-line

\begin{tabular}{|l|l|}
\hline Date - Date Range & Action \\
\hline February 6, 2017 & $\begin{array}{l}\text { Survey Available } \\
\text { Module with all Recruitment Materials Published } \\
\text { Physical Copies of Recruitment Materials Delivered to Classes }\end{array}$ \\
\hline February 13,2017 & Thank you email communication sent to faculty members \\
\hline February 16, 2017 & Announcement Sent to Students from Canvas Course \\
\hline February 20,2017 to & Fliers handed out on campus \\
\hline March 3, 2017 & Mass Email Announcement Sent to First Years \\
\hline March 5, 2017 & Survey Closed \\
\hline
\end{tabular}

$\underline{\text { Instrument }}$

An electronic survey instrument supported data collection efforts for the quantitative and qualitative elements (see Appendix J). The first page of the survey, indicated: (a) participation was voluntary, (b) details of the study, (c) implications for participating, (d) anonymity, and (e) researcher contact information. The quantitative component included two parts: (1) demographic questions on gender, age and racial/ethnic identity; and (2) a five level Likert-type scale for 54 performance statements divided among seven DLDs (Kurtz \& Peled, 2016). The Likert-type scale for each of the 54 performance statements included: (a) strongly disagree, (b) somewhat disagree, (c) neither disagree nor agree, (d) somewhat agree, and (e) strongly agree. Kurtz and Peled (2016) provided this researcher with access to their digital literacy self-assessment tool for this part of the study, an assessment tool reported as reliable. Each of the digital learning domains with corresponding performance statements follow in Table 3.2. 
Table 3.2 Digital Learning Domains with Corresponding Performance

\section{Statements}

\begin{tabular}{|l|}
\hline Information Research and Retrieval \\
\hline I know when I need to look for information. \\
I am able to identify information for research. \\
I am able to collect information from the web. \\
I can define the objective of the search. \\
I can articulate what information I need. \\
I know how to search effectively. \\
I can define research terms. \\
I can distinguish between types of search. \\
I can retrieve information from various sources. \\
I am able to collect information from databases. \\
I am able to re-locate information. \\
I am able to relocate a specific web page. \\
\hline Information Validation \\
\hline I am able to judge the degree to which information is practical or satisfies the \\
needs of the task. \\
I am able to determine the information required for a specific task. \\
I am able to assess the accuracy of information. \\
I am able to assess the credibility of information. \\
I am aware of the difference in credibility of information from various \\
sources. \\
\hline Information Management \\
\hline When I store a file, I give it a specific name. \\
I store my files in designated folders. \\
I tag my information. \\
\hline Processing and Presentation of Information \\
\hline I am able to interpret information from multiple sources. \\
I am able to analyze information from multiple sources. \\
I am able to synthesize information from multiple sources. \\
I am able to write an appropriate response to a post. \\
I am able to use information and communications technologies to design or \\
create new information from information already acquired. \\
I am able to visually organize data for learning purposes. \\
I can represent knowledge in a variety of ways such as PowerPoint, websites, \\
blogs, etc. \\
I am aware of the difference in written, graphic or video representations. \\
Team-based Learning in Digital Environments \\
During the preparation of a joint task I know how to fit in among team \\
members. \\
During the preparation of a joint task I share my thoughts and insights with \\
my peers. \\
\hline
\end{tabular}




\begin{tabular}{l} 
During the preparation of a joint task I know that I have an influence on the \\
work process. \\
During the preparation of a joint task I know what is expected of me. \\
While performing a joint task I feel that my contribution to the team is \\
meaningful. \\
My peers are aware of my abilities and of what I can contribute. \\
I have no reservation regarding joint tasks. \\
I like to work with my peers on a joint task. \\
Awareness of Digital Integrity \\
I understand the ethical consequences of the use of technology. \\
I understand the social consequences of the use of technology. \\
I do not acquire digital information, files, programs, databases, etc., via illegal \\
means. \\
I do not use technology for purposes that are intimidating or threatening. \\
I am aware of the prohibition of illegal file download. \\
I am aware of copyright issues. \\
I am aware of appropriate acknowledgment of sources I use. \\
I am aware of the danger of my data being online. \\
I am aware of cyber-bullying issues. \\
I am aware of identity theft issues. \\
I am aware of e-theft issues. \\
I am aware of the danger from my online activities. \\
I am aware of the influence my online data has. \\
I am able to identify/avoid online fraud or identity theft situations. \\
I am able to protect myself from online predators. \\
I adhere to the rules of discourse and proper behavior in social networks \\
I make sure not to reveal information about organizations without consent \\
\hline Social Responsibility
\end{tabular}

A secondary qualitative component of this embedded mixed methods study included an option for participants to email digital media files they believe demonstrate their digital literacy to the researcher. The instrument prompted participants to email evidence directly to the researcher using their own email provider, or use dedicated links assigned to each of the seven DLDs through a mail client on their phone or an Outlook client on their laptops. Examples of digital media files include the digital media artifact first year students at Messiah College produce in CIS 171 or CIS 181, courses frequently taken in the first semester of the first year; links to or screenshots of social media; or 
presentation artifacts. Reflection and/or explanation of practices or about artifacts were also given as examples. These optional qualitative components were included at the end of the survey so as not to disrupt the flow of participants responding to the primary quantitative component (Creswell, 2012). See Appendix J for the instrument.

Researcher memoing supported the qualitative data collected for this study. Memos include "ideas, musings, and reflections...thoughts, feelings and impressions" (Birks, Chapman, \& Francis, 2008, p. 69). Memos help a qualitative researcher reflect on the context, data collected, and how their own subjectivity may influence the study enabling knowledge generation (Birks et al., 2008). This researcher maintained memos on the data collection and analysis process, in a password protected Microsoft OneNote notebook.

\section{Data Analysis}

Analysis began with a close inspection of the data to ensure data quality. A report downloaded from Qualtrics, included results from 140 participants who started the survey between February 6 and March 5, 2017. These 140 participants also indicate "Yes. I read the information above and will participate." Six of the 140 cases did not respond to any of the PSs. These cases were eliminated, bringing the case total to 134 .

Two screening techniques included in the survey, one direct method and one archival method, highlighted responders who were not motivated or thoughtful in their responses. Desimone, Harms, and Desimone (2016) explain, "although researchers hope that participants are motivated to provide thoughtful responses to survey questions, it is well known that this often does not happen" (p. 171). Challenges existed with the proposed screening methods. A description of these challenges, justifications for 
modifying the proposed screening methods, and explanation of the ultimate screening and cleaning procedures used in this study follow, prior to an explanation of methods used for quantitative and qualitative analysis.

\section{Screening and Cleaning Quantitative Date}

Self-report indices, a direct screening technique, included at the beginning and at the end of the self-assessment portion of the survey, were set up on a five level Likerttype scale similar to the rest of the survey. Screening highlighted respondents answering 'strongly disagree' to the first self-report question, 'I will respond to survey thoughtfully and truthfully,' and 'strongly agree' to the second self-report question, 'I occasionally answered items without reading them' (Desimone et al., 2016). Nineteen respondents indicated 'strongly disagree' to the first self-report question, and seven respondents indicated 'strongly agree' to the second question. All 26 respondents screened by these self-report indices were independent of one another. None of the respondents presented an unfavorable response to both questions. However, upon closer inspection, three of these 26 cases provided the same response for all 54 Performance Statements. Desimone et al. (2016) define invariant responses as an archival screening method. These three cases providing an unwanted response to at least one of the self-report indices and nonvaried responses to all 54 PSs were eliminated, bringing the total number of cases to 131 . Response time, an archival screening method proposed to support the screening process (Desimone et al., 2016; Huang, Curran, Keeney, Poposki, \& DeShon, 2012), produced a challenge for the research. Based on the time it took test respondents to read, scroll, select options, and submit each of the seven pages assessing corresponding DLDs, a factor of six seconds per performance statement established a target page submission 
time threshold for each DLD. Table 3.3 shows the results of this screening method using a factor of six seconds per performance statement, indicating the number and percent of cases screened for falling below this response time threshold.

\section{Table 3.3 Results of Page Submission Time for each DLD}

\begin{tabular}{|l|c|c|}
\hline Digital Learning Domains & $\begin{array}{c}\text { Number of Cases Under } \\
6 \text { sec./PS Threshold }\end{array}$ & $\begin{array}{c}\text { Percent Cases Under } \\
6 \text { sec./PS Threshold }\end{array}$ \\
\hline $\begin{array}{l}\text { Information Research and Retrieval } \\
(\mathrm{N}=131)\end{array}$ & 106 & 80.9 \\
\hline Information Validation (N=129) & 85 & 65.9 \\
\hline Information Management (N=129) & 107 & 82.9 \\
\hline $\begin{array}{l}\text { Processing and Presentation of } \\
\text { Information (N=129) }\end{array}$ & 93 & 73.6 \\
\hline $\begin{array}{l}\text { Team-based Learning in Digital } \\
\text { Environments (N=129) }\end{array}$ & 95 & 84.3 \\
\hline Awareness of Digital Integrity (N=128) & 108 & 70.3 \\
\hline Social Responsibility (N=128) & 90 & 73 \\
\hline
\end{tabular}

Notes: PS = performance statement

This proposed page submission time threshold of $6 \mathrm{sec} . / \mathrm{PS}$ screened over $65.9 \%$ of the cases and was, therefore, not helpful to this exploratory study. Adjusting the proposed $6 \mathrm{sec}$./PS calculation to $2 \mathrm{sec}$./PS reduced the number of variables falling below the page submission time threshold, maintaining the proposed screening measure to eliminate responses given with little effort while at the same time maintaining as much data as possible for this exploratory study. Appendix K offers descriptive statistics on page submission times factored using the $6 \mathrm{sec} . / \mathrm{PS}$ threshold, providing further justification for this change to proposed procedure. 
Seventeen cases had at least one page submission time below the 2 sec./PS threshold. Figure 3 highlights all seventeen cases with a page submission time falling below the 2 sec./PS threshold, and identifies which of these seventeen cases provided an unwanted response to one of the self-report indices.

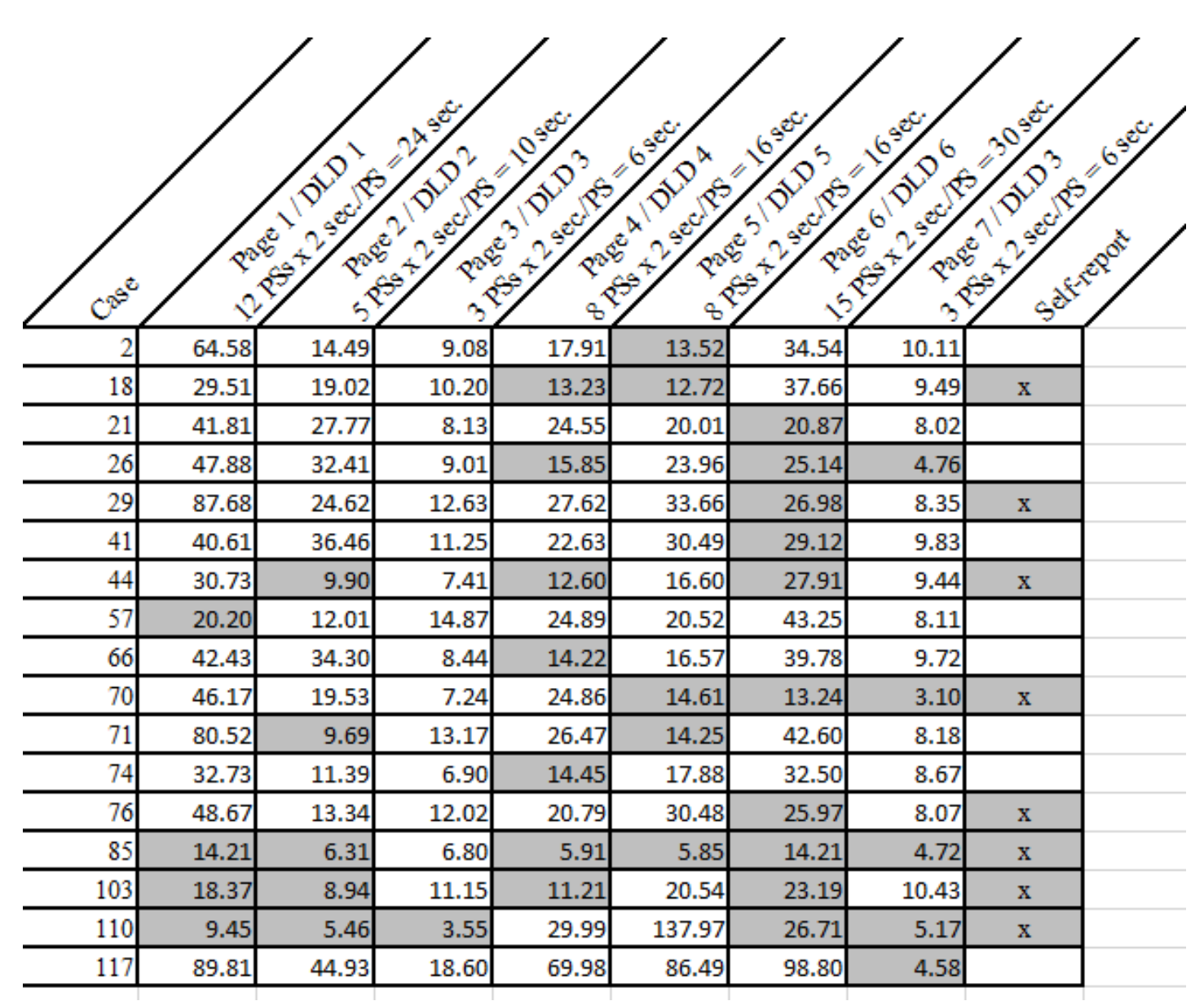

Figure 3. Visual highlights seventeen cases with page submission times below 2 sec./PS threshold. Times are in seconds, and ' $x$ ' indicates an unwanted response to at least one self-report indices

Six of the seventeen cases stood out. Cases 85, 103, and 110 had four or more page submission times under the $2 \mathrm{sec}$./PS threshold and provided an unwanted response to at least one of the self-report indices. Cases 18, 44, and 70 had two or three page 
submission times under the $2 \mathrm{sec} . / \mathrm{PS}$ threshold and provided an unwanted response to at least one of the self-report indices. A close inspection of remaining eleven cases with one to three of the seven page submission times under the 2 sec./PS threshold revealed no abnormalities. The six cases identified here $(18,44,70,85,103$, and 110) were

eliminated from the data set bringing the total number of cases to 125 .

In summary, the direct screening method that included two self-report indices was inconclusive in identifying respondents that completed the survey with insufficient effort. None of the respondents presented an unfavorable response to both questions. However, the 26 individual cases that provided an unfavorable response to at least one of the selfreport indices were identified for closer inspection. Three of these cases provided an unwanted response to at least one of the self-report indices and non-varied responses to all 54 PSs. These three cases were eliminated bringing the total number of case to 131 .

Page submit times were highly positively skewed with the mean submission times for each DLD relatively close to the proposed 6 sec./PS threshold making this proposed screening measure unhelpful to this exploratory study. Updating the seconds/PS factor from six seconds to two seconds offered a more reasonable screening measure. Six additional cases were identified for elimination using the revised page submission time threshold and self-report indices. Removing these 6 cases brought the total number of cases to 125 . This meets the study's proposed goal of 100 cases.

\section{Quantitative Analysis}

Analysis began by calculating the frequency and percent of gender, age and underrepresented racial/ethnic cultural populations within the data set $(N=125)$. When sample data are proportional to the total population inferences may be made between the 
sample data and the entire population (Hatcher, 2013). The survey instrument design supported this effort by offering the same categories for gender, age and underrepresented racial/ethnic populations as those listed in the Messiah College Fact Book (Messiah College, 2016). Further analysis of the responses to the 54 performance statements that were part of digital literacy self-assessment focused on answering the first research question: Based on Kurtz and Peled's (2016) digital learning domains, how digitally literate are Messiah College's first year undergraduate students?

Analysis of the descriptive statistics of the sample data for each DLD included calculating the frequency, percent, median, and interquartile range for each performance statement and DLD (Hatcher, 2013). In addition, calculating Cronbach's alpha using SPSS Statistics 23 for each DLD supported measurements for internal consistency (Hatcher, 2013), considering values above +.70 as acceptable (Hatcher, 2013; Nunnally, 1978).

Qualitative Analysis

The qualitative component of this study focused on answering the second research question: How do supporting digital files and text reflections and explanations extend Kurtz and Peled's (2016) instrument assessing digital literacy? Meaning systematically constructed from specific components found in the data (digital artifacts, text reflection/explanations, and researcher memos) as described by Schreier (2012) using qualitative content analysis (QCA) drove this analysis.

Screening and cleaning techniques included an initial review of the data submitted. Not all data were relevant to the study. Artifacts documented and deleted from this research included files, reflections, or explanations deemed inappropriate, irrelevant, 
or non-representative of the study (Schreier, 2012). Three emails received by students did not contain any digital artifact or text explanation, and one artifact was deemed nonrepresentative, as it was submitted by a student who was not a first year student. The artifact submitted was a link to an article for a senior capstone course. This study's target population focused on first year students during the 2016-17 academic year. Eliminating these cases brought the total number of qualitative cases to 27 . These 27 cases represented first year students who completed the initial quantitative self-assessment instrument and also chose to submit artifacts as a final step to the study.

Data included within these 27 cases were initially organized conceptually using Kurtz and Peled's (2016) DLDs as a framework. Table 3.4 provides sample evidence used as a coding frame for this conceptual organization. 
Table 3.4 Sample Evidence Supporting DLDs

\begin{tabular}{|l|l|}
\hline Digital Learning Domains & Sample Evidence \\
\hline $\begin{array}{l}\text { Information Research and } \\
\text { Retrieval }\end{array}$ & $\begin{array}{l}\text { Link to or screenshot of resource with } \\
\text { reflection/explanation on discovery process. }\end{array}$ \\
\hline Information Validation & $\begin{array}{l}\text { Link to or screenshot of resource with } \\
\text { reflection/explanation regarding evaluation process on } \\
\text { reliability and credibility of the information. }\end{array}$ \\
\hline $\begin{array}{l}\text { Information Management } \\
\text { Processing and } \\
\text { Information }\end{array}$ & $\begin{array}{l}\text { Screenshot of file structure with reflection/explanation } \\
\text { regarding personal organization of files. }\end{array}$ \\
\hline $\begin{array}{l}\text { Team-based Learning in } \\
\text { Digital Environments }\end{array}$ & $\begin{array}{l}\text { Rigital artifact with reflection/explanation regarding } \\
\text { production and presentation processes. } \\
\text { online discussions and online group projects. }\end{array}$ \\
\hline $\begin{array}{l}\text { Awareness of Digital } \\
\text { Integrity }\end{array}$ & $\begin{array}{l}\text { Reflection/explanation regarding active steps taken to } \\
\text { avoid and/or proactively address ethical issues online. }\end{array}$ \\
\hline $\begin{array}{l}\text { Social Responsibility } \\
\text { Reflection/explanation on actions regarding social } \\
\text { responsibility }\end{array}$ \\
\hline
\end{tabular}

A systematic data-driven analysis followed, identifying specific components from within these qualitative data submitted by 27 students to determine final categorizations, thus reducing the amount of data (Schreier, 2012). This data-driven coding began with open coding from grounded theory, a process by which the researcher describes the data with labels forming concepts (Corbin \& Strauss, 1990; Schreier, 2012). Additional analysis led to a conceptualization of properties, and the development of final categories (Corbin \& Strauss, 1990; Glaser, 1999; Schreier, 2012). A constant comparative approach supported the abstraction of concepts from data and categories from concepts 
(Glaser, 2002). Using this constant comparative, multi-pass, approach providing various checks of data at different times supported the need for consistency (Schreier, 2012).

Data analysis within this embedded mixed-methods study supported a fixed approach that maintains independent analysis for each component part, quantitative and qualitative. Only after both data sets were analyzed were the two strands mixed. Creswell \& Plano Clark (2011) explain this type of mixing occurs when the researcher compares and synthesizes element results providing a final interpretation in the discussion and conclusion. The final interpretation for this study appears in Chapter five.

\section{Limitations}

Limitations exist within this proposed research. To begin, this research was conducted at a single institution of higher education with a target population of only first year students during the 2016-17 academic year, reducing generalizability. In addition, self-assessment responses carry with them controversy on their reliability (Kaklauskas et al., 2010), and the main quantitative component of the study included 54 performance statements rated by self-report. Finally, sampling errors are inevitable between the sample and target population. While response rates produces acceptable data sets for both quantitative $(N=125 ; 18.9 \%$ of target population) and qualitative $(N=27 ; 21.6 \%$ of quantitative data set) components based on a $4 \%$ tolerance for error (Fowler, 1988), increased participation could improve results. Given these limitations and the understanding that the results are not generalizable to other institutions or populations, they still yield important information that may be useful for future research. 


\section{CHAPTER FOUR: RESULTS}

\section{Quantitative Data}

The quantitative data collected for this study included demographics and students' self-reported responses to 54 performance statements (PSs) divided among seven digital learning domains (DLDs). These data $(N=125)$ aim to answer the first research question: Based on Kurtz and Peled's (2016) digital learning domains, how digitally literate are Messiah College's first year undergraduate students? The results in this section include descriptive statistics on the demographics and responses to 54 PSs, as well as a reliability measure, Cronbach's alpha, for each of the seven DLDs.

\section{$\underline{\text { Demographics }}$}

First-year students attending Messiah College in the 2016-2017 academic year represent the target population for this study. The sample data used in this study $(N=$ 125) are relatively proportional to the target population according to age and racial/ethnic identity. Eighteen and nineteen year olds represent $90 \%$ of the sample, and $89 \%$ of target population. Underrepresented racial/ethnic populations represent of $19 \%$ of the sample, and greater than $17.4 \%$ of population. The sample was not as closely proportional to the target population on gender. Males represent only $32 \%$ of the sample, while males represent $39 \%$ of the target population. Figure 4 offers a graphical representation of the proportions of categories for gender, age, and racial/ethnic identity in the sample $(N=$ 125). 

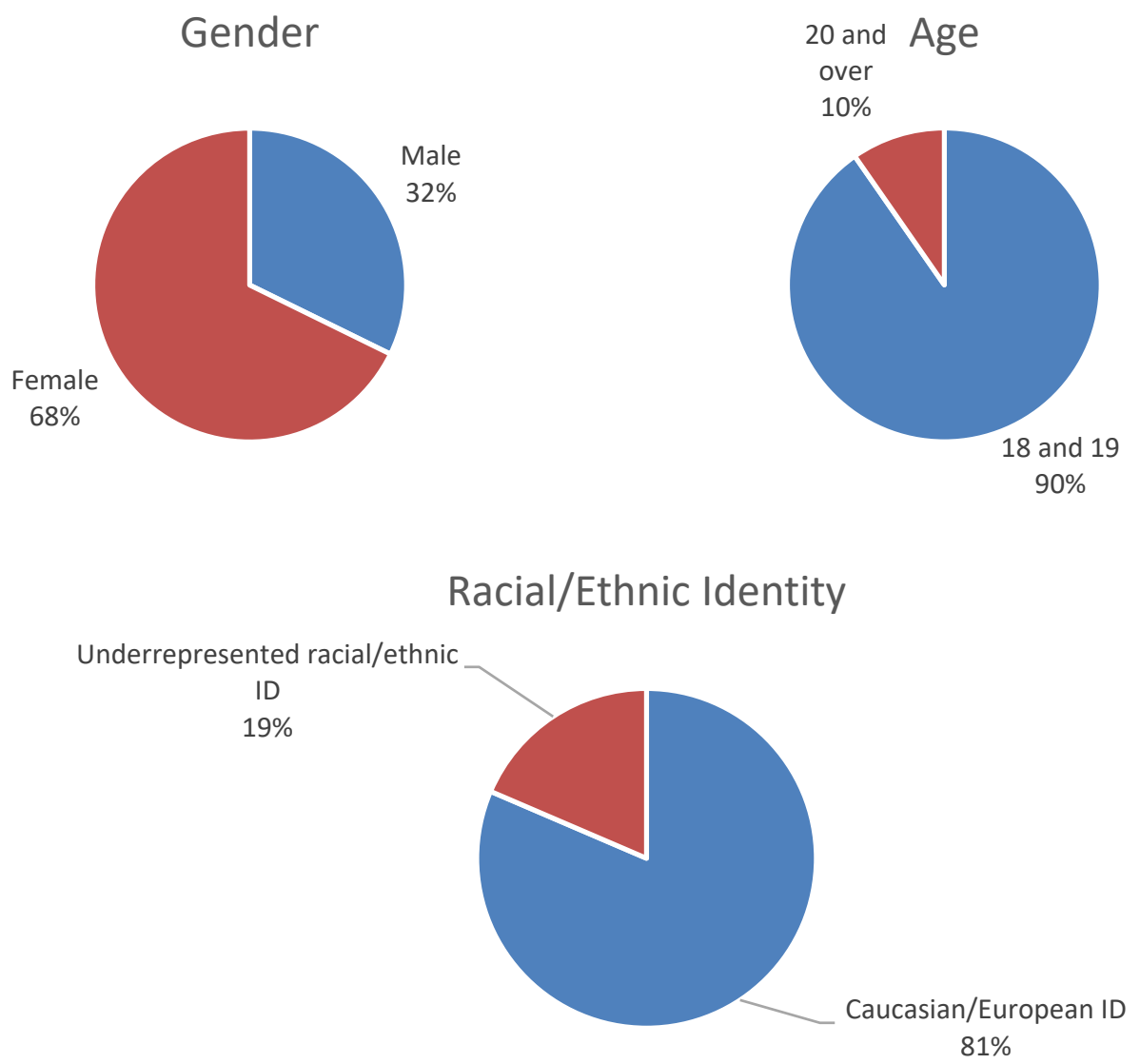

Figure 4. Graphical representation of the proportions of categories in sample data for gender, age, and racial/ethnic identity

\section{Digital Learning Domains' Descriptive Statistics}

This research uses 125 students' self-assessment responses to 54 performance statements (PSs) divided among seven digital learning domains (DLDs) to answer the first research question: Based on Kurtz and Peled's (2016) digital learning domains, how digitally literate are Messiah College's first year undergraduate students? This section highlights descriptive statistics for the 54 PSs associated with each of the seven DLDs, and includes the frequency, percent, median, and interquartile range for each. Cronbach's alpha, a measure of the internal consistency, is also reported here for each DLD. Microsoft's Excel and IBM's SPSS supported efforts to calculate and display these 
results. The seven digital learning domains provide a framework to present these results. Each section (DLD) begins with a stacked bar chart with aggregated results for the DLD. Appendix L displays box plots for each of the PSs associated with each DLD, providing additional visual representations for each DLD.

Information Research and Retrieval.

The stacked bar chart (Figure 5) displays aggregate responses to the 12 PSs within the information research and retrieval DLD. This bar chart combines the results from all 12 PSs and shows the percent of these aggregated responses for each level on the selfassessment scale (Strongly Disagree to Strongly Agree). A positive self-assessment (somewhat agree or strongly agree) describes $85.3 \%$ of the aggregated responses. A negative self-assessment (somewhat disagree or strongly disagree) describes $5.8 \%$ of the aggregated responses.

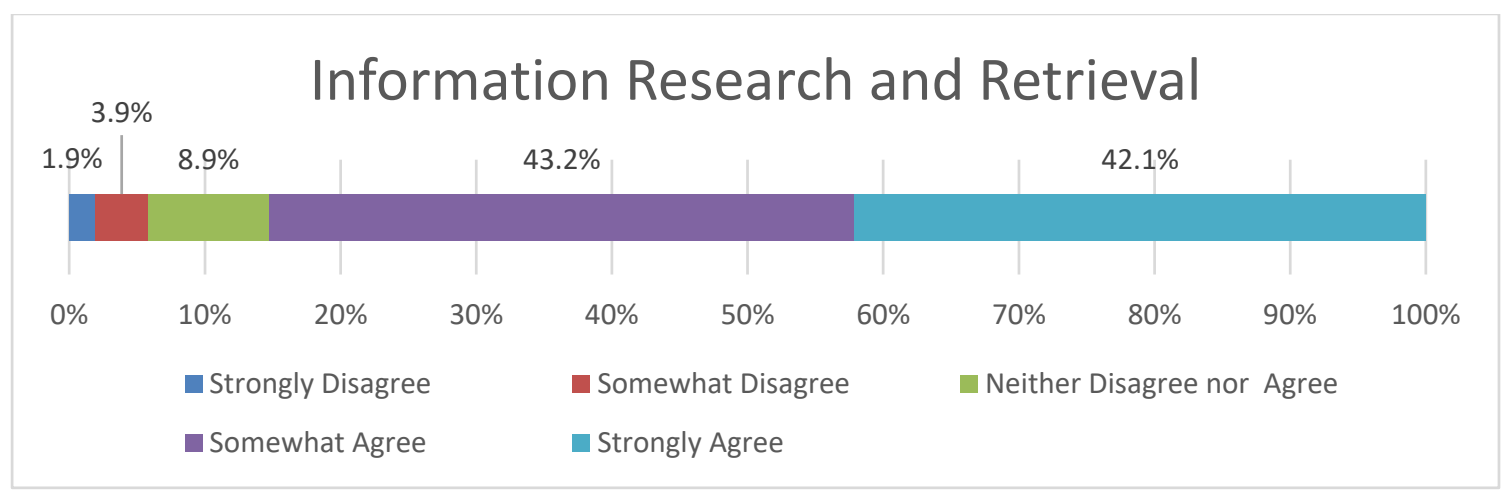

Figure 5. Stacked bar chart combining scaled responses for all 12 performance statements to information research and retrieval

A list of the 12 performance statements that make up the information research and retrieval digital learning domain precedes the results of these PSs.

1. I know when I need to look for information.

2. I am able to identify information for research. 
3. I am able to collect information from the web.

4. I can define the objective of the search.

5. I can articulate what information I need.

6. I know how to search effectively.

7. I can define research terms.

8. I can distinguish between types of search.

9. I can retrieve information from various sources.

10. I am able to collect information from databases.

11. I am able to re-locate information.

12. I am able to relocate a specific web page.

Table 4.1 shows the frequency, percent, median, and interquartile range for each of the 12 PSs for the information research and retrieval DLD. In addition, the summated frequencies for each rating scale along with their respective percentages, and the median and interquartile range of this DLD are included in Table 4.1. Of the 125 cases in this data set for information research and retrieval, the median response on the rating scale is four and the interquartile range is one. Cronbach's alpha for information research and retrieval is 0.94, an acceptable value for reliability (Nunnally, 1978). 
Table 4.1 Descriptive Statistics for each PS in Information Research and Retrieval

\begin{tabular}{|r|c|c|c|c|c|c|c|}
\hline & \multicolumn{5}{|c|}{ Rating scale (1-5) } & & \\
\hline \multicolumn{1}{|l|}{ PS } & 1 & 2 & 3 & 4 & 5 & $M d n$ & IR \\
\hline 1 & $4(3.2 \%)$ & $0(0.0 \%)$ & $1(0.8 \%)$ & $51(40.8 \%)$ & $69(55.2 \%)$ & 5 & 1 \\
\hline 2 & $3(2.4 \%)$ & $1(0.8 \%)$ & $3(2.4 \%)$ & $64(51.2 \%)$ & $54(43.2 \%)$ & 4 & 1 \\
\hline 3 & $3(2.4 \%)$ & $1(0.8 \%)$ & $2(1.6 \%)$ & $34(27.2 \%)$ & $85(68.0 \%)$ & 5 & 1 \\
\hline 4 & $2(1.6 \%)$ & $3(2.4 \%)$ & $8(6.4 \%)$ & $60(48.0 \%)$ & $52(41.6 \%)$ & 4 & 1 \\
\hline 5 & $3(2.4 \%)$ & $3(2.4 \%)$ & $3(2.4 \%)$ & $66(52.8 \%)$ & $50(40.0 \%)$ & 4 & 1 \\
\hline 6 & $2(1.6 \%)$ & $4(3.2 \%)$ & $9(7.2 \%)$ & $67(53.6 \%)$ & $43(34.4 \%)$ & 4 & 1 \\
\hline 7 & $1(0.8 \%)$ & $6(4.8 \%)$ & $26(21.0 \%)$ & $56(45.2 \%)$ & $35(28.2 \%)$ & 4 & 2 \\
\hline 8 & $2(1.6 \%)$ & $15(12.0 \%)$ & $27(21.6 \%)$ & $54(43.2 \%)$ & $27(21.6 \%)$ & 4 & 1 \\
\hline 9 & $3(2.4 \%)$ & $3(2.4 \%)$ & $2(1.6 \%)$ & $50(40.0 \%)$ & $67(53.6 \%)$ & 5 & 1 \\
\hline 10 & $1(0.8 \%)$ & $10(8.0 \%)$ & $12(9.6 \%)$ & $48(38.4 \%)$ & $54(43.2 \%)$ & 4 & 1 \\
\hline 11 & $3(2.4 \%)$ & $6(4.8 \%)$ & $22(17.6 \%)$ & $51(40.8 \%)$ & $43(34.4 \%)$ & 4 & 2 \\
\hline 12 & $2(1.6 \%)$ & $6(4.8 \%)$ & $19(15.2 \%)$ & $46(36.8 \%)$ & $52(41.6 \%)$ & 4 & 1 \\
\hline Total & $29(1.9 \%)$ & $58(3.9 \%)$ & $134(8.9 \%)$ & $647(43.2 \%)$ & $631(42.1 \%)$ & 4 & 1 \\
\hline
\end{tabular}

Note. $N=125$. PS=Performance Statement. $1=$ Strongly disagree, $2=$ Somewhat disagree, $3=$ Neither disagree nor agree, $4=$ Somewhat agree, $5=$ Strongly agree. $M d n=$ Median. IR=Interquartile Range.

\section{Information Validation.}

The stacked bar chart (Figure 6) displays aggregate responses to the five PSs within the information validation DLD. This bar chart combines the results from all five PSs and shows the percent of these aggregated responses for each level on the selfassessment scale (Strongly Disagree to Strongly Agree). A positive self-assessment (somewhat agree or strongly agree) describes $84.7 \%$ of the aggregated responses. A negative self-assessment (somewhat disagree or strongly disagree) describes $6.2 \%$ of the aggregated responses. 


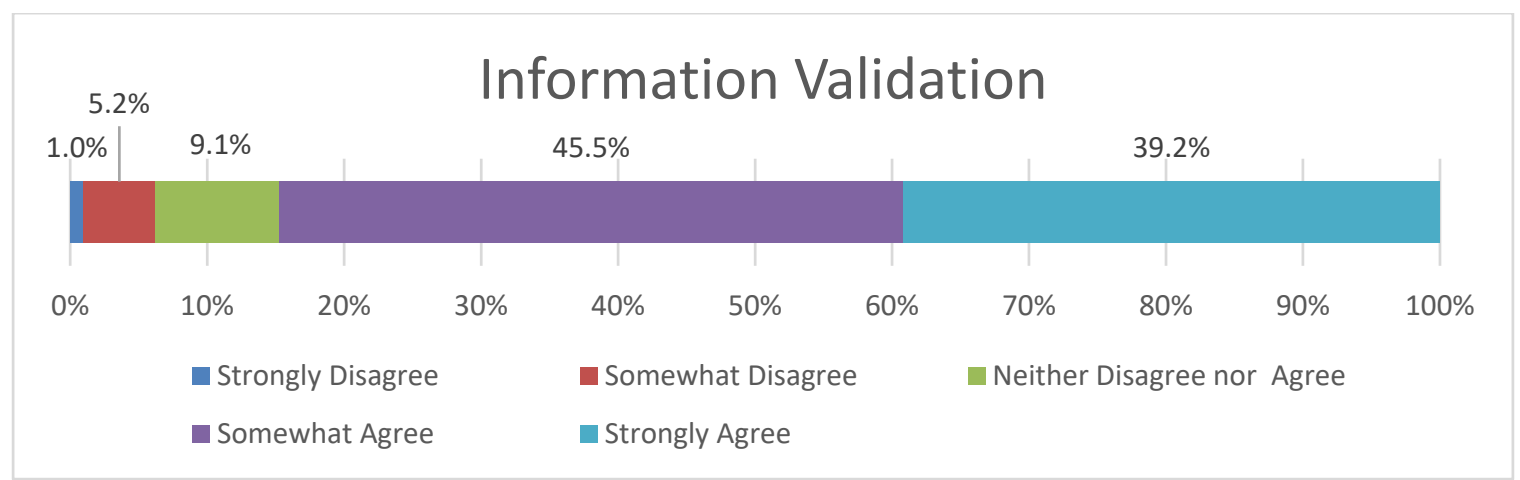

Figure 6. Stacked bar chart combining scaled responses for all five performance statements to information validation

A list of the five performance statements that make up the information validation digital learning domain precedes the results of these PSs.

1. I am able to judge the degree to which information is practical or satisfies the needs of the task.

2. I am able to determine the information required for a specific task.

3. I am able to assess the accuracy of information.

4. I am able to assess the credibility of information.

5. I am aware of the difference in credibility of information from various sources.

Table 4.2 shows the frequency, percent, median, and interquartile range for each of the five PSs for the information validation DLD. In addition, Table 4.2 includes the summated frequencies for each rating scale along with their respective percentages, and the median and interquartile range of this DLD. Of the 123 cases in this data set for information validation, the median response on the rating scale is four and the interquartile range is one. Cronbach's alpha for information research and retrieval is 0.87 , an acceptable value for reliability (Nunnally, 1978). 


\section{Table 4.2 Descriptive Statistics for each PS for Information Validation}

\begin{tabular}{|r|c|c|c|c|c|c|c|}
\hline & \multicolumn{5}{|c|}{ Rating scale (1-5) } & & \\
\hline PS & 1 & 2 & 3 & 4 & 5 & $M d n$ & IR \\
\hline 1 & $2(1.6 \%)$ & $4(3.3 \%)$ & $8(6.5 \%)$ & $60(48.8 \%)$ & $49(39.8 \%)$ & 4 & 1 \\
\hline 2 & $1(0.8 \%)$ & $5(4.1 \%)$ & $4(3.3 \%)$ & $57(46.3 \%)$ & $56(45.5 \%)$ & 4 & 1 \\
\hline 3 & $1(0.8 \%)$ & $7(5.7 \%)$ & $16(13.0 \%)$ & $66(53.7 \%)$ & $33(26.8 \%)$ & 4 & 1 \\
\hline 4 & $1(0.8 \%)$ & $9(7.3 \%)$ & $17(13.8 \%)$ & $50(40.7 \%)$ & $46(37.4 \%)$ & 4 & 1 \\
\hline 5 & $1(0.8 \%)$ & $7(5.7 \%)$ & $11(8.9 \%)$ & $47(38.2 \%)$ & $57(46.3 \%)$ & 4 & 1 \\
\hline Total & $6(1.0 \%)$ & $32(5.2 \%)$ & $56(9.1 \%)$ & $280(45.5 \%)$ & $241(39.2 \%)$ & 4 & 1 \\
\hline
\end{tabular}

Note. $N=123$. PS=Performance Statement. $1=$ Strongly disagree, $2=$ Somewhat disagree, $3=$ Neither disagree nor agree, $4=$ Somewhat agree, $5=$ Strongly agree. $M d n=$ Median. IR=Interquartile Range.

\section{Information Management.}

The stacked bar chart (Figure 7) displays aggregate responses to the three PSs within the information management DLD. This bar chart combines the results from all three PSs and shows the percent of these aggregated responses for each level on the selfassessment scale (Strongly Disagree to Strongly Agree). A positive self-assessment (somewhat agree or strongly agree) describes $69.7 \%$ of the aggregated responses. A negative self-assessment (somewhat disagree or strongly disagree) describes $18.2 \%$ of the aggregated responses. 


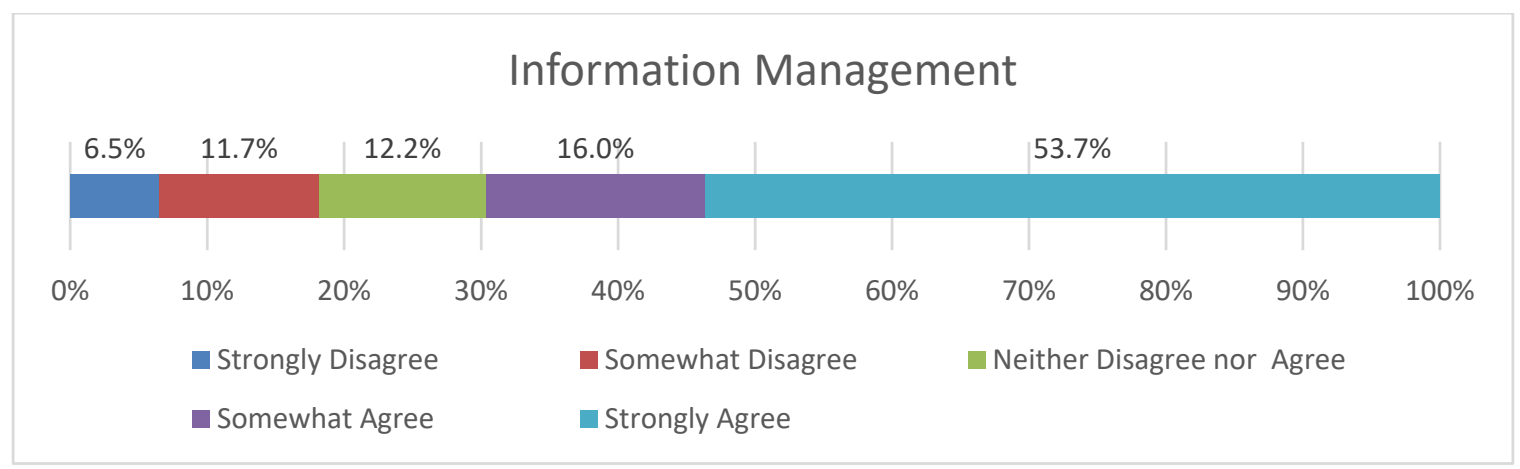

Figure 7. Stacked bar chart combining scaled responses for all three performance statements to information management

A list of the three performance statements that make up the information management digital learning domain precedes the results of these PSs.

1. When I store a file, I give it a specific name.

2. I store my files in designated folders.

3. I tag my information.

Table 4.3 shows the frequency, percent, median, and interquartile range for each of the three PSs for the information management. In addition DLD, Table 4.3 includes the summated frequencies for each rating scale along with their respective percentages, and the median and interquartile range of this DLD. Of the 123 cases in this data set for information management, the median response on the rating scale is five and the interquartile range is two. Cronbach's alpha for information management is 0.53 . This is not an acceptable value for reliability (Nunnally, 1978). 
Table 4.3 Descriptive Statistics for each PS for Information Management

\begin{tabular}{|r|c|c|c|c|c|c|c|}
\hline & \multicolumn{5}{|c|}{ Rating scale (1-5) } & & \\
\hline \multicolumn{1}{|c|}{ Prequency and Percent } & & \\
\hline & 1 & 2 & 3 & 4 & 5 & $M d n$ & IR \\
\hline 1 & $1(0.8 \%)$ & $3(2.4 \%)$ & $4(3.3 \%)$ & $16(13.0 \%)$ & $99(80.5 \%)$ & 5 & 0 \\
\hline 2 & $5(4.1 \%)$ & $9(7.3 \%)$ & $6(4.9 \%)$ & $21(17.1 \%)$ & $82(66.7 \%)$ & 5 & 1 \\
\hline 3 & $18(14.6 \%)$ & $31(25.2 \%)$ & $35(28.5 \%)$ & $22(17.9 \%)$ & $17(13.8 \%)$ & 3 & 2 \\
\hline Total & $24(6.5 \%)$ & $43(11.7 \%)$ & $45(12.2 \%)$ & $59(16.0 \%)$ & $198(53.7 \%)$ & 5 & 2 \\
\hline
\end{tabular}

Note. $N=123$. PS=Performance Statement. $1=$ Strongly disagree, $2=$ Somewhat disagree, $3=$ Neither disagree nor agree, $4=$ Somewhat agree, 5=Strongly agree. $M d n=$ Median. IR=Interquartile Range.

\section{Processing and Presentation of Information.}

The stacked bar chart (Figure 8) displays aggregate responses to the eight PSs within the processing and presentation of information DLD. This bar chart combines the results from all eight PSs and shows the percent of these aggregated responses for each level on the self-assessment scale (Strongly Disagree to Strongly Agree). A positive selfassessment (somewhat agree or strongly agree) describes $85.4 \%$ of the aggregated responses. A negative self-assessment (somewhat disagree or strongly disagree) describes $5.7 \%$ of the aggregated responses.

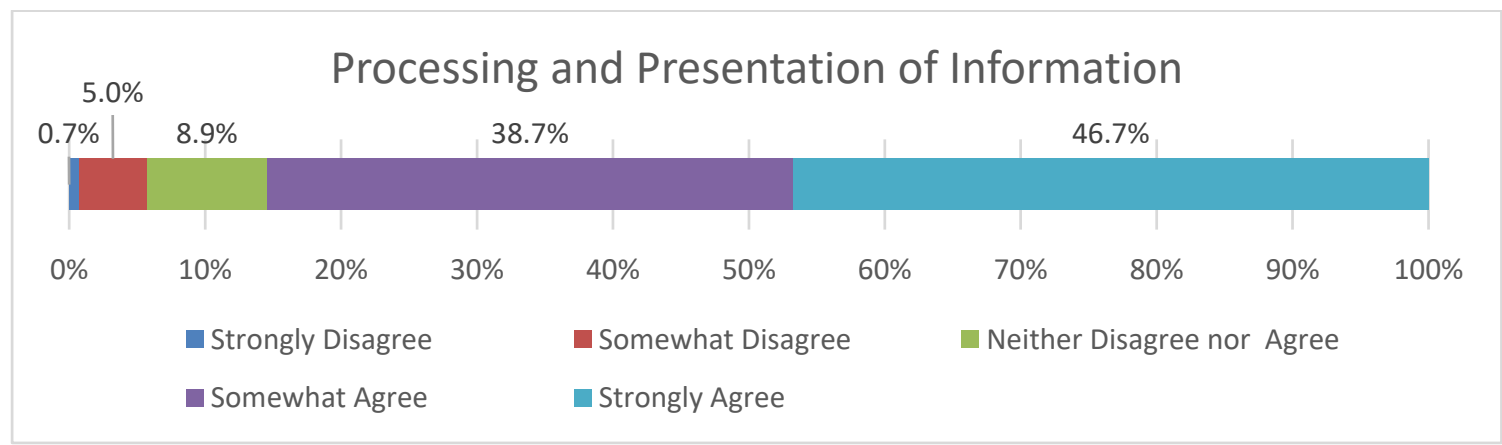

Figure 8. Stacked bar chart combining scaled responses for all eight performance statements to processing and presentation of information

A list of the eight performance statements that make up the processing and presentation of information digital learning domain precedes the results of these PSs. 
1. I am able to interpret information from multiple sources.

2. I am able to analyze information from multiple sources.

3. I am able to synthesize information from multiple sources.

4. I am able to write an appropriate response to a post.

5. I am able to use information and communications technologies to design or create new information from information already acquired.

6. I am able to visually organize data for learning purposes.

7. I can represent knowledge in a variety of ways such as PowerPoint, websites, blogs, etc.

8. I am aware of the difference in written, graphic or video representations.

Table 4.4 shows the frequency, percent, median, and interquartile range for each of the eight PSs for the processing and presentation of information DLD. In addition, Table 4.4 includes the summated frequencies for each rating scale along with their respective percentages, and the median and interquartile range of this DLD. Of the 123 cases in this data set for processing and presentation of information, the median response on the rating scale is four and the interquartile range is one. Cronbach's alpha for information management is 0.90, an acceptable value for reliability (Nunnally, 1978). 
Table 4.4 Descriptive Statistics for each PS for Processing and Presentation of Information

\begin{tabular}{|c|c|c|c|c|c|c|c|}
\hline \multirow[b]{2}{*}{ PS } & \multicolumn{5}{|c|}{$\begin{array}{c}\text { Rating scale (1-5) } \\
\text { Frequency and Percent }\end{array}$} & \multirow[b]{2}{*}{$M d n$} & \multirow[b]{2}{*}{ IR } \\
\hline & 1 & 2 & 3 & 4 & 5 & & \\
\hline 1 & $1(0.8 \%)$ & $3(2.4 \%)$ & $6(4.9 \%)$ & $53(43.1 \%)$ & $60(48.8 \%)$ & 4 & 1 \\
\hline 2 & $1(0.8 \%)$ & $6(4.9 \%)$ & $4(3.3 \%)$ & $52(42.3 \%)$ & $60(48.8 \%)$ & 4 & 1 \\
\hline 3 & $1(0.8 \%)$ & $7(5.7 \%)$ & $17(13.8 \%)$ & $51(41.5 \%)$ & 47 (38.2\%) & 4 & 1 \\
\hline 4 & $2(1.6 \%)$ & $6(4.9 \%)$ & $6(4.9 \%)$ & $50(40.7 \%)$ & $59(48.0 \%)$ & 4 & 1 \\
\hline 5 & $0(0.0 \%)$ & $8(6.5 \%)$ & $17(13.8 \%)$ & $51(41.5 \%)$ & $47(38.2 \%)$ & 4 & 1 \\
\hline 6 & $1(0.8 \%)$ & $5(4.1 \%)$ & $20(16.3 \%)$ & $53(43.1 \%)$ & $44(35.8 \%)$ & 4 & 1 \\
\hline 7 & $1(0.8 \%)$ & $7(5.7 \%)$ & $10(8.1 \%)$ & $39(31.7 \%)$ & 66 (53.7\%) & 5 & 1 \\
\hline 8 & $2(1.6 \%)$ & $7(5.7 \%)$ & $7(5.7 \%)$ & $31(25.2 \%)$ & 76 (61.8\%) & 5 & 1 \\
\hline Total & $7(0.7 \%)$ & $49(5.0 \%)$ & 87 (8.9\%) & $380(38.7 \%)$ & $459(46.7 \%)$ & 4 & 1 \\
\hline
\end{tabular}

Note. $N=123$. PS=Performance Statement. $1=$ Strongly disagree, $2=$ Somewhat disagree, $3=$ Neither disagree nor agree, $4=$ Somewhat agree, $5=$ Strongly agree. $M d n=$ Median. IR=Interquartile Range.

Team-based Learning in Digital Environments.

The stacked bar chart (Figure 9) displays aggregate responses to the eight PSs within the team-based learning in digital environments DLD. This bar chart combines the results from all 8 PSs and shows the percent of these aggregated responses for each level on the self-assessment scale (Strongly Disagree to Strongly Agree). A positive selfassessment (somewhat agree or strongly agree) describes $76.6 \%$ of the aggregated responses. A negative self-assessment (somewhat disagree or strongly disagree) describes $10.8 \%$ of the aggregated responses. 


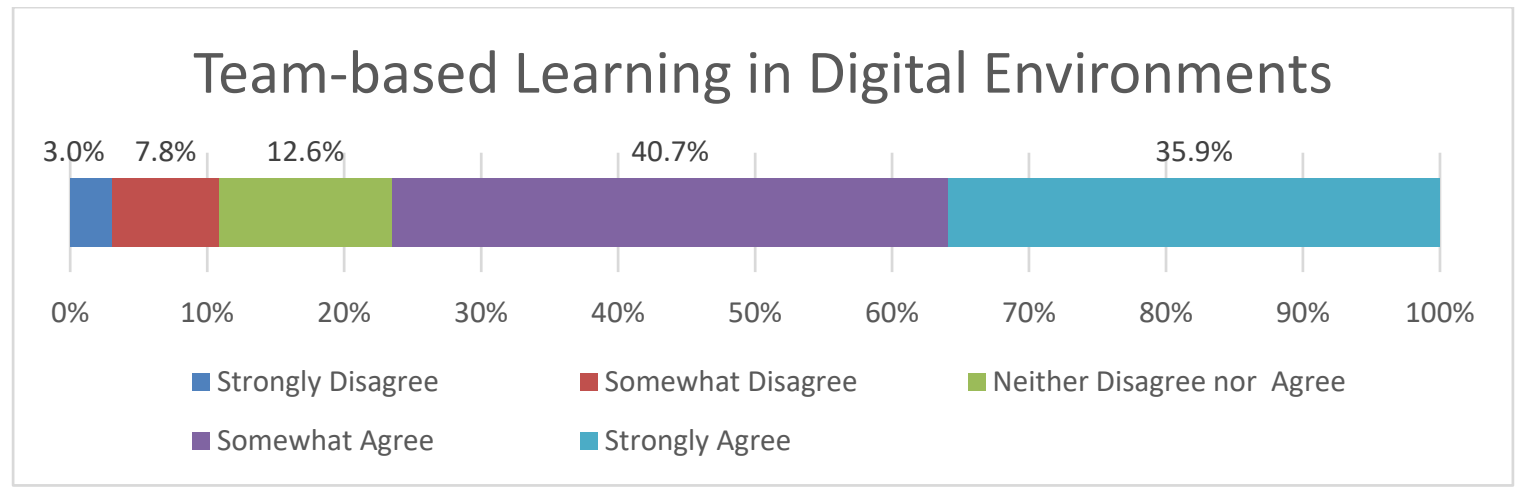

Figure 9. Stacked bar chart combining scaled responses for all eight performance statements to team-based learning in digital environments

A list of the eight performance statements that make up the team-based learning in digital environments digital learning domain precedes the results of these PSs.

1. During the preparation of a joint task I know how to fit in among team members.

2. During the preparation of a joint task I share my thoughts and insights with my peers.

3. During the preparation of a joint task I know that I have an influence on the work process.

4. During the preparation of a joint task I know what is expected of me.

5. While performing a joint task I feel that my contribution to the team is meaningful.

6. My peers are aware of my abilities and of what I can contribute.

7. I have no reservation regarding joint tasks.

8. I like to work with my peers on a joint task.

Table 4.5 shows the frequency, percent, median, and interquartile range for each of the 8 PSs for the team-based learning in digital environments DLD. In addition, Table 
4.5 includes the summated frequencies for each rating scale along with their respective percentages, and the median and interquartile range of this DLD. Of the 123 cases in this data set for team-based learning in digital environments, the median response on the rating scale is four and the interquartile range is one. Cronbach's alpha for team-based learning in digital environments is 0.89 , an acceptable value for reliability (Nunnally, 1978). This score improved to 0.90 with the elimination of the eighth PS.

Table 4.5 Descriptive Statistics for each PS for Team-based Learning in Digital Environments

\begin{tabular}{|r|l|l|l|l|l|r|r|}
\hline & \multicolumn{5}{|c|}{ Rating scale (1-5) } & & \\
\hline PS & \multicolumn{1}{|c|}{1} & \multicolumn{1}{|c|}{2} & \multicolumn{1}{|c|}{3} & \multicolumn{1}{|c|}{4} & \multicolumn{1}{|c|}{5} & Mdn & IR \\
\hline 1 & $3(2.4 \%)$ & $5(4.1 \%)$ & $14(11.4 \%)$ & $57(46.3 \%)$ & $44(35.8 \%)$ & 4 & 1 \\
\hline 2 & $2(1.6 \%)$ & $7(5.7 \%)$ & $6(4.9 \%)$ & $55(44.7 \%)$ & $53(43.1 \%)$ & 4 & 1 \\
\hline 3 & $3(2.4 \%)$ & $3(2.4 \%)$ & $9(7.3 \%)$ & $54(43.9 \%)$ & $54(43.9 \%)$ & 4 & 1 \\
\hline 4 & $1(0.8 \%)$ & $6(4.9 \%)$ & $6(4.9 \%)$ & $52(42.3 \%)$ & $58(47.2 \%)$ & 4 & 1 \\
\hline 5 & $4(3.3 \%)$ & $4(3.3 \%)$ & $12(9.8 \%)$ & $45(36.6 \%)$ & $58(47.2 \%)$ & 4 & 1 \\
\hline 6 & $0(0.0 \%)$ & $9(7.3 \%)$ & $23(18.7 \%)$ & $52(42.3 \%)$ & $39(31.7 \%)$ & 4 & 2 \\
\hline 7 & $6(4.9 \%)$ & $20(16.3 \%)$ & $33(26.8 \%)$ & $44(35.8 \%)$ & $20(16.3 \%)$ & 4 & 1 \\
\hline 8 & $11(8.9 \%)$ & $23(18.7 \%)$ & $21(17.1 \%)$ & $41(33.3 \%)$ & $27(22.0 \%)$ & 4 & 2 \\
\hline Total & $30(3.0 \%)$ & $77(7.8 \%)$ & $124(12.6 \%)$ & $400(40.7 \%)$ & $353(35.9 \%)$ & 4 & 1 \\
\hline
\end{tabular}

Note. $N=123$. PS=Performance Statement. 1=Strongly disagree, $2=$ Somewhat disagree, $3=$ Neither disagree nor agree, 4=Somewhat agree, 5=Strongly agree. $M d n=$ Median. IR=Interquartile Range.

\section{Awareness of Digital Integrity.}

The stacked bar chart (Figure 10) displays aggregate responses to the 15 PSs within the awareness of digital integrity DLD. This bar chart combines the results from all 15 PSs and shows the percent of these aggregated responses for each level on the selfassessment scale (Strongly Disagree to Strongly Agree). A positive self-assessment (somewhat agree or strongly agree) describes $88.5 \%$ of the aggregated responses. A negative self-assessment (somewhat disagree or strongly disagree) describes $6.4 \%$ of the 
aggregated responses.

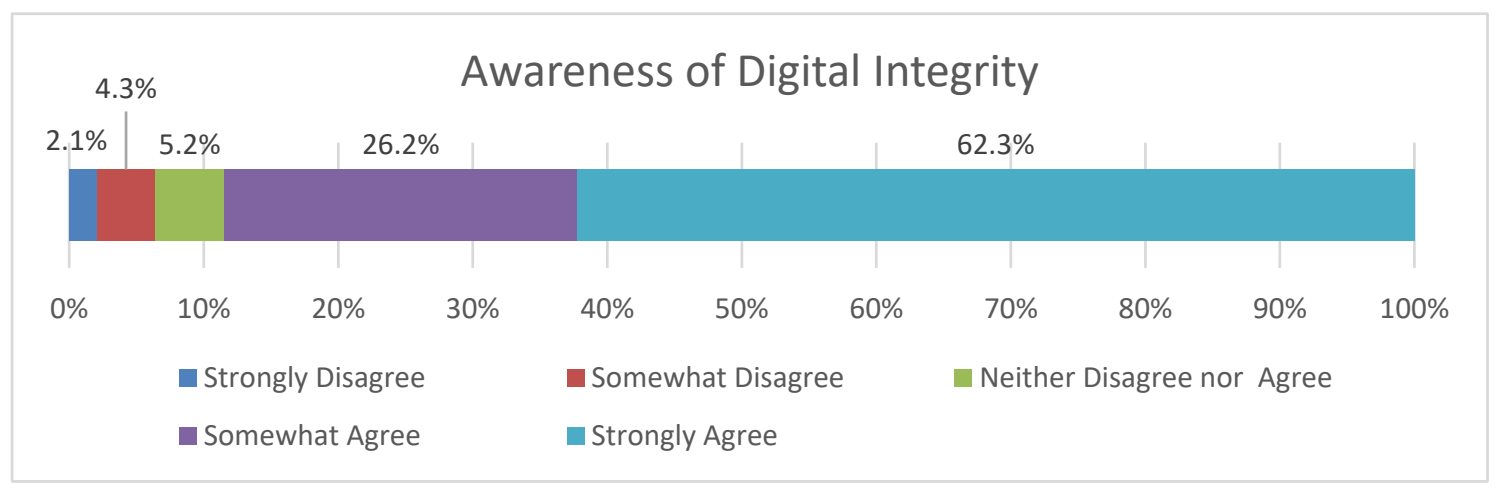

Figure 10. Stacked bar chart combining scaled responses for all 15 performance statements to awareness of digital integrity

A list of the 15 performance statements that make up the awareness of digital integrity digital learning domain precedes the results of these PSs.

1. I understand the ethical consequences of the use of technology.

2. I understand the social consequences of the use of technology.

3. I do not acquire digital information, files, programs, databases, etc., via illegal means.

4. I do not use technology for purposes that are intimidating or threatening.

5. I am aware of the prohibition of illegal file download

6. I am aware of copyright issues.

7. I am aware of appropriate acknowledgment of sources I use.

8. I am aware of the danger of my data being online.

9. I am aware of cyber-bullying issues.

10. I am aware of identity theft issues.

11. I am aware of e-theft issues.

12. I am aware of the danger from my online activities. 
13. I am aware of the influence my online data has.

14. I am able to identify/avoid online fraud or identity theft situations.

15. I am able to protect myself from online predators.

Table 4.6 shows the frequency, percent, median, and interquartile range for each of the 15 PSs for the awareness of digital integrity DLD. In addition, Table 4.6 includes the summated frequencies for each rating scale along with their respective percentages, and the median and interquartile range of this DLD. Of the 122 cases in this data set for awareness of digital integrity, the median response on the rating scale is five and the interquartile range is one. Cronbach's alpha for awareness of digital integrity is 0.93 , an acceptable value for reliability (Nunnally, 1978). This score improved to 0.94 with the elimination of the third PS.

Table 4.6 Descriptive Statistics for each PS for Awareness of Digital Integrity

\begin{tabular}{|c|c|c|c|c|c|c|c|}
\hline \multirow[b]{2}{*}{ PS } & \multicolumn{5}{|c|}{$\begin{array}{c}\text { Rating scale (1-5) } \\
\text { Frequency and Percent }\end{array}$} & \multirow[b]{2}{*}{$M d n$} & \multirow[b]{2}{*}{ IR } \\
\hline & 1 & 2 & 3 & 4 & 5 & & \\
\hline 1 & $1(0.8 \%)$ & $6(5.0 \%)$ & $6(5.0 \%)$ & $49(40.5 \%)$ & $59(48.8 \%)$ & 4 & 1 \\
\hline 2 & $1(0.8 \%)$ & $5(4.1 \%)$ & $2(1.7 \%)$ & $50(41.3 \%)$ & $63(52.1 \%)$ & 5 & 1 \\
\hline 3 & $4(3.3 \%)$ & $9(7.4 \%)$ & $14(11.5 \%)$ & $21(17.2 \%)$ & $74(60.7 \%)$ & 5 & 1 \\
\hline 4 & $4(3.3 \%)$ & $1(0.8 \%)$ & $2(1.6 \%)$ & $15(12.3 \%)$ & $100(82.0 \%)$ & 5 & 0 \\
\hline 5 & $3(2.5 \%)$ & $2(1.6 \%)$ & $8(6.6 \%)$ & $21(17.2 \%)$ & $88(72.1 \%)$ & 5 & 1 \\
\hline 6 & $2(1.7 \%)$ & $3(2.5 \%)$ & $5(4.2 \%)$ & $34(28.3 \%)$ & $76(63.3 \%)$ & 5 & 1 \\
\hline 7 & $2(1.6 \%)$ & $2(1.6 \%)$ & $2(1.6 \%)$ & $29(23.8 \%)$ & $82(71.3 \%)$ & 5 & 1 \\
\hline 8 & $4(3.3 \%)$ & $3(2.5 \%)$ & $4(3.3 \%)$ & $29(23.8 \%)$ & $82(67.2 \%)$ & 5 & 1 \\
\hline 9 & $2(1.6 \%)$ & $2(1.6 \%)$ & $5(4.1 \%)$ & $18(14.8 \%)$ & 95 (77.9\%) & 5 & 0 \\
\hline 10 & $2(1.6 \%)$ & $4(3.3 \%)$ & $6(4.9 \%)$ & $27(22.1 \%)$ & $83(68.0 \%)$ & 5 & 1 \\
\hline 11 & $2(1.6 \%)$ & 14 (11.5\%) & $10(8.2 \%)$ & $36(29.5 \%)$ & $60(49.2 \%)$ & 4 & 1 \\
\hline 12 & $3(2.5 \%)$ & $6(4.9 \%)$ & $5(4.1 \%)$ & $35(28.7 \%)$ & 73 (59.8\%) & 5 & 1 \\
\hline 13 & $3(2.5 \%)$ & $8(6.6 \%)$ & $10(8.2 \%)$ & $33(27.1 \%)$ & $68(55.7 \%)$ & 5 & 1 \\
\hline 14 & $4(3.3 \%)$ & $7(5.7 \%)$ & $9(7.4 \%)$ & $40(32.8 \%)$ & $62(50.8 \%)$ & 5 & 1 \\
\hline 15 & $1(0.8 \%)$ & $6(4.9 \%)$ & $7(5.7 \%)$ & $41(33.6 \%)$ & 67 (54.9\%) & 5 & 1 \\
\hline Total & $38(2.1 \%)$ & 78 (4.3\%) & 95 (5.2\%) & 478 (26.2\%) & $\begin{array}{l}1137 \\
(62.3 \%)\end{array}$ & 5 & 1 \\
\hline
\end{tabular}


Note. $N=119$. PS=Performance Statement. $1=$ Strongly disagree, $2=$ Somewhat disagree, $3=$ Neither disagree nor agree, $4=$ Somewhat agree, 5=Strongly agree. $M d n=$ Median. IR=Interquartile Range.

\section{Social Responsibility.}

The stacked bar chart (Figure 11) displays aggregate responses to the three PSs within the social responsibility DLD. This bar chart combines the results from all 3 PSs and shows the percent of these aggregated responses for each level on the self-assessment scale (Strongly Disagree to Strongly Agree). A positive self-assessment (somewhat agree or strongly agree) describes $90.2 \%$ of the aggregated responses. A negative selfassessment (somewhat disagree or strongly disagree) describes $3.3 \%$ of the aggregated responses.

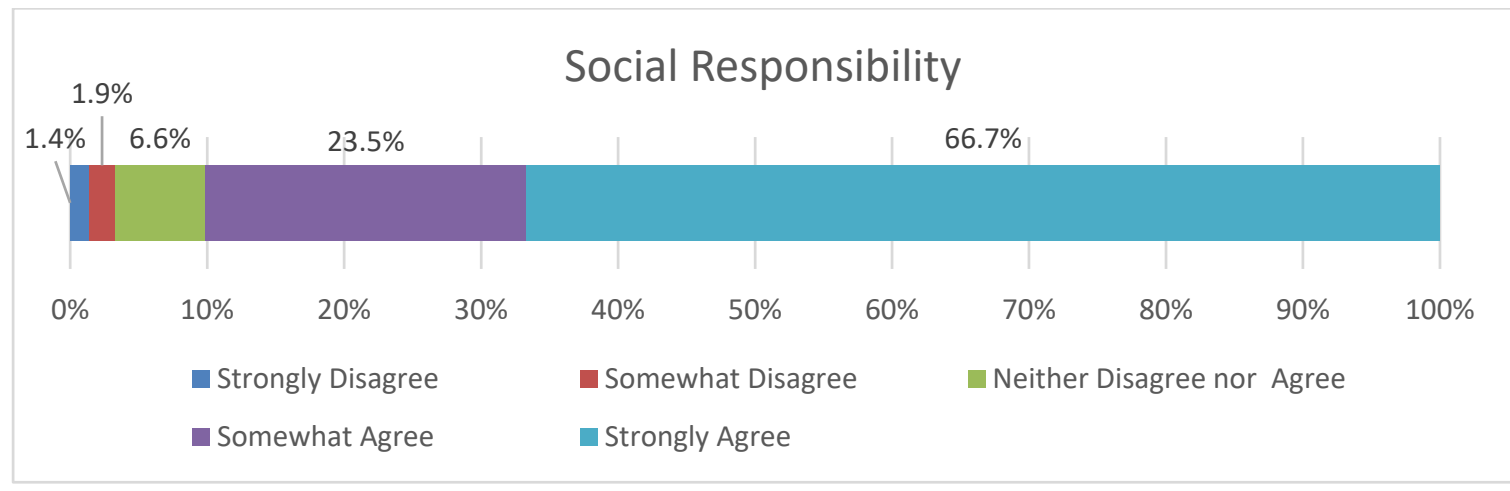

Figure 11. Stacked bar chart combining scaled responses for all three performance statements to social responsibility

A list of the three performance statements that make up the social responsibility digital learning domain precedes the results of these PSs.

1. I adhere to the rules of discourse and proper behavior in social networks.

2. I make sure not to reveal information about organizations without consent.

3. I make sure not to hurt others - people and organizations - online. 
Table 4.7 shows the frequency, percent, median, and interquartile range for each of the three PSs for the social responsibility DLD. In addition, Table 4.7 includes the summated frequencies for each rating scale along with their respective percentages, and the median and interquartile range of this DLD. Of the 122 cases in this data set for social responsibility, the median response on the rating scale is five and the interquartile range is one. Cronbach's alpha for social responsibility is 0.88 , an acceptable value for reliability (Nunnally, 1978).

Table 4.7 Descriptive Statistics for each PS for Social Responsibility

\begin{tabular}{|c|c|c|c|c|c|c|c|}
\hline \multicolumn{8}{|c|}{$\begin{array}{l}\text { Rating scale (1-5) } \\
\text { Frequency and Percent }\end{array}$} \\
\hline PS & 1 & 2 & 3 & 4 & 5 & Mdn & IR \\
\hline 1 & $2(1.6 \%)$ & $1(0.8 \%)$ & $4(3.3 \%)$ & $31(25.4 \%)$ & $84(68.9 \%)$ & 5 & 1 \\
\hline 2 & $0(0.0 \%)$ & $5(4.1 \%)$ & 15 (12.3\%) & $34(27.9 \%)$ & $68(55.7 \%)$ & 5 & 1 \\
\hline 3 & $3(2.5 \%)$ & $1(0.8 \%)$ & $5(4.1 \%)$ & $21(17.2 \%)$ & $92(75.4 \%)$ & 5 & 0 \\
\hline Total & $5(1.4 \%)$ & $7(1.9 \%)$ & $24(6.6 \%)$ & $86(23.5 \%)$ & $244(66.7 \%)$ & 5 & 1 \\
\hline
\end{tabular}

Note. $N=122$. PS=Performance Statement. $1=$ Strongly disagree, $2=$ Somewhat disagree, $3=$ Neither disagree nor agree, $4=$ Somewhat agree, $5=$ Strongly agree. $M d n=$ Median. IR=Interquartile Range.

\section{Quantitative Summary}

Given the recruitment procedures, a 95\% chance of sample having similar characteristics to the total population, and a $4 \%$ tolerance for error, the sample size expected for this research was 100 (Fowler, 1988). The sample $(N=125)$ exceeded the pre-determined goal of 100, and the demographics of the sample were in line with the total population. Table 4.8 provides a summary of the descriptive statistics for each of the digital learning domains. Only information management received an unacceptable reliability score of $\alpha=0.53$. All other DLDs received acceptable reliability scores of $\alpha=$ 
0.87 to $\alpha=0.94$. All DLDs with acceptable reliability scores had an interquartile range of one indicating scores were highly concentrated.

The DLDs with acceptable reliability, $\alpha$ above 0.87 , and concentrated data, IR $=$ one, maintained positive responses to self-assessment PSs. Awareness of digital integrity and social responsibility reported a median of five (strongly agree), and information research and retrieval, information validation, processing and presentation of information, and team-based learning in digital environments reported a median of four (somewhat agree). Only team-based learning in digital environments reported negative responses (strongly disagree or somewhat disagree) above ten percent (See Table 4.8 and Figure 12).

Table 4.8 Descriptive Statistics for each DLD

\begin{tabular}{|l|c|c|c|c|c|c|}
\hline DLD & $\begin{array}{c}\text { Negative } \\
\text { Response }\end{array}$ & $\begin{array}{c}\text { Neutral } \\
\text { Response }\end{array}$ & $\begin{array}{c}\text { Positive } \\
\text { Response }\end{array}$ & $M d n$ & IR & $\begin{array}{c}\text { Cronbach's } \\
\text { Alpha }\end{array}$ \\
\hline $\begin{array}{l}\text { Information research } \\
\text { and retrieval }\end{array}$ & $5.8 \%$ & $8.9 \%$ & $85.3 \%$ & 4 & 1 & 0.94 \\
\hline Information validation & $6.2 \%$ & $9.1 \%$ & $84.7 \%$ & 4 & 1 & 0.87 \\
\hline $\begin{array}{l}\text { Information } \\
\text { management }\end{array}$ & $18.2 \%$ & $12.1 \%$ & $69.7 \%$ & 5 & 2 & 0.53 \\
\hline $\begin{array}{l}\text { Processing and } \\
\text { presentation of info. }\end{array}$ & $5.7 \%$ & $8.9 \%$ & $85.4 \%$ & 4 & 1 & 0.90 \\
\hline $\begin{array}{l}\text { Team-based learning in } \\
\text { digital environments }\end{array}$ & $10.8 \%$ & $12.6 \%$ & $76.6 \%$ & 4 & 1 & 0.89 \\
\hline $\begin{array}{l}\text { Awareness of digital } \\
\text { integrity }\end{array}$ & $6.4 \%$ & $5.1 \%$ & $88.5 \%$ & 5 & 1 & 0.93 \\
\hline Social responsibility & $3.3 \%$ & $6.5 \%$ & $90.2 \%$ & 5 & 1 & 0.88 \\
\hline
\end{tabular}

Note. $N=125$. DLD=Digital Learning Domain. Negative Response=Percent combined Stronglydisagree and Somewhat-disagree responses. Positive Response=Percent combined Somewhatagree and Strongly-agree responses. $M d n=$ Median. IR=Interquartile Range. 


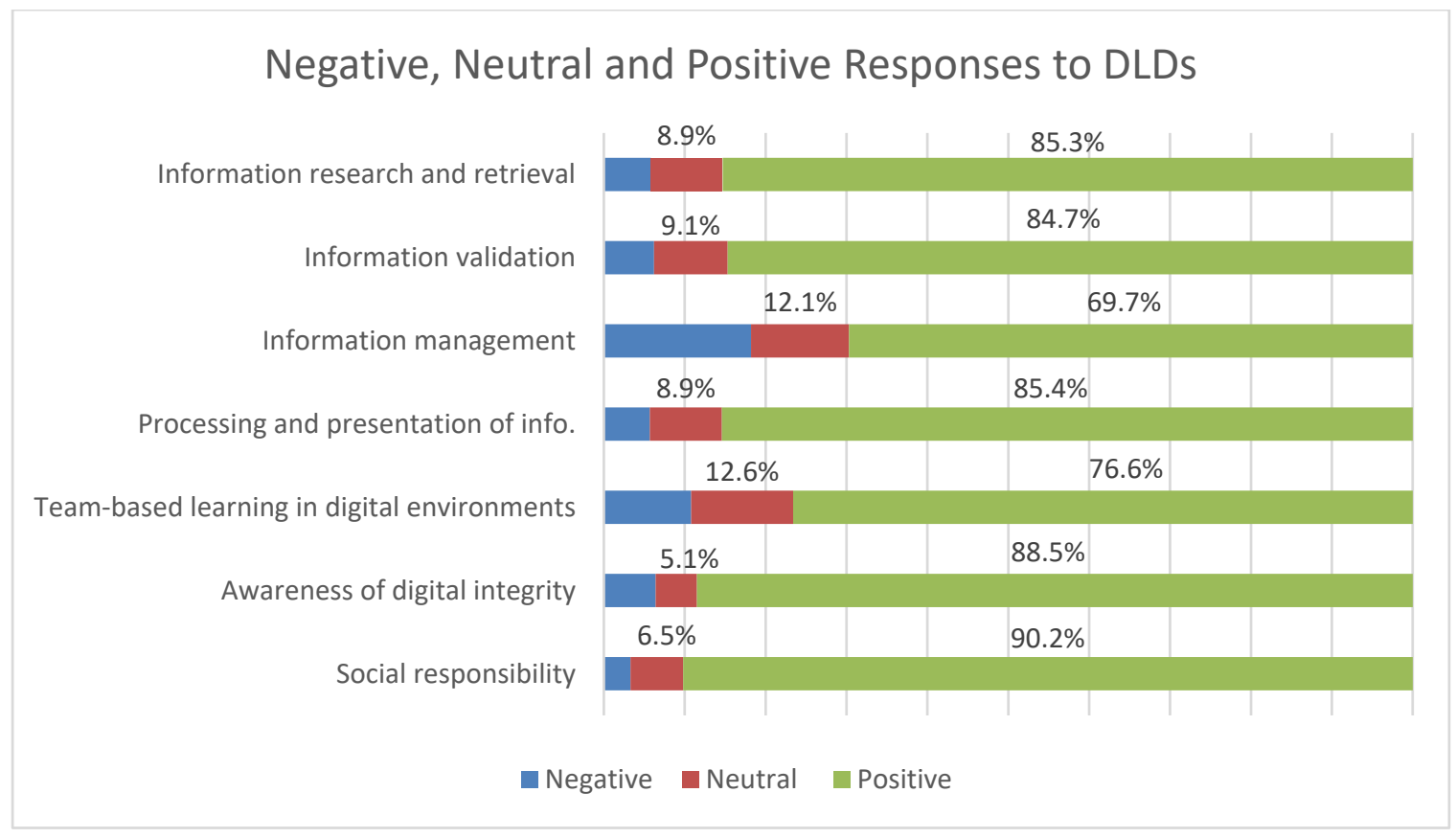

Figure 12. A graphical representation of negative, neutral, and positive responses to DLDs. Note information management $(\square=\mathbf{0 . 5 3})$

\section{Qualitative Data}

The qualitative data collected for this study included digital artifacts, reflections and explanations from 27 students. These data aim to answer the second research question: How do supporting digital files and text reflections and explanations extend Kurtz and Peled's (2016) instrument assessing digital literacy? The results in this section, systematically constructed using qualitative content analysis (QCA), follow the conceptual organization of Kurtz and Peled's (2016) seven DLDs. Within this conceptual organization section, results presented for each DLD begin with the prompt provided to students. Prompts were only provided to offer students examples of what they might choose to submit. As indicated at the beginning of the qualitative page of the survey, "Examples are not intended to be exhaustive. Feel free to offer a reflection and/or explanation of any evidence you believe supports earlier responses." In addition, a 
systematic data driven analysis using a constant comparative approach produced interesting findings beyond the DLD framework. The data driven analysis section reports these findings. Microsoft's Excel and NVivo 11 Starter supported the analysis and representation of the results in both sections.

\section{Conceptual Organization}

Each subsection here (DLD) begins with the prompt given to students, includes descriptive aspects of the data collected that are representative of the DLD, and includes examples of students' artifacts, reflections, and explanations. A multi-pass approach reveled some artifacts were representative of multiple DLDs. Where appropriate, explanations are included.

Information Research and Retrieval. Prompt: "Link to or screenshot of resource from prior research with reflection/explanation of why and where you found it." Only one student provided qualitative data for information research and retrieval. A screenshot of an article found in Messiah College's library database accompanied an explanation of the resource. The student indicated the article provided supporting evidence for a group persuasive speech on the importance of vaccinations, and further explained the research process stating, "I found it using the 'Academic Search Complete' link from the Messiah College Murray Library website. I used the search term 'immunization benefits' and limited the results to full-text articles from scholarly journals."

Information Validation.

Prompt: "Link to or screenshot of resource with reflection/explanation of how you evaluated the reliability and credibility of the information." No qualitative data were 
received for the information validation DLD. Chapter five includes a discussion on the absence of data for this DLD.

Information Management.

Prompt: "Provide screenshot of file structure with reflection/explanation as to how you organize your files." Eleven students provided qualitative data for the information management DLD. In addition, one student who submitted data for the awareness of digital integrity DLD referenced the use of bookmarking web pages for organizational purposes, making the total number of students supplying qualitative evidence to this DLD twelve. Figure 13 shows the nodes used in NVivo to organize these artifacts.

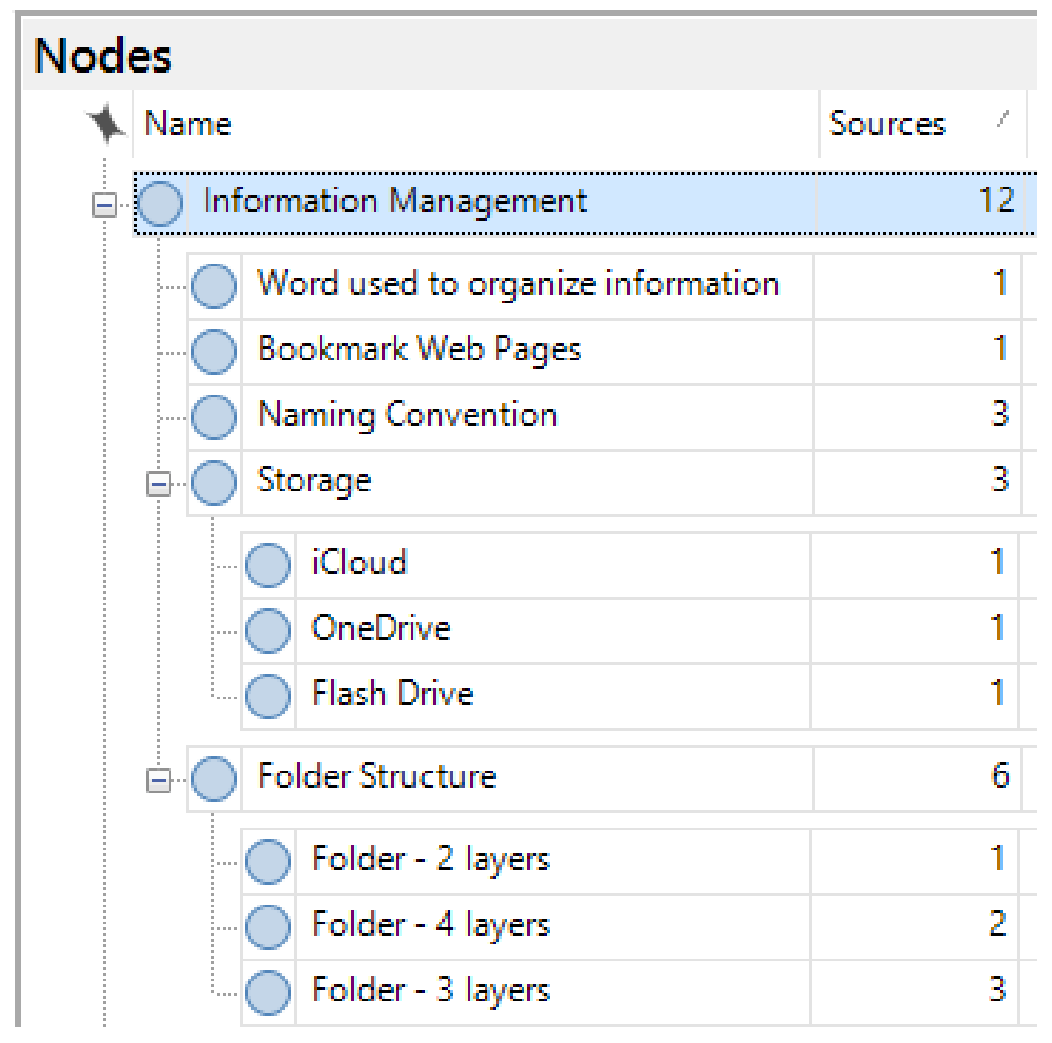

Figure 13. A screenshot of nested nodes within NVivo for the Information Management DLD 
Six students discussed the layers of their folder structure. Three students

referenced file storage, with one mentioning the use of a flash drive for back up and two others indicating their use of cloud storage (iCloud and OneDrive). Three students

referenced file naming conventions. Finally, one student provided a text only submission stating, "I organize my information on word."

Eight students submitted screenshots, with six including text descriptions. One student included the following explanation with screen shots appearing in Figure 14.

Hello!! I organize my files first by the year, and then by the semester. After that I break down each semester into each of my different classes or schedules for that semester. How I organize from there depends on the class. If there is a regular kind of assignment I normally organize those in files within the class folder, but other than that, I just have everything related to that class in that file. I like being really organized."

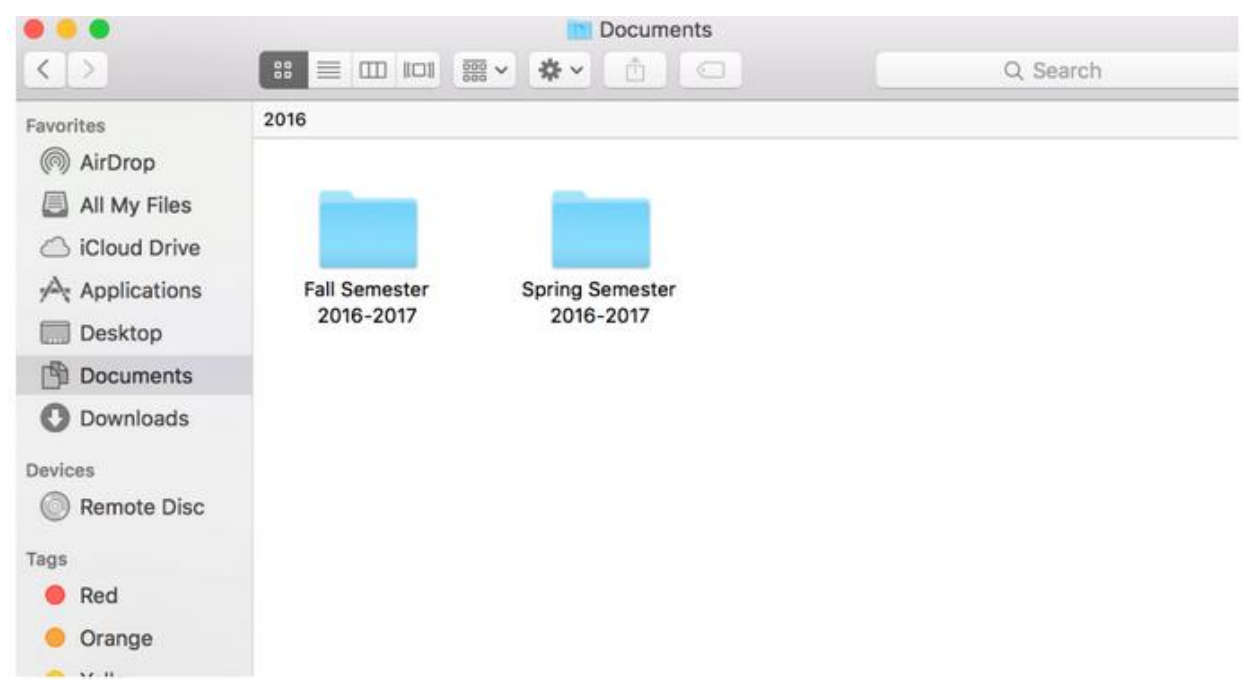




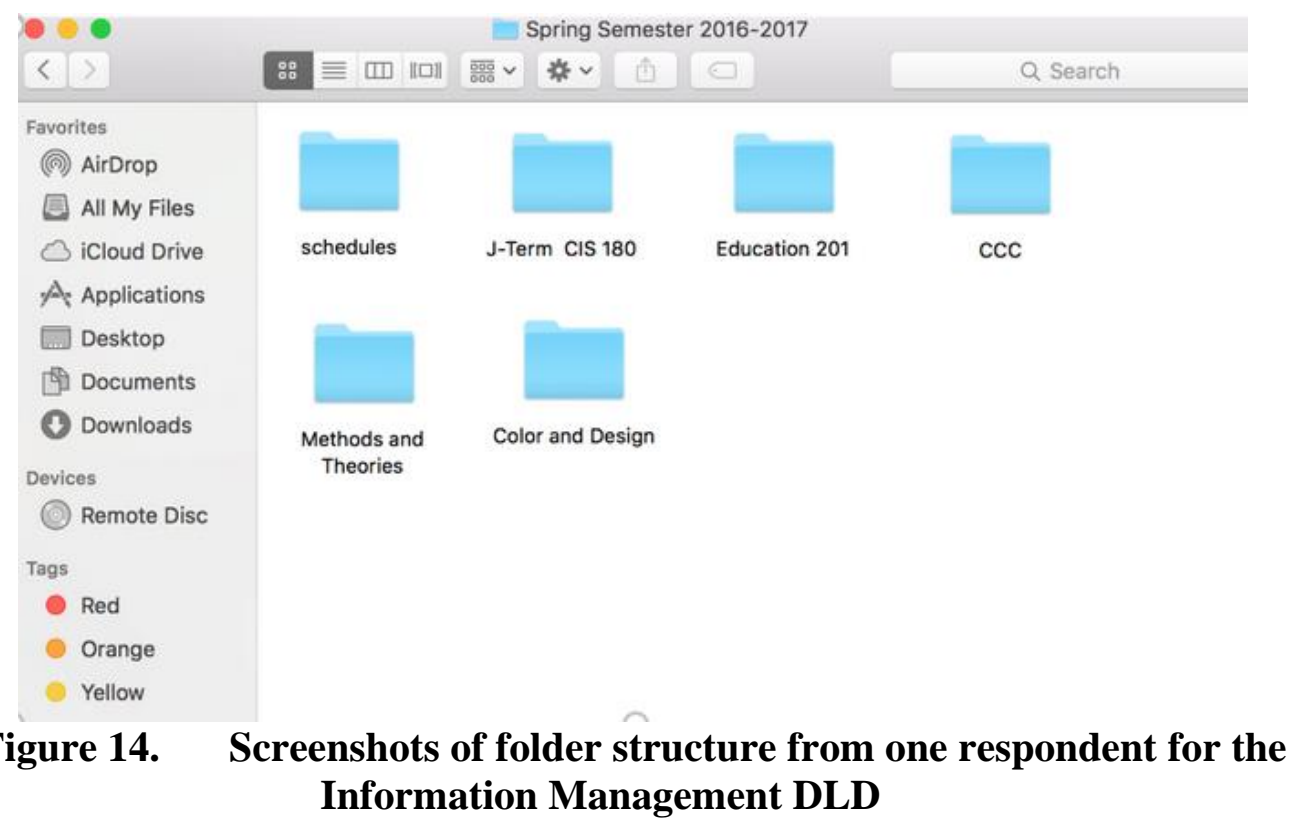

Processing and Presentation of Information.

Prompt: "Link to or attach presentation completed in prior course work with reflection/explanation on how you processed and created the artifact." Five students submitted artifacts to the processing and presentation of information DLD. The digital artifacts and text responses displayed a variety of tools used to support the presentation of information, including: Excel, Piktochart, HTML/CSS, Video, and PowerPoint. Three students mentioned their artifacts supported group work. The five cases presented here give a sense of the breadth and depth of work submitted. One student submitted artifacts from two group projects, a PowerPoint presentation and an infographic (Figure 15). 


\section{Healthy Family Infographic What makes a family healthy?}
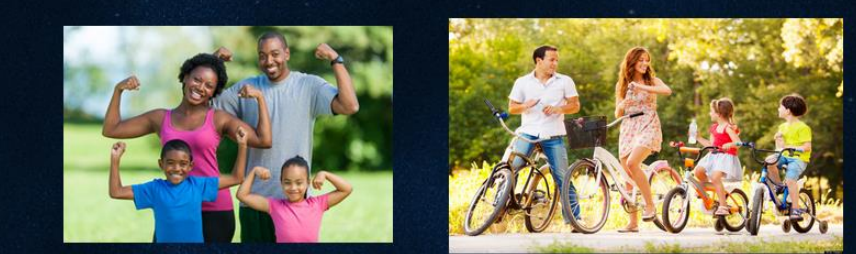

a) Slide Preview In Transition Delaut v $\because$ Expand To Fit $\mathbf{E}$

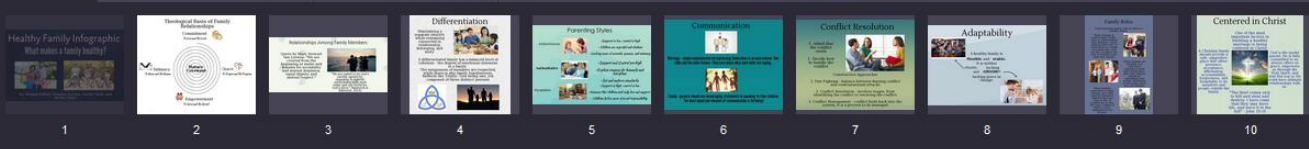

Figure 15. A screenshot of a public infographic developed as a group project for a class

One student submitted a video (Figure 16) they created to include within a larger group

PowerPoint project.

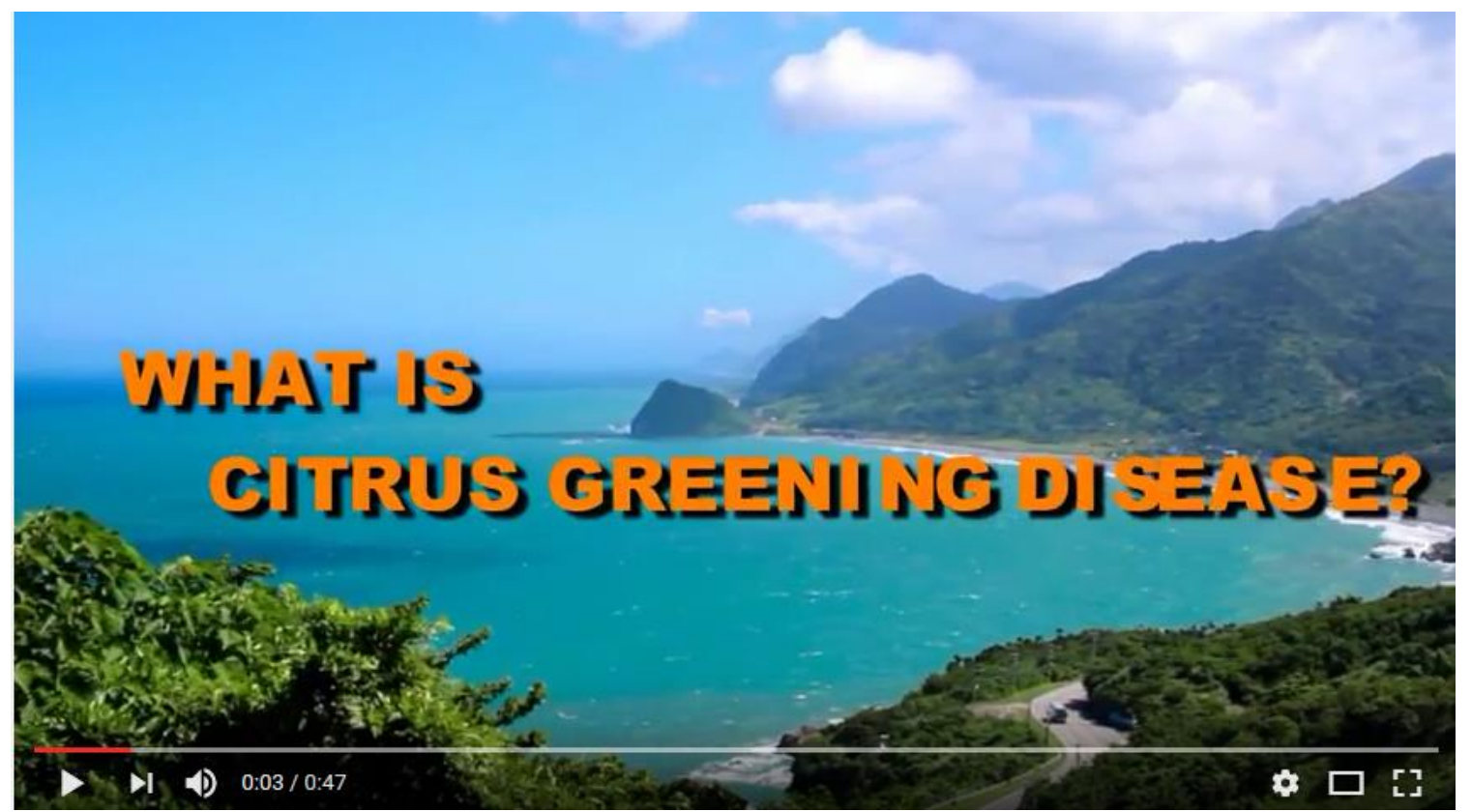

Figure 16. A screenshot of a video developed as a component of a larger group PowerPoint presentation 
One student submitting a PowerPoint artifact and also shared a detailed explanation of

their intended purpose for selecting PowerPoint and their struggles with the tool.

The task was to include seven words or fewer per slide, since our professor wanted us to be speaking French extemporaneously, and not reading from the screen.

Because of that restriction, I had to create an almost entirely image-based presentation, using words only for the titles of each section and for displaying various unfamiliar terms. To keep things cohesive, I used a total of six background images to correspond to the six different categories of research. Also, because a slide stuffed with busy images isn't always the easiest to look at and understand, I decided to present one image at a time, and only proceed to the next when I was done talking about the previous one. That way, my audience could focus on only the image I was using to illustrate my point, and not becoming distracted by all the visual noise around them. By the time I was done with each slide, the potentially chaotic patchwork of imagery could represent a cohesive, meaningful whole.

To do this, I relied heavily on PowerPoint's animation feature, a much more convenient alternative to creating a new slide for each tiny change - e.g. slides 714, which I think I had trouble using the animation feature with and ended up just relying on the old-school method. What I wanted to accomplish with slides 15-34 was maybe a little beyond the scope of animations, as well, since I wanted to display only one image and make the others disappear for the moment. So although it had its hiccups, I learned a lot about how useful the animation tool can be for adding elements within a slide itself, and in the end cleared up the clutter of the hundreds of slides I may have had without it.

One student shared a website they created using HTML and CSS as part of a computer and information systems class (Figure 17). 


\section{\begin{tabular}{l|l|l|l} 
Home & Benefits of Prayer & Prayer Methods & Prayer Topics
\end{tabular} Prayer Has Power \\ Devote yourselves to prayer, being watchful and thankful. - Colossians 4:2 (NIV)}

Poverty. Homelessness. Terrorism. Violence. Racism. Sexism. Addictions. These tragedies are occuring not only throughout our nation, but also throughout the world. Society as a whole is in desperate need of prayer, as that is the only method to truly begin to combat the above metioned issues. From the creation of this website, I hope to help Christians and non-Christians alike grow closer to the Lord through the power of prayer.

Within this website, I plan to introduce a few of the many benefits of prayer in order to hopefully show readers how valuable spending time in prayer can be. In addition, I will make known several methods of prayer to aid in readers' confidence in prayer as well as spiritual growth. Finally, I will discuss prayer topics to inspire readers to begin praying for more than just themselves.

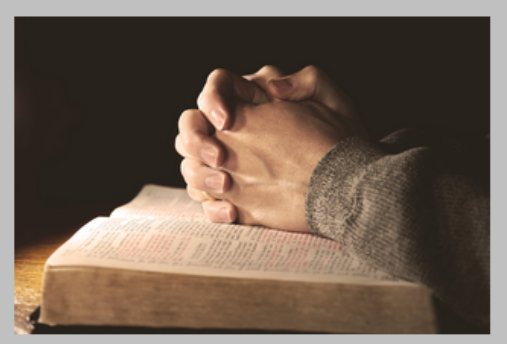

As previously mentioned, the world is in desperate need of prayer. Prayer for safety. Prayer for guidance. Prayer for salvation. The Lord is gradually breaking

my heart for what breaks His. In doing so, He has made me more and more aware of the issues in the world today, and He has also taught me that regardless of what we can or can't do to help, prayer is the best answer.

Figure 17. A screenshot of a public website developed with HTML and CSS for a class

One student shared an Excel document (Figure 18) used to "give [information] a cohesive look." 


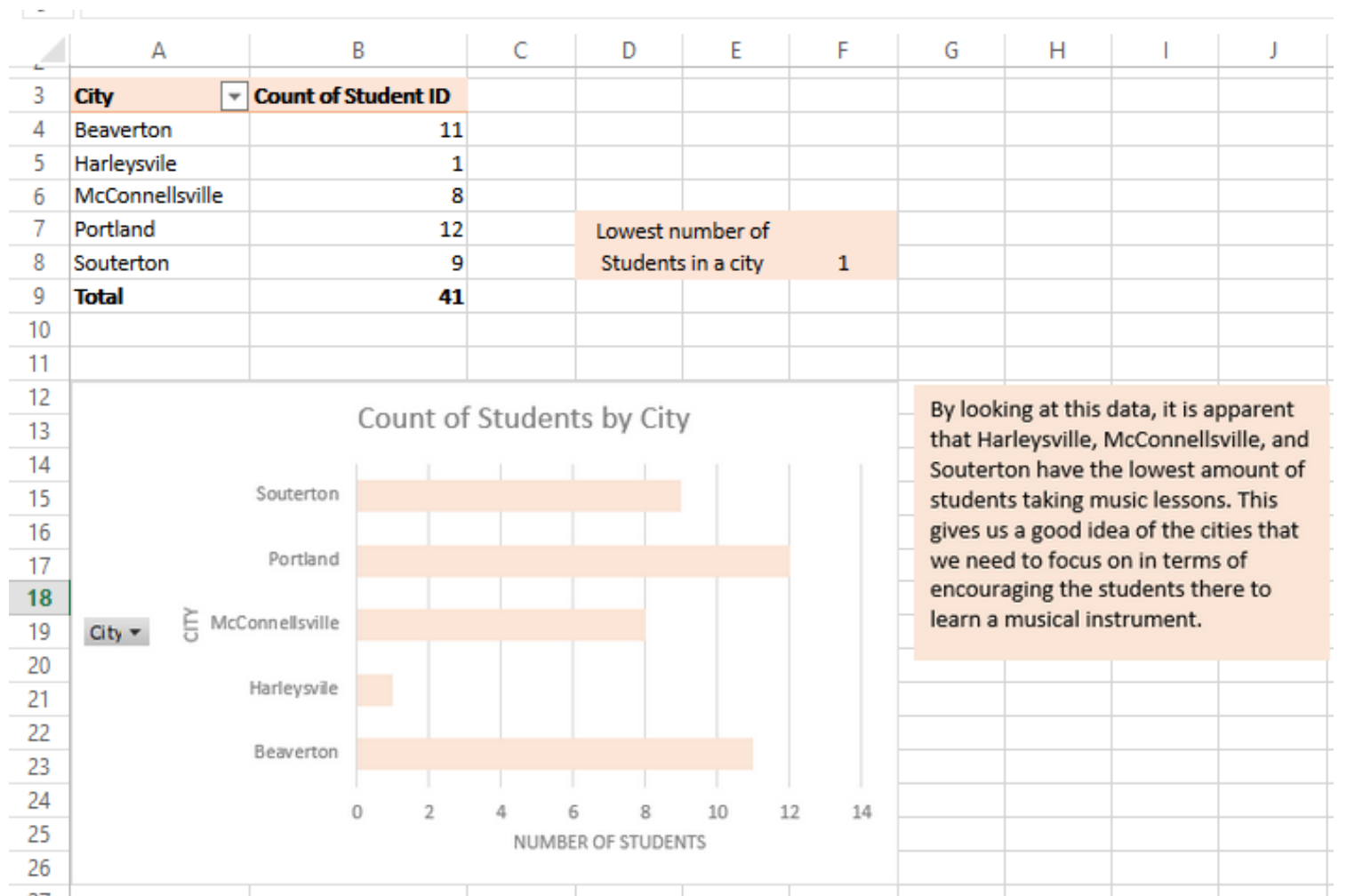

\section{Figure 18. A screenshot of one sheet in an Excel project used to display information}

Team-based Learning in Digital Environments.

Prompt: "Reflect/explain your learning experiences in online discussions and

online group projects." Three students submitted qualitative artifacts to the team-based learning in digital environments DLD. Two of the respondents referenced collaboration, with one highlighting Google Drive as being instrumental for working on projects, and another expressing the benefits of group work,

"I personally feel I learn more in group discussions and projects because in groups, it is not just my mind that is thinking on a topic. I feel this allows various viewpoints to be mentioned and an entire new way of thinking to emerge."

Text reflections and explanations also reflected benefits for planning, time management, and leadership. One student noted, "I have liked learning online and online group projects 
because I am busy with my schedule it helps me be more effective with the time I need to complete the task."

Another student submitting qualitative data for the processing and presentation of information DLD included a group PowerPoint and group infographic. While these artifacts have a greater affinity for the processing and presentation of information DLD, they are mentioned here as well because the student indicated they were group projects for a class presentation.

\section{Awareness of Digital Integrity.}

Prompt: "Provide reflection/explanation regarding active steps you take to avoid and/or proactively address ethical issues online." Two students submitted text artifacts to the awareness of digital integrity DLD. Concerns related to copyright included in both text reflections address the legal and ethical issues representative of this domain. One student reported the following:

Because I used to pirate a lot of content in middle school, I am well aware of copyright issues when it comes to movie, video, and program files. I remember when SOPA emerged and got scared as Megaupload closed and the likes.

The other student indicated: "I am sure to bookmark [resources from the web] and cite them in my paper if I am using a concept or idea from that webpage."

Two other students submitted qualitative data for the processing and presentation of information DLD that included: a works cited page, and an explanation of artifacts used in a group project. The attribution of sources for these projects fits well in the awareness of digital integrity DLD. As one participant explained,

"I created this video to be included in a group Ecology/Sustainability class as an element of a larger PowerPoint presentation. Most audiovisual aspects were public domain. Content creators of other visual elements were attributed in the PowerPoint." 
In addition, two students submitted qualitative data for the social responsibility DLD that included reference to legality. They stated, "You shouldn't use [social media] for illegal purposes" and "I do not engage in illegal downloading since it is not ethical." These artifacts share properties within the awareness of digital integrity DLD and are, therefore, referenced here.

\section{Social Responsibility.}

Prompt: "Reflect/explain on your actions regarding your social responsibility."

Five students submitted text artifacts to the social responsibility DLD. Ethics and appropriate use of technology were concepts repeated most frequently $(N=3)$. The importance of active participation against cyber bullying and illegal behaviors, and respecting others were concepts repeated more than once. Four participants' responses are included here.

"To me, my social responsibility is to not cyberbully in regards to social literacy. Being an active participant in several platforms of social media it is important for me to stand up for people when they are being degraded via internet and be constantly aware of how my words and comments online can be taken."

"I feel that I act very responsibly on social media. I do not post things that would be considered rude or inappropriate to others. In fact, I hardly post at all! When I do, it is photos on Instagram. Even when doing this, I am very careful that the photos I post and captions I use will not reflect negatively on myself or anyone else in the photo to ensure that others will not be offended by any content and that it will not affect my ability to get a job. Thanks!"

"For me, social responsibility is imperative since it is so easy to forget the impact that our actions have. That being said, I actively try to make sure that the things I post on various social media platforms are appropriate."

"Being responsible on social media is of the upmost importance. Your social media is an extension of you... Nowadays employers actually look at your social media because they often show ones true character." 


\section{Summary of Conceptual Organization.}

In summary, students provided qualitative artifacts to all but one of the DLDs, information validation. While the artifacts from 27 cases were easily organized within the remaining six DLDs, six student artifacts included properties significant to multiple DLDs. Five of the six cases included properties relevant to awareness of digital integrity. These five cases shared properties with three other DLDs (one with information management, two with social responsibility, and two with processing and presentation of information). One case shared properties between team-based learning in digital environments and processing and presentation of information. Figure 19 represents the overlapping features described here. Each circle is sized proportionally to the number of cases with overlapping features representative to that particular DLD. Black lines represent cases.

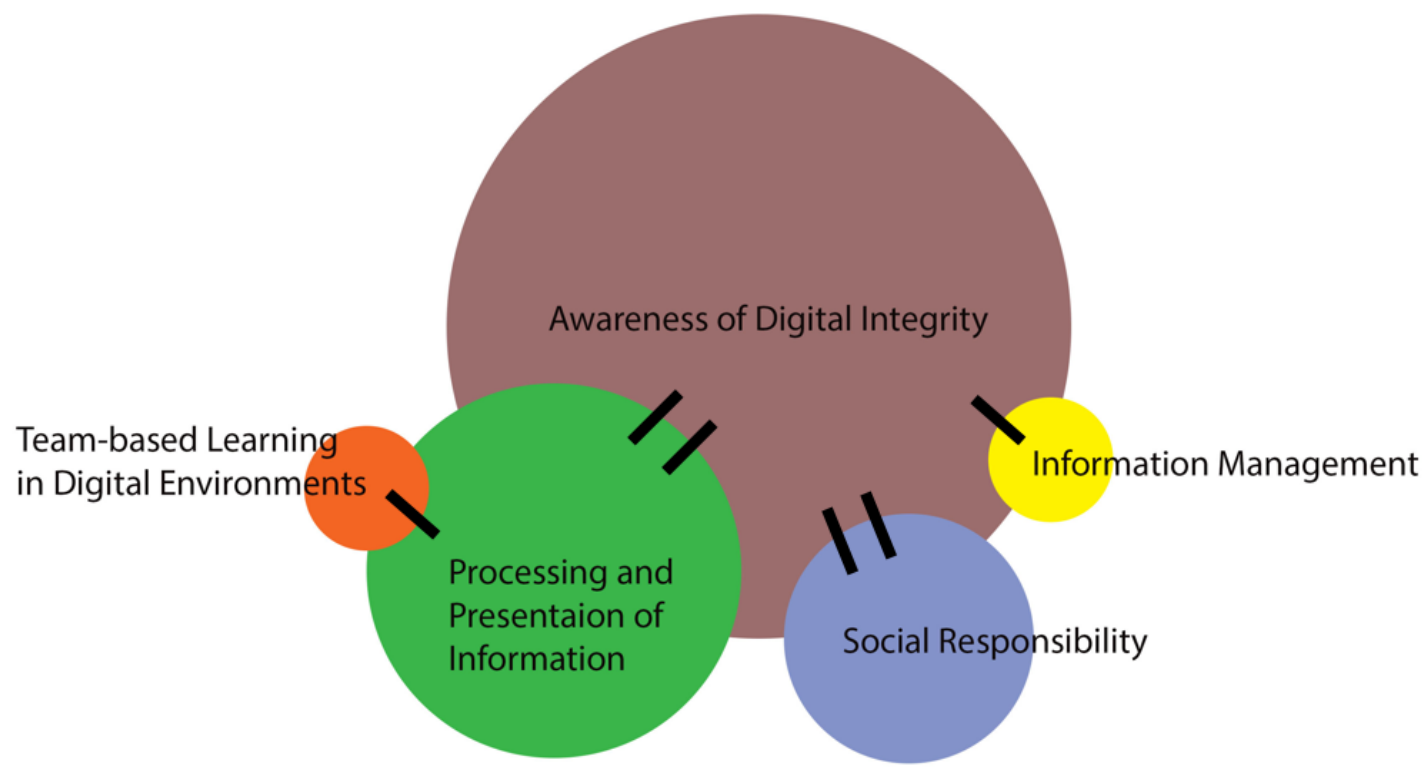

Figure 19. Cases with properties overlapping multiple DLDs. Circle size proportional to number of cases 


\section{Data Driven Analysis}

A systematic data-driven analysis supported the abstraction of concepts that ultimately resulted in the emergence of a category separate from the conceptual organization of the DLDs. This category, emotion, appeared in 15 of the of the 27 cases. All but one of the 15 students shared positive emotions. Six students presented care/concern and four students presented confidence in their submissions. Only fear emerged as a negative emotion. Figure 20 shows the nodes used in NVivo to code these emotions.

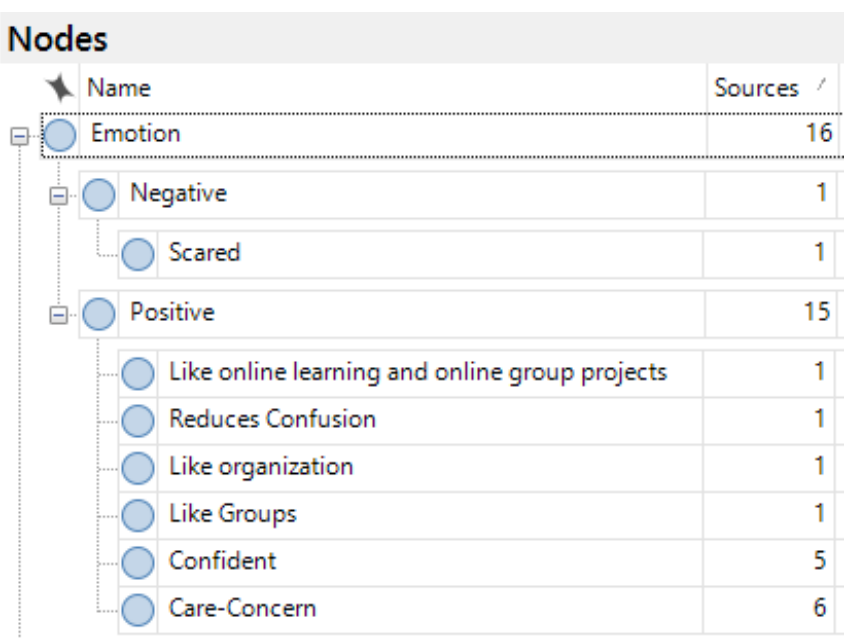

Figure 20. A screenshot of nested nodes within NVivo for emotion

Included below are quotes from the qualitative data where this researcher observed specified negative and positive emotions.

- Scared - "I remember when SOPA emerged and got scared as Megaupload closed and the likes."

- Like online learning - "I have liked learning online and online group projects because I am busy with my schedule it helps me be more effective with the time I need to complete the task." 
- Reduces confusion - "I make sure to save all my work for that class in the same place so I am not confused about where the file is later."

- Like organization - "I like being really organized."

- Like groups - "I personally feel I learn more in group discussions and projects because in groups, it is not just my mind that is thinking on a topic. I feel this allows various viewpoints to be mentioned and an entire new way of thinking to emerge."

- Confident - "I am the Media Team leader for Minds Matter, a campus organization th[at] promotes mental health. I oversee the social media pages, but my leadership position also requires me to work with leaders on the other teams as well as with the group president. As we only meet once a week, the majority of our communication takes place over e-mail and instant message, however, I have never had a problem with miscommunication. Cloud storage spaces like Google Drive are also instrumental to our group, as it allows us to collaborate on projects outside of meetings."

- Care-concern - "To me, my social responsibility is to not cyberbully in regards to social literacy. Being an active participant in several platforms of social media it is important for me to stand up for people when they are being degraded via internet and be constantly aware of how my words and comments online can be taken.”

Artifacts representing confidence bridged three DLDs: information management, processing and presentation of information, and team-based learning in digital environments. Artifacts representing care/concern bridged two DLDs, awareness of 
digital integrity and social responsibility. Interestingly, all five of the students submitting digital artifacts to the social responsibility DLD expressed care/concern. Figure 21 shows each of the emotions presented according to their respective DLDs.

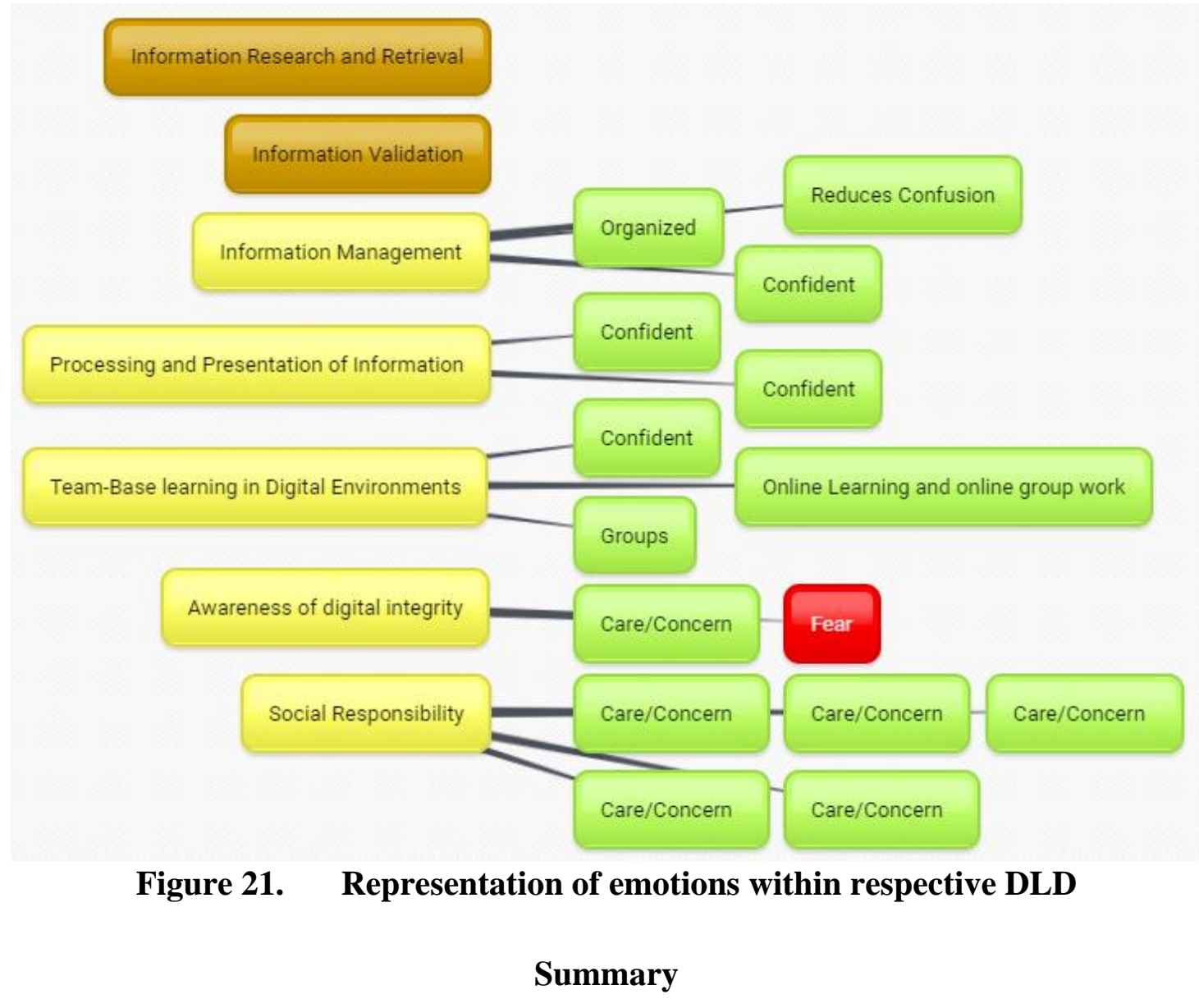

The quantitative data set $(N=125)$ met the sample size expectation for this study, and the descriptive statistics of the demographics of the data set were in line with the demographics of the target population of first year students at Messiah College. Reliability of the seven DLDs were acceptable for all but one DLD. Only information management received an unacceptable reliability score of $\alpha=0.53$. All other DLDs received acceptable reliability scores between $\alpha=0.87$ and $\alpha=0.94$. Scores were highly concentrated on the positive end of the scale for all DLDs having an acceptable 
reliability. These DLDs presented an interquartile range of one and a median of four (somewhat agreeable) or five (strongly agreeable).

The qualitative data set $(N=27)$ offered artifacts for all but one of the DLDs, information validation. Digital artifacts included in this data set offered evidence of students understanding of each of the DLDs represented. These data reveal the complexity of digital literacy, as six cases offered artifacts with properties relevant to multiple DLDs. Emotion emerged as its own category from a systematic data-driven analysis of these digital artifacts. Emotion appeared in all but the information research and retrieval and information validation DLDs. Care/concern, and confidence emerged across multiple DLDs. 


\section{CHAPTER FIVE: SYNTHESIS, INTERPRETATIONS, AND}

\section{FINAL THOUGHTS}

The acceleration of information and communications technologies (ICTs) over the last half of the $20^{\text {th }}$ century and initial decades in the $21^{\text {st }}$ century is facilitating a shift in nearly all socio-cultural elements around the globe (Jenkins et al., 2006; UNESCO, 2016). It is essential for institutions of higher education to align their institutional frameworks with society's emerging realities (Ewell, 2015). The purpose of this study was to support Messiah College in its efforts to align its guiding principles with the socio-cultural environment by measuring first year students' digital literacies.

This exploratory study followed an embedded mixed methods design, including quantitative and qualitative components within one traditional design (Creswell, 2012; Creswell \& Plano Clark, 2011). First year students at Messiah College participating in the study completed a survey that began with a primary quantitative component and ended with a supplementary qualitative component. The quantitative component, provided by Kurtz and Peled (2016), includes 54 performance statements organized among seven digital learning domains: (a) information research and retrieval, (b) information validation, (c) information management, (d) processing and presentation of information, (e) team-based learning in digital environments, (f) awareness of digital integrity, and (g) social responsibility. First year students at Messiah College participating in the study rated themselves on a five point Likert-type scale for each of the 54 performance statements. Analysis of the quantitative data sets produced descriptive statistics for each 
DLD. The supporting qualitative component, provided opportunities for respondents to submit digital artifacts demonstrating their digital literacy. Qualitative content analysis of the qualitative data set: (a) provided additional insights to students' understanding of each DLD, (b) demonstrated digital literacies complexity; and (c) presented an additional relevant category, emotion. A synthesis of the results of these independent analyses follows. Researcher interpretations and final thoughts complete Chapter five.

\section{Synthesis of Quantitative and Qualitative Components}

A synthesis of the quantitative and qualitative results provides for a more detailed assessment of Messiah College's first year students' digital literacy. Details of this synthesis of the quantitative and qualitative components begins with the DLD reported as the students' strongest digital learning domain, social responsibility; and concludes with the DLDs reported to have a relatively lower combined assessment.

Social responsibility was the only DLD with quantitative results producing positive responses over $90 \%$. In addition, five digital artifacts supplied qualitative data representing students' strength in this area and established connections to other DLDs. Students' attitudes demonstrating care and concern about their: (a) appropriate use of technology, (b) active participation, and (c) respect for others when engaging in digital environments were evident. The combined results for this DLD produced the strongest assessment relative to the combined results of all other DLDs.

The quantitative results for the awareness of digital integrity and processing and presentation of information produced positive responses between $80 \%$ and $90 \%$. In addition, the digital artifacts supplied for these DLDs demonstrated students' strengths in these areas and established connections to other DLDs. Students' levels of confidence 
were evident in their descriptions of multimedia productions, and they presented both positive and negative emotions related to the legal and ethical issues of awareness of digital integrity.

Combined results for information management and team-based learning in digital environments were not as strong as results for social responsibility, awareness of digital integrity, and processing and presentation of information. To begin, the quantitative results for information management were not reliable, and the digital artifacts submitted for this DLD, while numerous, did not present a strong sense of understanding regarding file storage and back-up options. While students' confidence and positive emotions were apparent in the digital artifacts submitted for team-based learning in digital environments, demonstrating the benefits of collaboration and group work, the quantitative results were lower than all other DLDs, with positive responses between $70 \%$ and $79 \%$.

Finally, combined results for information research and retrieval and information validation produced a relatively lower assessment as compared to all other DLDs. While quantitative results for both DLDs produced positive responses between $80 \%$ and $89 \%$, qualitative results (supporting digital artifacts) were lacking. Information research and retrieval received only one artifact, and no emotion or further connections to other DLDs were apparent. Information validation did not receive any digital artifacts. Reduced engagement with the qualitative component of the study in these DLDs is of particular interest, and addressed further in the final section of this chapter. Figure 22 combines these quantitative and qualitative results for each DLD in summary format. 


\begin{tabular}{|c|c|c|c|c|c|}
\hline \multicolumn{6}{|l|}{ Digital Learning Domains (DLDs) } \\
\hline Information research and retrieval & $\begin{array}{l}\text { Over } \\
80 \%\end{array}$ & 1 & Library Database & 0 & None \\
\hline Information validation & $\begin{array}{l}\text { Over } \\
80 \%\end{array}$ & 0 & None & 0 & None \\
\hline Information management & $\begin{array}{c}\text { Not } \\
\text { Reliable }\end{array}$ & 11 & $\begin{array}{c}\text { Cloud storage representative in } \\
\text { only } 2 \text { cases }\end{array}$ & 1 & $\begin{array}{l}2 \text { Organization } \\
1 \text { Confident }\end{array}$ \\
\hline $\begin{array}{l}\text { Processing and presentation of } \\
\text { inforomation }\end{array}$ & $\begin{array}{l}\text { Over } \\
80 \%\end{array}$ & 5 & $\begin{array}{c}\text { Variety, breadth and deapth of } \\
\text { creative work deomonstrated } \\
\text { using a variety of tools }\end{array}$ & 3 & 2 Confident \\
\hline $\begin{array}{l}\text { Team-based learning in digital } \\
\text { environments }\end{array}$ & $\begin{array}{l}\text { Over } \\
70 \%\end{array}$ & 3 & $\begin{array}{c}\text { Collaboration and benefits of } \\
\text { group work (planning, } \\
\text { management, leadership) } \\
\end{array}$ & 1 & $\begin{array}{l}1 \text { Confident } \\
1 \text { Likes Groups } \\
1 \text { Likes Online } \\
\end{array}$ \\
\hline Awareness of digital integrity & $\begin{array}{l}\text { Over } \\
80 \% \\
\end{array}$ & 2 & Copyright-Legal-Ethical Issues & 5 & $\begin{array}{c}1 \text { Care-Concern } \\
1 \text { Fear }\end{array}$ \\
\hline Social responsibility & $\begin{array}{l}\text { Over } \\
90 \%\end{array}$ & 5 & $\begin{array}{c}\text { Appropriate use of technology; } \\
\text { Active participation and respect } \\
\text { for others }\end{array}$ & 2 & 5 Care-Concern \\
\hline
\end{tabular}

Figure 22. Summary of combined quantitative and qualitative results for each DLD. Positive response equals the combined percent for Somewhat-agree and Strongly-agree responses. Emotions are positive except for fear

\section{Interpretations}

Independent results of the quantitative and qualitative components of the study are reveling. The quantitative analysis shows Kurtz and Peled's (2016) instrument produced a reliable assessment for all but one DLD, information management. For all DLDs with acceptable reliability, students assess themselves highest in social responsibility with a $90 \%$ positive rating, and lowest in team-based learning in digital environments with a $77 \%$ positive rating. Students rated themselves in all other DLDs between $80 \%$ and $89 \%$. The conceptual organization and data driven analysis of the qualitative data revealed evidence of digital literacies complexities as indicated by the many overlapping features that exist among multiple DLDs. In addition, emotion emerged as a category relevant to the majority of the DLDs, offering another layer of complexity. Yet, it was though the synthesis of the two components of the study that a detailed assessment of first year students' digital literacy emerged. 
Prioritizing the DLDs according to the synthesized assessment for each DLD (Figure 22) informs Messiah College of emerging realities where additional programing may help support and improve students' digital literacies (Ewell, 2015). Information research and retrieval and information validation emerged as DLDs with the highest need for focused programming. Information management and team-based learning in digital environments emerged as areas where students self-report success. Yet, continued campus conversations and programming related to file storage and methods for improving group work in digital environments could improve students' competencies in these areas. Processing and presentation of information, awareness of digital integrity, and social responsibility emerged as DLDs where students need the least amount of support. Current campus programing and culture likely already establish a positive context for these areas.

Table 5.1 displays the DLDs in prioritized order. Prioritizing the DLDs in three tiers places information research and retrieval and information validation in tier one, needing the most institutional attention/resources. This prioritization places information management and team-based learning in digital environments in tier two; and processing and presentation of information, awareness of digital integrity, and social responsibility in tier three, needing the least institutional attention/resources. 
Table 5.1 DLDs Synthesized Assessment Prioritized

\begin{tabular}{|l|l|}
\hline & Digital Learning Domains \\
\hline $\begin{array}{l}\text { Tier } \mathbf{1} \\
\text { High } \\
\text { Priority }\end{array}$ & Information research and retrieval \\
\cline { 2 - 2 } Tier 2 & Information validation \\
\cline { 2 - 2 } & Team-based learning in digital environments \\
\hline \multirow{2}{*}{$\begin{array}{l}\text { Tier } \mathbf{3} \\
\text { Low } \\
\text { Priority }\end{array}$} & Processing and presentation of information \\
\cline { 2 - 2 } & Awareness of digital integrity \\
\cline { 2 - 2 } & Social responsibility \\
\hline
\end{tabular}

\section{Final Thoughts}

This section begins with final thoughts on the results of this research, followed by a review of this study's thoroughness, generalizability, and usefulness to the educational community. A consideration of future research opportunities concludes this section. $\underline{\text { Results }}$

Qualitative results validated some, but not all, quantitative results for the seven DLDs. While the qualitative results supported the quantitative results for social responsibility, awareness of digital integrity, processing and presentation of information, and team-based learning in digital environments, the lack of qualitative data for information validation challenged the quantitative results for this DLD. It is interesting that while students rated themselves strongly on information validation, not one student provided a digital artifact to this DLD. For this reason, information validation emerges as an area of primary concern where institutional prioritization for programming is vital. 
Was the prompt: "Link to or screenshot of resource with reflection/explanation of how you evaluated the reliability and credibility of the information" too difficult a task? How are Messiah College's first year students evaluating the reliability and credibility of information? This competency can be learned, but it takes effort to be mindful of information and representations (media) to filter the irrelevant information that is so prevalent in today's society (Gilster, 1997; Rheingold, 2012). Improving programming related to analysis, evaluation, reflection, and problem solving will support efforts to improve in this area (Gilster, 1997; Hobbs, 2010).

Qualitative content analysis uncovered a category separate from, yet relevant to, the seven DLDs . Quite to the surprise of this researcher, emotion emerged as a separate category. Driven by methodological assumptions that focus on the details of a study more than the perspectives of the participants (Creswell, 2013), and working pragmatically through this study's methods, this researcher was not looking for and did not expect to see emotion emerge. It is, therefore, believed to be important to the topic of digital literacy and addressed further here.

Kim and Pekrun (2014) acknowledge the reciprocal influence emotions have with: (a) cognitive processes and strategies, (b) decision making, and (c) motivation, yet address the need for further research. They state, "further research should continue to develop a design framework for cultivating learners' positive emotions and thereby motivation to learn and perform better in the area of emotions" (Kim \& Pekrun, 2014, p. 72). For now, with emotion emerging as a relevant category, it is important for Messiah College to consider students' emotions when establishing programming to advance learning in any of the DLDs. 


\section{$\underline{\text { Generalizability }}$}

This exploratory mixed-methods design was well suited to respond to the research questions posed for this study. Data collection processes yielded sufficient data sets for the quantitative $(N=125)$ and qualitative $(N=27)$ components, improving the rigor of this study. Likewise, triangulating independent results in the final analysis improved the reliability and validity of this study (Creswell \& Plano Clark, 2011), providing an informative response to both research questions.

This study is specific to Messiah College's first year students, and is not, therefore, generalizable to all students or other schools. "Despite these limitations, the data yield important findings that can be used to guide future [studies]" (Creswell \& Plano Clark, 2011, p. 405). The results can inform other institutions of higher education interested in similar goals associated with digital literacy. In addition, this study expands the limited research currently available on the assessment of digital literacies (Literat, 2014; Mills, 2010), thus extending the research on the assessment of digital literacies in the field of education as called for by Ainley et al. (2016), Rheingold (2012), and UNESCO (2016).

\section{$\underline{\text { Future Research }}$}

Further testing to develop Kurtz and Peled's (2016) instrument assessing digital literacy is encouraged. Reducing the number of performance statements overall, specifically with awareness of digital integrity, would reduce the amount of time it takes to complete the self-assessment. In addition, because this study calculated a Cronbach's Alpha less than 0.7 for information management further testing and/or revisions to the 
performance statements for this DLD is encouraged. Finally, future mix-methods studies on the assessment of digital literacies are encouraged. 


\section{REFERENCES}

Ainley, J., Schulz, W., Fraillon, J. (2016). A global measure of digital and ICT literacy skills. Global Education Monitoring Report. Retrieved from http://unesdoc.unesco.org/images/0024/002455/245577E.pdf

American Library Association. (2000). Information literacy competency standards for higher education. Retrieved from http://www.ala.org/acrl/standards/informationliteracycompetency

Association for Media Literacy (AML). (n.d.). What is the Association for Media Literacy? Retrieved from http://www.aml.ca/what-is-the-association-for-media$\underline{\text { literacy/ }}$

Association of American Colleges and Universities (AAC\&U). (2002). Greater Expectations: A New Vision for Learning as a Nation Goes to College. Washington, DC: AAC\&U.

Association of College and Research Libraries (ACRL). (2016, January 11). Framework for information literacy for higher education. Retrieved from http://www.ala.org/acrl/standards/ilframework

Baller, S., Dutta, S., \& Lanvin, B. (2016). The global information technology report website: http://www3.weforum.org/docs/GITR2016/WEF_GITR_Full_Report.pdf

Beaudoin, M., Kurtz, G., Jung, I., Suzuki, K. \& Grabowski, B. (2013). Online learner competencies: Attitudes, knowledge, and skills for successful learning. USA: Information Age Publishing.

Birks, M., Chapman, Y., \& Francis, K. (2008). Memoing in qualitative research: Probing data and processes. Journal of Research in Nursing, 13, 68-75. 
Blummer, B. (2015). Some visual literacy initiatives in academic institutions: A literature review from 1999 to the present. Journal of Visual Literacy, 34, 1-34.

Boh Podgornik, B., Dolnicar, D., Šorgo, A., \& Tomaž, B. (2015). Developing, testing, and validation of an information literacy test (ILT) for higher education. Journal of the association for Information Science and Technology, 1-17.

Chartered Institute of Library and Information Professionals. (2013, July 15). Information literacy - Definition. Retrieved from http://www.cilip.org.uk/cilip/advocacycampaigns-awards/advocacy-campaigns/information-literacy/information-literacy

Corbin, J., \& Strauss, A. (1990). Grounded theory research: Procedures, canons, and evaluative criteria. Qualitative Sociology, 13, 3-21.

Cortina, J. (1993). What is coefficient alpha? An examination of theory and applications. Journal of Applied Psychology, 78, 98-104.

Creswell, J. W. (2012). Educational research: Planning, conducting, and evaluating quantitative and qualitative research. Upper Saddle River, NJ: Pearson Education Inc.

Creswell, J. W. (2013). Qualitative inquiry and research design: Choosing among five approaches. Los Angeles, CA: Sage Publications, Inc.

Creswell, J. W., \& Plano Clark, V. L. (2011). Designing and conducting mixed methods research [Kindle DX version] Retrieved from read.amazon.com

Dede, C. (2010). Comparing frameworks for 21 st century skills. In J. Bellanca, \& R. Brandt (Eds.), 21st century skills: Rethinking how students learn (pp. 51-76). Retrieved from https://books.google.com/books

Desimone, J. A., Harms, P. D., \& Desimone, A. J. (2016). Best practice recommendations for data screening. Journal of Organizational Behavior, 36, 171-181.

Dewey, J. (1916). Democracy and education: An introduction to the philosophy of education. The MacMillan Company. Retrieved from https://books.google.com/ebooks 
emrecaglayan. (2016, March 8). How does digital literacy challenge and shape the way we learn? Retrieved from https://ucalearningandteaching.wordpress.com/2016/03/08/how-does-digitalliteracy-challenge-and-shape-the-way-we-learn/

Ewell, P. T. (2015, March). Transforming institutional accreditation in U.S. higher education. National Center for Higher Education Management Systems (NCHEMS). Retrieved from http://nchems.org/documents/GatesAccreditationWhitePaper.pdf

Fowler, F. J. (1988). Survey research methods. United States of America: Sage Publications, Inc.

Gilster, P. (1997). Digital Literacy. United States of America: John Wiley \& Sons, Inc.

Glaser, B. (1999). The future of grounded theory. Qualitative Health Research, 9, 836845.

Glaser, B. (2002). Conceptualization: On theory and theorizing using grounded theory. International Journal of Qualitative Methods, 1(2), 23-38.

Goodfellow, R. (2011). Literacy, literacies and the digital in higher education. Teaching in Higher Education, 16, 131-144.

Greenberg, A. D., \& Zanetis, J. (2012). The impact of broadcast and streaming video in education. San Jose, CA. Retrieved from http://www.cisco.com/web/strategy/docs/education/ciscovideowp.pdf

Hatcher, L. (2013). Advanced statistics in research: Reading, understanding, and writing up data analysis results. Saginaw, MI: Shadow Finch Media.

Hobbs, R. (2010). Digital and media literacy: A plan of action. The Aspen Institute.

Huang, J. L., Curran, P. G., Keeney, J., Poposki, E. M., \& DeShon, R. P. (2012). Detecting and deterring insufficient effort responding to surveys. Journal of Business and Psychology, 27, 99-114. 
Hung, H.-T., Chiu, Y.-C. J., \& Yeh, H.-C. (2013). Multimodal assessment of and for learning: A theory-driven design rubric. British Journal of Educational Technology, 44, 400-409.

Janssen, J., Stoyanov, S., Ferrari, A., Punie, Y., Pannekeet, K., \& Sloep, P. (2013). Experts' Views on Digital Competence: Commonalities and differences. Computers and Education, 68, 473-481. http://doi.org/10.1016/j.compedu.2013.06.008

Jenkins, H., Clinton, K., Purushotma, R., Robison, A. J. \& Weigel, M. (2006, October 19). Confronting the challenges of participatory culture: Media education for the 21 st century. Retrieved from https://www.macfound.org/press/publications/whitepaper-confronting-the-challenges-of-participatory-culture-media-education-forthe-21st-century-by-henry-jenkins/

Jocius, R. (2013). Exploring adolescents' mulitmodal responses to The Kite Runner: Understanding how students use digital media for academic purposes. Journal of Media Literacy Education, 5, 310-325.

Jolls, T., \& Wilson, C. (2014). Voices from the field the core concepts: Fundamental to media literacy yesterday, today and tomorrow. Journal of Media Literacy Education, 6, 68-78.

Johnson, L., Adams Becker, S., Cummins, M., Estrada, V., Freeman, A., \& Hall, C. (2016). The NMC horizon report: 2016 higher education edition. Austin, TX. Retrieved from http://cdn.nmc.org/media/2016-nmc-horizon-report-he-EN.pdf Kaklauskas, A., Zavadskas, E. K., Pruskus, V., Vlasenko, A., Seniut, M., Kaklauskas, G., Matuliauskaite, A., Gribniak, V. (2010). Biometric and intelligent self-assessment of student progress system. Computers \& Education, 55(2), 821-833.

Keeffe, C. (2016). Information literacy and employability. An Leabharlann, 25, 4-10.

Kim, C., \& Pekrun, R. (2014). Emotions and Motivation in Learning and Performance. In J. M. Spector et al. (Eds.), Handbook of Research on Educational 
communications and Technology (65-75). New York: Springer Science+Business Media.

Klomsri, T., \& Tedre, M. (2016). Poor information literacy skills and practices as barriers to academic performance: A mixed methods study of the University of Dar es Salaam. Reference \& User Services Quarterly, 55, 293-305.

Kurbanoglu, S. S., Akkoyunlu, B., \& Umay, A. (2004). Developing the information literacy self-efficacy scale. Journal of Documentation, 62, 730-743.

Kurtz, G., \& Peled, Y. (2016). Digital learning literacies - A validation study. Issues in Informing Science and Information Technology, 13, 145-158. Retrieved from http://www.informingscience.org/Publications/3479

Lankshear, C., \& Knobel, M. (2007). Researching new literacies: Web 2.0 practices and insider perspectives. E-Learning, 4, 224-240.

Lau, J. (2013). Conceptual relationship of information literacy and media literacy. World Summit on the Information Society (WSIS) (pp. 76-89). Paris, France: United Nations Educational, Scientific and Cultural Organization (UNESCO).

Lee, A. Y. L. (2013). Literacy and competencies required to participate in knowledge societies. World Summit on the Information Society (WSIS) (pp. 3-62). Paris, France: United Nations Educational, Scientific and Cultural Organization (UNESCO).

Literat, I. (2014). Measuring new media literacies: Towards the development of a comprehensive assessment tool. Journal of Media Literacy Education, 6, 15-27.

Martens, H. (2010). Evaluating media literacy education: Concepts, theories and future directions. Journal of Media Literacy Education, 2, 1-22.

Martin, J. (2006). Social cultural perspectives in educational psychology. In: P.H. Winne \& P.A. Alexander (Eds.) Handbook of educational psychology. (pp. 595-614). New York: Routledge. 
Messiah College (2016). Fact Book. Retrieved from http://mcweb.messiah.edu/documents/institutionalresearch/secure/Factbook/2016-17/2016-17\%20Factbook\%20FINAL.pdf

Mills, K. A. (2010). A review of the "digital turn" in the new literacy studies. Review of Educational Research, 80, 246-271.

National Association for Media Literacy Education. (2007, November). Core principles of media literacy education in the United States. Retrieved from https://drive.google.com/file/d/0B8j2T8jHrlgCYXVHSVJidWtmbmc/view

Nunnally, J. (1978). Psychometric theory. New York: McGraw-Hill.

Park, Y. (2016, June 3). 8 digital skills we must teach our children. Retrieved from https://www.weforum.org/agenda/2016/06/8-digital-skills-we-must-teach-ourchildren

Rheingold, H. (2012). Net smart: How to thrive online. Cambridge, MA: MIT Press.

Ribble, M. (2016). Nine themes of digital citizenship. Retreived from: http://www.digitalcitizenship.net/Nine_Elements.html

Rogow, F. (2011) Ask, don't tell: Pedagogy for media literacy education in the next decade. Journal of Media Literacy Education, 3, 16-22.

Roxin, I. \& Rusitoru, M.-V. (2016, June 12-14). Digital literacy for the emerging educational resources in the context of lifelong learning. Paper presented at International Conference on Education and New Developments, Ljubljana, Slovenia. Portugal: World Institute for Advanced Research and Science (WIARS).

Saldaña, J. (2016). The coding manual for qualitative researchers [Kindle DX version] Retrieved from read.amazon.com

Schreier, M. (2012). Qualitative content analysis in practice [Kindle DX version] Retrieved from read.amazon.com 
Sharma, R., Fantin, A.-R., Prabhu, N., Guan, C., \& Dattakumar, A. (2016). Digital literacy and knowledge societies: A grounded theory investigation of sustainable development. Telecommunications Policy, 40, 628-643.

Snelson, C., \& Perkins, R. A. (2009). From silent film to YouTube TM: Tracing the historical roots of motion picture technologies in education. Journal of Visual Literacy, 28, 1-27.

Šorgo, A., Bartol, T., Dolničar, D., \& Podgornik, B. B. (2016). Attributes of digital natives as predictors of information literacy in higher education. British Journal of Educational Technology, 00, 0-19.

Tan, E. (2013). Informal learning on YouTube: Exploring digital literacy in independent online learning. Learning, Media and Technology, 38, 463-477. doi:10.1080/17439884.2013.783594

The EDUCAUSE Center for Analysis and Research. (2016). [Infographic: 2016 Student and Technology Research Study]. Retrieved from https://library.educause.edu/ /media/files/library/2016/10/eig1605.pdf

Tondeur, J., Aesaert, K., Pynoo, B., van Braak, J., Fraeyman, N., \& Erstad, O. (2015). Developing a validated instrument to measure preservice teachers' ICT competencies: Meeting the demands of the 21st century. British Journal of Educational Technology, 46, 1-11.

United Nations Educational, Scientific, and Cultural Organization (UNESCO) (2016). Education for people and planet: Creating sustainable futures for all. Global Education Monitoring Report. Retrieved from http://unesdoc.unesco.org/images/0024/002457/245752e.pdf

Walsh, M. (2010). Multimodal literacy: What does it mean for classroom practice? Australian Journal of Language and Literacy, 33, 211-239. 
Yousef, A. M. F., Chatti, M. A., \& Schroeder, U. (2014). Video-based learning: A critical analysis of the research published in 2003-2013 and future visions. In eLmL 2014: The Sixth International Conference on Mobile, Hybrid and On-line Learning (pp. 112-119). Retrieved from http://www.thinkmind.org/download.php?articleid=elml_2014_5_30_50050 
APPENDIX A 


\section{Messiah College Strategic Plan 2016-2020}

STRATEGIC PLAN 2016-2020

"EMBRACING CHANGE AS OPPORTUNITY"

Preamble:

In 2012, Messiah College committed to the following vision: "By 2020, Messiah College will be the first choice among undergraduate and graduate students from the eastern United States who desire a Christian higher education characterized by educational excellence and a commitment to gracious Christianity." The proposed 2016-2020 institutional strategic plan builds on the successful strides of the previous strategic plan toward achieving that shared institutional vision. This new plan for our future, "Embracing Change as Opportunity," recognizes that the pace of change in higher education and in our nation in the past four years has rapidly increased. Change in our circumstances requires innovative action as we continue to affirm our foundational values and commitments while advancing our educational mission and live out our Christian identity.

Change is always challenging. But this plan welcomes and embraces change as an opportunity. We are convinced, as an institution of Christ-centered higher education, that God has not given us a spirit of fear but a spirit of active hope and confidence as we successfully prepare undergraduate and graduate students to lead and serve as they participate in God's reconciling work in the world. Building new educational programs, recruiting new constituencies and supporting and developing new professional abilities are actions through which we serve our students and equip them for the $21^{\text {st }}$ Century. To pursue this end, the community of Messiah College commits itself to achieving the goals of the 2016-2020 strategic plan outlined below.

\section{Theme 1 - Advancing Mission and Identity in a Changing Culture}

Focus

Building on Theme 1 of the previous strategic plan (2012-2016), we seek to nurture improved institutional selfunderstanding and external messaging as we endeavor to communicate our educational mission and the desire to promote the common good.

- Goal 1: Messiah College will effectively and graciously advocate for institutional self-determination within a religiously pluralistic society.

1. Participate in CCCU collaborative efforts with Christian institutions and interfaith organizations concerning religious freedom, work alongside the College's legal counsel, and report outcomes to the campus community via the president's update.

2. Engage in a continuous review of religious freedom challenges and proactively prepare effective institutional responses to potential legislative, regulatory and/or accreditation challenges.

3. Continue educational focus groups for employees and student leaders regarding the College's mission, values and behavioral codes of conduct and these sessions will be integrated into established campus programming.

- Goal 2: Messiah College will nurture a campus community ethos characterized by hospitality rooted in Christian conviction as informed by the College's founding theological traditions.

1. Conduct a climate survey of the campus environment for all employees and students to identify institutional strengths and concerns.

2. Develop employee and student programs, protocols and policies to leverage opportunities and address concerns identified by the survey results.

- Goal 3: Messiah College will successfully promote the outcomes of its positive economic and social impact on the mid-Atlantic region and beyond.

1. Appoint a task force to compile a report of economic and social contributions of the Messiah community to the mid-Atlantic region to serve as an integrated source for communicating positive impact. 
2. Review and implement changes based on the recently completed Community Engagement Committee's summary report and publish an account of the College's ongoing efforts to serve the mid-Atlantic region as an intellectual, economic, artistic and community service resource.

3. Design and launch a webpage and other resources to share the narrative of the positive economic and social impact of Messiah College.

4. Institute a campus-wide theme of "Promoting the Common Good" for 2018-2019 - keynote lecturers will be invited to address this theme, focus on theme at Community Day, in the fall issue of the Bridge, etc.

- Goal 4: Messiah College will determine whether to apply for university status in response to the needs of student recruitment and the changing academic program.

1. Appoint a presidentially led task force to conduct a review and make a recommendation to the board of trustees and campus governance groups for discussion and deliberation in the 2018-2019 academic year.

Theme 2 - Expanding Enrollment and Retention of a Changing Constituency

Focus

Higher education is well into a shift that takes us beyond our common sense of a four-year residential college experience. This Theme is focused on programming designed to recruit and retain students in this challenging environment defined by changing demographics.

- Goal 1: Messiah College will effectively recruit and retain a more diverse student population with no less than $20 \%$ of the total undergraduate student body being a combination of domestic underrepresented students and international students.

1. Develop intercultural recruitment strategies related to building relationships with key schools, churches, and community leaders, with an emphasis on recruiting and retaining more Hispanic/Latino students.

2. Develop and implement recruitment and retention strategies for students from domestic underrepresented populations outside of the Martin and Amigo scholarship programs.

3. Expand our global engagement through strategic recruitment of international students by building partnerships with key schools, churches and organizations in new markets (e.g., China and Indonesia).

- Goal 2: Messiah College will increase its number of transfer students through recruitment and retention.

1. Expand online undergraduate programming to meet enhanced recruitment goals in transfer enrollment.

2. Complete program to program articulation agreements with regional community colleges where general transfer agreements currently exist.

3. Revise transfer credit policies and procedures to facilitate timely completion of degrees.

4. Implement strategies to increase retention of transfer students.

- Goal 3: Messiah College will enhance its efforts to recruit high school students through dual enrollment and summer academic programming.

1. Expand online undergraduate programming to meet enhanced recruitment goals for dual enrollment.

2. Develop an integrated summer academic camp program.

- Goal 4: Messiah College will successfully expand and support new graduate programs, and other programs for non-traditional adult students.

1. Fully implement a School of Graduate Studies. 
2. Launch graduate programming in occupational therapy, physical therapy and a doctorate in nursing practice.

3. Develop additional graduate programming with particular attention to athletic training.

4. Develop internal accelerated undergraduate to graduate degree programs.

5. Expand stand-alone certificate and other non-degree programs.

Theme 3: Promoting Educational Excellence for a Changing Student Body

Focus

Consistent with the shift in instructional venues and demographics introduced in Theme 2, this Theme provides strategies to support student success, develop our entire workforce, foster our use of high-impact educational practices and plan wisely for the optimum use of facilities.

- Goal 1: Messiah College will provide programs and services that promote student success for a changing student body.

1. Create or enhance programs and services designed to assist students to succeed in a college learning environment based upon ongoing research and assessment data.

- Goal 2: Messiah College will develop engaged employees who will be prepared to mentor and educate our 21 st century student body.

1. Design and deliver professional development opportunities which promote employee success at supporting the priorities of the strategic plan.

2. Implement the recently adopted new standards for ranked faculty term tenure and promotion.

3. Review the current employee orientation and performance appraisal process to enhance a strong connection between expectations and the College's mission, values and priorities.

- Goal 3: Messiah College will prepare educators to cultivate appropriate teaching and learning outcomes that meet the needs of a changing student body.

1. Design and implement a development plan for faculty that is supportive of the revised Term-tenure and Promotion expectations and include strategies for nurturing intercultural competencies.

2. Fully implement the Teaching and Learning Initiative.

3. Review and revise the College Wide Educational Objectives in light of the changing environment with attention to digital proficiency and intercultural competencies.

- Goal 4: Messiah College will more effectively recruit and retain a diverse employee base.

1. Improve hiring processes to identify, cultivate, and successfully recruit employees from diverse populations.

2. Identify and implement contextually-appropriate best practices for retention of employees from diverse populations.

- Goal 5: Messiah College will increase available opportunities for mentored undergraduate student research.

1. Develop a structure to promote and support undergraduate research.

2. Raise funds to support undergraduate research across disciplines.

- Goal 6: Messiah College will offer the necessary equipment and facilities to support the educational experience of our students.

1. Action steps will be coordinated with the College's facilities master plan, and will address needs including the commuter lounge, residence hall renovations, finance lab and others.

2. Review capital equipment replacement protocols and update deferred maintenance backlog reporting. 
Theme 4-Investing Resources for a Flourishing Financial Future

Focus

The College has flourished in these challenging times as a result of its sound financial resource base, and this theme provides strategies to grow its balance sheet via fundraising and investment strategies designed to achieve returns in excess of spending and to make more efficient use of existing human, operational and programming resources.

- Goal 1: Messiah College will pursue new revenue streams to diversify and create long-term stability for our financial portfolio.

1. Support the Rider-Musser Development, LLC as it initiates the residential and commercial development of the properties.

2. Offer meeting spaces and catering for an increased number of external constituents.

- Goal 2: Messiah College will increase its financial resource base by $\$ 45$ million.

1. Increase the institutional endowment to $\$ 140$ million.

$\neg$ Employ investment strategies designed to achieve growth of 8.5 percent annually.

$\neg$ Raise \$5-\$7 million in new endowment funds.

2. Raise $\$ 15$ million in annual restricted funds.

3. Generate cash flow operating surpluses that equal 1-2 percent of annual operating revenue.

- Goal 3: Messiah College will implement strategies to make effective use of existing operational and programming resources.

1. Develop and implement a process to review undergraduate educational programs and their contribution to the College's mission and financial margin in order to better guide strategic investments.

2. Review divisional policies, processes, and programs to increase efficiency and productivity.

- Goal 4: Messiah College will offer an excellent and affordable educational experience to its students.

1. Provide financial aid options designed to minimize student loan debt.

2. Develop and enhance strategies for our students to maintain our historically low loan default rates.

3. Implement additional action steps that will be developed by the Financial Aid Strategy Team and spelled out in the College's strategic enrollment plan. 
APPENDIX B 


\section{Methods Diagram}

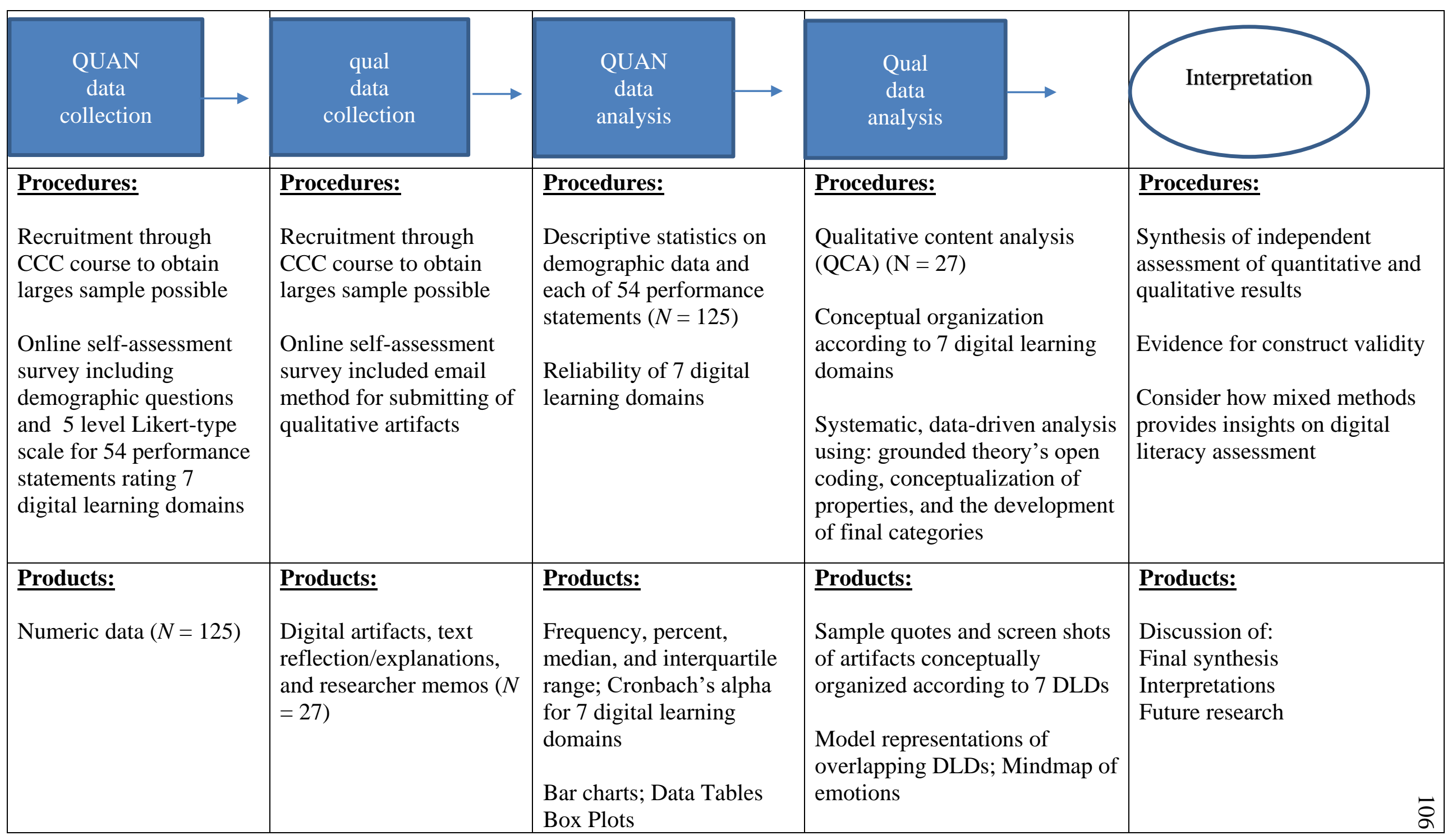


APPENDIX C 


\section{Script}

Read by faculty teaching CCC courses:

"A research study is being conducted on digital literacy. Digital literacy includes social responsibility, the ability to validate information and work collaboratively to share new knowledge using multiple systems and formats available in this digital age. Susan Shannon, the Director of Learning Technology Services at Messiah College, and doctoral candidate at Boise State University is asking participants to complete a survey that will take approximately 15 minutes.

If you would be interested in participating in this survey, you may access the survey in the Modules section of this course, or you may access the survey from a forthcoming Announcement that will include a link to the survey.

If you are not interested, you may disregard the Announcement on Digital Literacy." 
APPENDIX D 
Post Card (Front)

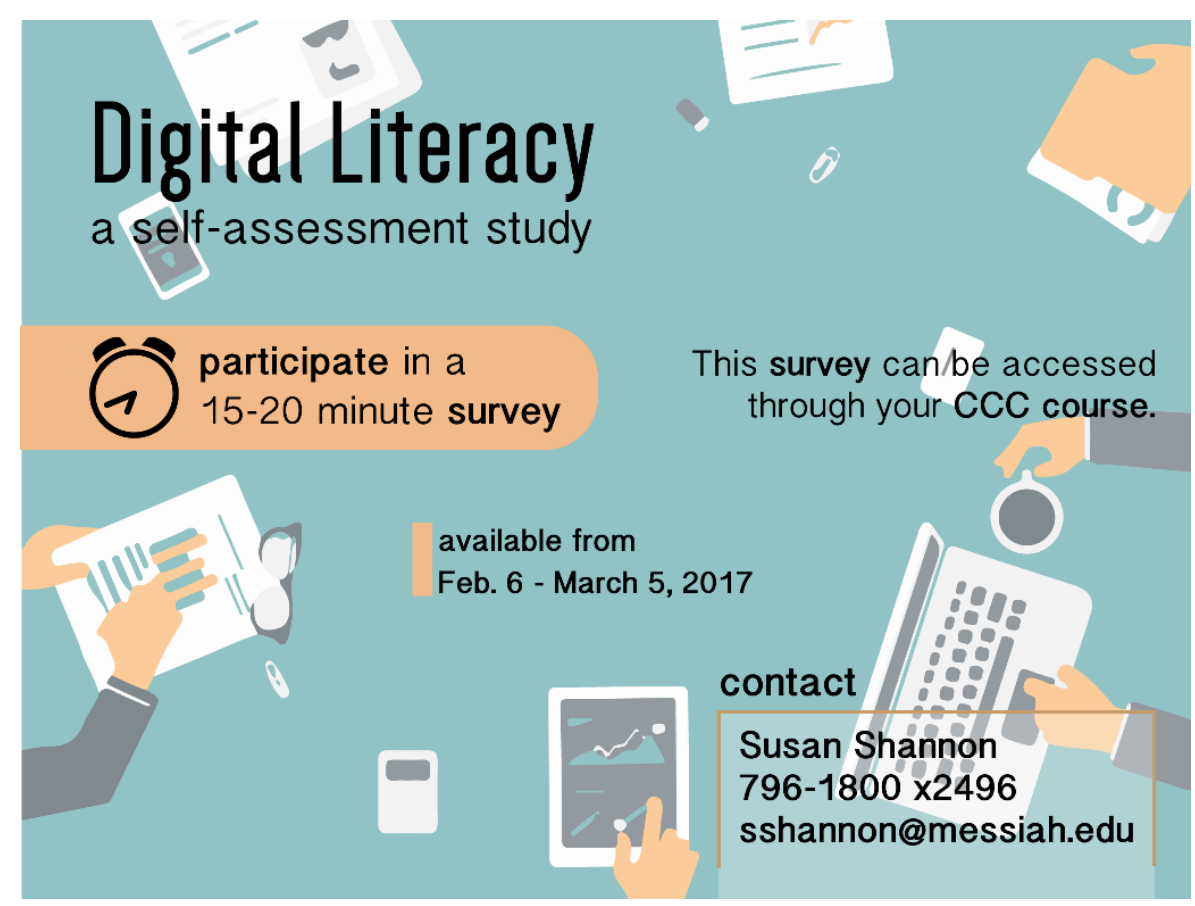

\section{Post Card (Back)}

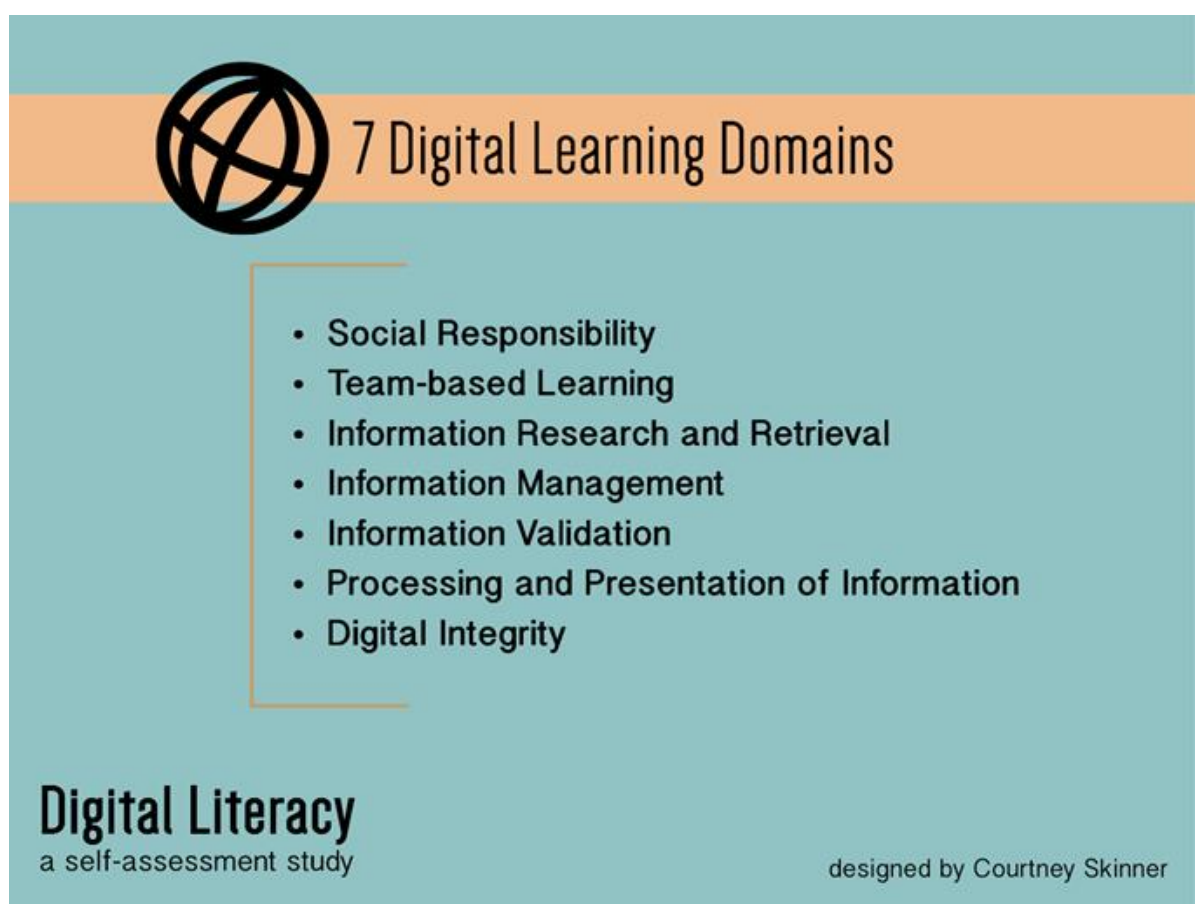


APPENDIX E 


\section{Announcement}

Greetings,

My name is Susan Shannon. I am the Director of Learning Technology Services at Messiah College, and a doctoral candidate working with Dr. Chareen Snelson at Boise State University. We are conducting a research study about digital literacies. Last week in your CCC course you received an invitation to participate in this research. Thank you to those who already participated!

For everyone else, I am emailing to ask if you would like to take about 15 minutes to complete a survey for this research. Participation is completely voluntary and your answers will be anonymous.

If you are interested, please learn more from the video introduction and access the survey using the links below:

- Video Introduction (1:41)

- Survey Instrument

If you have any questions, please do not hesitate to contact me (sshannon@messiah.edu) or Dr. Chareen Snelson (csnelson@boisestate.edu).

Thank you for your time.

Susan Shannon

Doctoral Candidate

Boise State University 
APPENDIX F 


\section{Cover Letter}

\section{A Mixed Methods Assessment of Digital Literacy in Higher Education}

Susan Shannon, a graduate student at Boise State University and Director of Learning Technology Services at Messiah College is conducting a research study on the digital literacies of first year students at Messiah College. Students in this course are being asked to complete this survey because most of you are first year students.

Participation is voluntary. The survey will take approximately 15 to complete. You must be at least 18 years old to take this survey.

This study involves no foreseeable serious risks. We ask that you try to answer all questions; however, if there are any items that make you uncomfortable or that you would prefer to skip, please leave the answer blank. Your responses to the selfassessment rating scale are anonymous. No personal identifying information such as name or email address is collected.

Digital media files and associated reflections/explanations participants provide to the study demonstrating their digital literacy are not expected to include any data that is considered private or sensitive. Digital media files and explanations may be emailed to the researcher directly through Outlook or anonymously using an email application on your phone or Outlook client on their laptop. Students selecting the direct email option will not be anonymous. If a participant submits a digital file, reflection, or explanation with personal identifiers, anonymity cannot be maintained. However, confidentiality will be maintained. All responses will be secured in password protected systems. The researcher will not disclose participant's identities.

If you have any questions or concerns, feel free to contact Susan or her faculty advisor:

\section{Susan Shannon Doctoral Candidate}

\section{Educational Technology susanshannon@u.boisestate.edu}

\author{
Dr. Chareen Snelson \\ Associate Chair \& Associate \\ Professor \\ Educational Technology \\ csnelson@boisestate.edu
}

If you have questions about your rights as a research participant, you may contact the Boise State University Institutional Review Board (IRB), which is concerned with the protection of volunteers in research projects. You may reach the board office between 8:00 AM and 5:00 PM, Monday through Friday, by calling (208) 426-5401 or by writing: Institutional Review Board, Office of Research Compliance, Boise State University, 1910 University Dr., Boise, ID 83725-1138.

If you would prefer not to participate, please do not complete the survey. If you consent to participate, please complete the survey. 
APPENDIX G 


\section{Flyer}

\section{VOLUNTEERS WANTED FOR A RESEARCH STUDY}

\section{Assessing Digital Literacies in Higher Education}

Are you over the age of 18 and currently in your first year at Messiah College? We are conducting a research study about digital literacy and looking for your input!

The purpose of this research is to support Messiah College at it attempts to revise its college wide educational objectives. Baseline data from this study will be valuable to the College as it works toward building educational outcomes that are in sync with today's digital and socio-cultural landscape.

The survey includes three parts:

1. Demographic information

2. A five level Likert-type scale for 54 performance statements divided into seven digital learning domains offering choices from strongly disagree to strongly agree.

3. An area for you to upload digital files you believe demonstrate your digital literacy and provide reflection and/or explanation.

This survey will take approximately 15 minutes to complete, and is open to students age 18 or older in their first year at Messiah College.

There are no risks associated with this research. Your participation will improve the results of this study which will provide a measurable and detailed interpretation of Messiah College's first year students' digital literacies, supporting efforts to improve learning opportunities.

A personalized report indicating participants' personal choices (mean score) for each performance statement is automatically generated at the end of the survey. This report may be exported and saved by the participant as a PDF.

This research is conducted under the direction of Dr. Chareen Snelson, Associate Chair \& Associate Professor at Boise State University.

(IRB number: \#555-SB13-111) 
APPENDIX $\mathrm{H}$ 


\section{Mass Email}

Any questions regarding this mass email may be directed to Susan Shannon at Ext.

2496 or sshannon@messiah.edu.

\section{To All First Year Students:}

Greetings,

My name is Susan Shannon. I am the Director of Learning Technology Services at Messiah College, and a doctoral candidate working with Dr. Chareen Snelson at Boise State University. Thank you to those who already participated in the research on digital literacy!

For everyone else, this is my final communication asking if you would like to take about 15 minutes to complete a survey for this research. Participation is completely voluntary and your answers will be anonymous.

If you are interested, please learn more from the video introduction and access the survey using the links below by March 5:

https://www.youtube.com/watch?v=5ioDWpKw9EQ\&feature=youtu.be https://messiah.qualtrics.com/SE/?SID=SV dbTi5rSmv1z8NcV

If you have any questions, please do not hesitate to contact me (sshannon@messiah.edu) or Dr. Chareen Snelson (csnelson@boisestate.edu).

Thank you for your time!

Susan Shannon 
APPENDIX I 


\section{Organized Packet of Materials Delivered to Faculty}

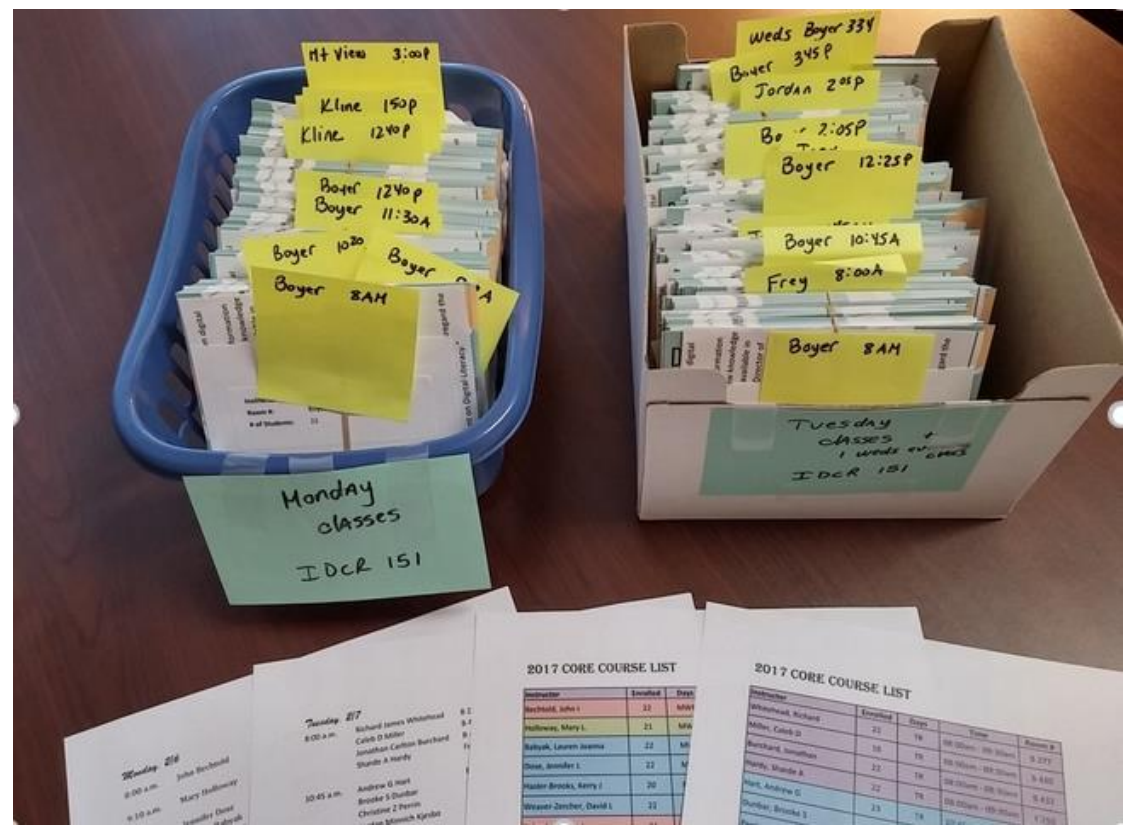

\section{Sample Email to Faculty Members}

Hi Faculty Name!

I'm conducting research on digital literacy in higher education. My target population is first year Messiah College students over the age of 18. I'm recruiting students from all CCC sections for this research.

I will personally deliver some recruitment materials to your CCC classroom (K 113) on Wednesday just before 12:40pm. You will receive:

- postcards (for your students)

- a faculty script (a printed copy for you)

I'm asking all CCC faculty to pass out the post cards and read the script to their classes this week.

Here is a preview of the script for your reference.

\section{Professor Script}

"A research study is being conducted on digital literacy. Digital literacy includes social responsibility, the ability to validate information and work collaboratively to share new knowledge using multiple systems and formats available in this digital age. Susan Shannon, the Director of Learning Technology Services at Messiah College, and 
doctoral candidate at Boise State University is asking participants to complete a survey that will take approximately 15 minutes.

If you would be interested in participating in this survey, you may access the survey in the Modules section of this course, or you may access the survey from a forthcoming Announcement that will include a link to the survey.

If you are not interested, you may disregard the Announcement on Digital Literacy."

Thank you for supporting my recruitment efforts!

I'll see you Wednesday. 
APPENDIX J 


\section{Self-assessment Survey Instrument}

Please read instructions provided here and indicate your consent to participate at the bottom of this page before proceeding.

\section{Purpose}

The purpose of this research is to support Messiah College in its attempt to revise its college wide educational objectives. This baseline data will be valuable to the College as it works toward building educational outcomes that are in syne with today's digital and socio-cultural landscape. Relevant college wide educational objectives provide a supporting framework for educators as they develop program and course objectives, and design student learning activities. In addition, this study will expand what limited research is currently available on the assessment of digital literacies.

\section{Procedures}

This electronic survey includes three parts:

1. Questions on age, gender and $\mathrm{racial} / \mathrm{ethnic}$ identity.

2. A five level Likert-type scale for 54 performance statements divided into seven digital learning domains. The Likert-type scale includes the following choices for each performance statement: (a) strongly disagree, (b) somewhat disagree, (c) neither disagree nor agree, (d) somewhat agree, and (e) strongly agree.

3. An area for you to upload digital media files you believe demonstrate your digital literacy. Examples may include the digital media artifact you produced in CIS 171 or CIS 181, links to your social media posts or other digital projects you have worked on. Your contributions should provide evidence of your digital literacy. Please also include a reflection and/or explanation of your files and/or links. 


\section{Risks/Benefits}

There are no risks associated with this research. Your participation will improve the results of this study which will provide a measurable and detailed interpretation of Messiah College's first year students' digital literacies.

\section{Time}

Completing this survey is expected to take 15-20 minutes if you already determined which digital media file(s) you are willing to contribute at the end of the survey.

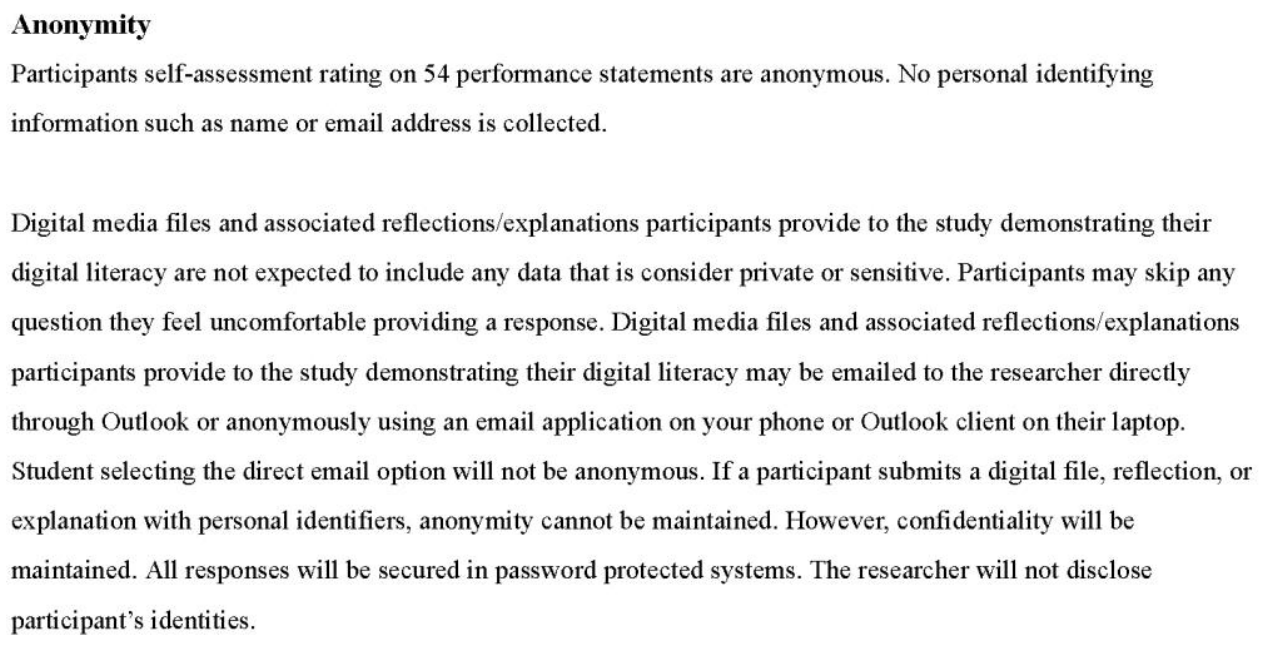

\section{Confidentiality}

Your participation in this research is confidential. A password protects the data collected and stored via Qualtrics and Microsoft Office 365's applications. The research team will have access to the data. In addition, the Department of Health and Human Services' Office for Human Research Protections may review records related to this research study. In the event of a publication or presentation resulting from the research, no personally identifiable information will be shared.

\section{Researcher Contact Information}

Please contact Susan Shannon at (717)796-1800 Ext. 2496 with questions, complaints or concerns about this research. You can also call this number if you feel this study has harmed you. Questions about your rights as a research participant may be directed to Messiah College's Office of the Provost at (717) 
766-2511 Ext. 5375. You may also call this number if you cannot reach the research team or with to talk to someone else.

This survey will be available from February 6, 2017 through March 4, 2017.

Please indicate your willingness to participate.

Yes. I read the information above and will participate.

No. I will not participate.

\section{Block 2}

This study is only open to students who are 18 years of age or older.

Are you 18 years of age or older?

Yes

No

Thank your for your interest.

However, this study is only open to students who are 18 years of age or older.

Demographic information collected in this study includes gender and racial/ethnic identity.

What is your gender?

Male

Female 
Qualtrics Survey Software

What is your age?

18

19

20

21

22

23

24

25-29

30-34

35 and over

What is your racial/ethnic identity?

Black/African American

American Indian/Alaska Native

Asian

Native Hawaiian/Pacific Islander

Hispanic/Latino-Latina

Multi-Ethnic/two or more races

Caucasian/European

Self-report of Data Quality

$\begin{array}{lcccc}\text { Strongly } & \text { Somewhat } & \text { Neither } & & \\ \text { disagree } & \text { Somewhat } & \text { Strongly } \\ \text { disagree } & \text { disagree } & \text { nor agree } & \text { agree } & \text { agree }\end{array}$

I will respond to survey thoughtfully and truthfully
https://messiah.qualtrics.com/ControlPanel/Ajax.php?action=GetSurveyP... 
Information Research and Retrieval

\begin{tabular}{|c|c|c|c|c|c|}
\hline & $\begin{array}{l}\text { Strongly } \\
\text { disagree }\end{array}$ & $\begin{array}{c}\text { Somewhat } \\
\text { disagree }\end{array}$ & $\begin{array}{c}\text { Neither } \\
\text { disagree } \\
\text { nor agree }\end{array}$ & $\begin{array}{l}\text { Somewhat } \\
\text { agree }\end{array}$ & $\begin{array}{l}\text { Strongly } \\
\text { agree }\end{array}$ \\
\hline $\begin{array}{l}\text { 1. I know when I } \\
\text { need to look for } \\
\text { information }\end{array}$ & 0 & 0 & 0 & 0 & 0 \\
\hline $\begin{array}{l}\text { 2. I am able to } \\
\text { identify information } \\
\text { for research }\end{array}$ & 0 & 0 & 0 & 0 & 0 \\
\hline $\begin{array}{l}\text { 3. I am able to } \\
\text { collect information } \\
\text { from the web }\end{array}$ & 0 & 0 & 0 & 0 & 0 \\
\hline $\begin{array}{l}\text { 4. I can define the } \\
\text { objective of the } \\
\text { search }\end{array}$ & 0 & 0 & 0 & 0 & 0 \\
\hline $\begin{array}{l}\text { 5. I can articulate } \\
\text { what information I } \\
\text { need }\end{array}$ & 0 & 0 & 0 & 0 & 0 \\
\hline $\begin{array}{l}\text { 6. I know how to } \\
\text { search effectively }\end{array}$ & 0 & 0 & 0 & 0 & 0 \\
\hline $\begin{array}{l}7 . \text { I can define } \\
\text { research terms }\end{array}$ & 0 & 0 & 0 & 0 & 0 \\
\hline $\begin{array}{l}\text { 8. I can distinguish } \\
\text { between types of } \\
\text { search }\end{array}$ & 0 & 0 & 0 & 0 & 0 \\
\hline $\begin{array}{l}\text { 9. I can retrieve } \\
\text { information from } \\
\text { various sources }\end{array}$ & 0 & 0 & 0 & 0 & 0 \\
\hline $\begin{array}{l}\text { 10. I am able to } \\
\text { collect information } \\
\text { from databases }\end{array}$ & 0 & 0 & 0 & 0 & 0 \\
\hline $\begin{array}{l}11 . \text { I am able to } \\
\text { re-locate } \\
\text { information }\end{array}$ & 0 & 0 & 0 & 0 & 0 \\
\hline
\end{tabular}


Information Validation

\begin{tabular}{|c|c|c|c|}
\hline trongly & $\begin{array}{l}\text { Somewhat } \\
\text { disagree }\end{array}$ & $\begin{array}{c}\text { Neither } \\
\text { disagree } \\
\text { nor agree }\end{array}$ & $\begin{array}{c}\text { Somewhat } \\
\text { agree }\end{array}$ \\
\hline
\end{tabular}

1. I am able to judge the degree to which information is practical or satisfies the needs of the task

2. I am able to determine the information required for a specific task

3. I am able to assess the accuracy of information

4. I am able to assess the credibility of information

5. I am aware of the difference in credibility of information from various sources

○<smiles>O</smiles><smiles>O</smiles>

O<smiles>O</smiles>

O<smiles>O</smiles>

O

O<smiles>O</smiles>

O

O

O

$\mathrm{O}$

O

O

O

O

O

O

O

$$
\text { O }
$$

O

O

O

Information Management

\begin{tabular}{|c|c|c|c|c|}
\hline Strongly & $\begin{array}{c}\text { Somewhat } \\
\text { disagree }\end{array}$ & $\begin{array}{c}\text { Neither } \\
\text { disagree } \\
\text { nor agree }\end{array}$ & $\begin{array}{c}\text { Somewhat } \\
\text { agree }\end{array}$ & $\begin{array}{c}\text { Strongly } \\
\text { agree }\end{array}$ \\
\hline
\end{tabular}

1. When I store a

file, I give it a

0

O

2. I store my files in designated folders

O

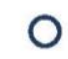

0

O

O

3. I tag my

information

O

O

O

O

O 
Processing and Presentation of Information

\begin{tabular}{|c|c|c|c|c|c|}
\hline & $\begin{array}{l}\text { Strongly } \\
\text { disagree }\end{array}$ & $\begin{array}{l}\text { Somewhat } \\
\text { disagree }\end{array}$ & $\begin{array}{c}\text { Neither } \\
\text { disagree } \\
\text { nor agree }\end{array}$ & $\begin{array}{l}\text { Somewhat } \\
\text { agree }\end{array}$ & $\begin{array}{c}\text { Strongly } \\
\text { agree }\end{array}$ \\
\hline $\begin{array}{l}\text { 1. I am able to } \\
\text { interpret information } \\
\text { from multiple } \\
\text { sources }\end{array}$ & 0 & 0 & 0 & 0 & 0 \\
\hline $\begin{array}{l}\text { 2. I am able to } \\
\text { analyze information } \\
\text { from multiple } \\
\text { sources }\end{array}$ & 0 & 0 & 0 & 0 & 0 \\
\hline $\begin{array}{l}\text { 3. I am able to } \\
\text { synthesize } \\
\text { information from } \\
\text { multiple sources }\end{array}$ & 0 & 0 & 0 & 0 & 0 \\
\hline $\begin{array}{l}\text { 4. I am able to write } \\
\text { an appropriate } \\
\text { response to a post }\end{array}$ & 0 & 0 & 0 & 0 & 0 \\
\hline $\begin{array}{l}\text { 5. I am able to use } \\
\text { ICT to design or } \\
\text { create new } \\
\text { information from } \\
\text { information already } \\
\text { acquired }\end{array}$ & 0 & 0 & 0 & 0 & 0 \\
\hline $\begin{array}{l}\text { 6. I am able to } \\
\text { visually organize } \\
\text { data for learning } \\
\text { purposes }\end{array}$ & 0 & 0 & 0 & 0 & 0 \\
\hline $\begin{array}{l}7 . \text { I can represent } \\
\text { knowledge in a } \\
\text { variety of ways such } \\
\text { as Power Point, } \\
\text { websites, blogs, etc. }\end{array}$ & 0 & 0 & 0 & 0 & 0 \\
\hline $\begin{array}{l}\text { 8. I am aware of the } \\
\text { difference in written, } \\
\text { graphic or video } \\
\text { representations }\end{array}$ & 0 & 0 & 0 & 0 & 0 \\
\hline
\end{tabular}


Team-based Learning in Digital Environments

\begin{tabular}{|c|c|c|c|c|c|}
\hline & $\begin{array}{l}\text { Strongly } \\
\text { disagree }\end{array}$ & $\begin{array}{c}\text { Somewhat } \\
\text { disagree }\end{array}$ & $\begin{array}{c}\text { Neither } \\
\text { disagree } \\
\text { nor agree }\end{array}$ & $\begin{array}{l}\text { Somewhat } \\
\text { agree }\end{array}$ & $\begin{array}{c}\text { Strongl } \\
\text { agree }\end{array}$ \\
\hline $\begin{array}{l}\text { 1. During the } \\
\text { preparation of a } \\
\text { joint task I know } \\
\text { how to fit in among } \\
\text { team members }\end{array}$ & 0 & 0 & 0 & 0 & 0 \\
\hline $\begin{array}{l}\text { 2. During the } \\
\text { preparation of a } \\
\text { joint task I share my } \\
\text { thoughts and } \\
\text { insights with my } \\
\text { peers }\end{array}$ & 0 & 0 & 0 & 0 & 0 \\
\hline $\begin{array}{l}\text { 3. During the } \\
\text { preparation of a } \\
\text { joint task I know that } \\
\text { I have an influence } \\
\text { on the work process }\end{array}$ & 0 & 0 & 0 & 0 & 0 \\
\hline $\begin{array}{l}\text { 4. During the } \\
\text { preparation of a } \\
\text { joint task I know } \\
\text { what is expected of } \\
\text { me }\end{array}$ & 0 & 0 & 0 & 0 & 0 \\
\hline $\begin{array}{l}\text { 5. While performing } \\
\text { a joint task I feel } \\
\text { that my contribution } \\
\text { to the team is } \\
\text { meaningful }\end{array}$ & 0 & 0 & 0 & 0 & 0 \\
\hline $\begin{array}{l}\text { 6. My peers are } \\
\text { aware of my abilities } \\
\text { and of what I can } \\
\text { contribute }\end{array}$ & 0 & 0 & 0 & 0 & $C$ \\
\hline $\begin{array}{l}7 . \text { I have no } \\
\text { reservation } \\
\text { regarding joint tasks }\end{array}$ & 0 & 0 & 0 & 0 & 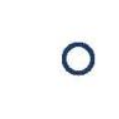 \\
\hline 8. I like to work with & $\frown$ & $\frown$ & $\frown$ & $\frown$ & \\
\hline
\end{tabular}


Awareness of Digital Integrity

\begin{tabular}{|c|c|c|c|c|c|}
\hline & $\begin{array}{l}\text { Strongly } \\
\text { disagree }\end{array}$ & $\begin{array}{l}\text { Somewhat } \\
\text { disagree }\end{array}$ & $\begin{array}{l}\text { Neither } \\
\text { disagree } \\
\text { nor agree }\end{array}$ & $\begin{array}{l}\text { Somewhat } \\
\text { agree }\end{array}$ & $\begin{array}{l}\text { Strons } \\
\text { agre }\end{array}$ \\
\hline $\begin{array}{l}\text { 1. I understand the } \\
\text { ethical } \\
\text { consequences of } \\
\text { the use of } \\
\text { technology }\end{array}$ & 0 & 0 & 0 & 0 & 0 \\
\hline $\begin{array}{l}\text { 2. I understand the } \\
\text { social } \\
\text { consequences of } \\
\text { the use of } \\
\text { technology }\end{array}$ & 0 & 0 & 0 & 0 & 0 \\
\hline $\begin{array}{l}\text { 3. I do not acquire } \\
\text { digital information, } \\
\text { files, programs, } \\
\text { databases, etc., via } \\
\text { illegal means }\end{array}$ & 0 & 0 & 0 & 0 & 0 \\
\hline $\begin{array}{l}\text { 4. I do not use } \\
\text { technology for } \\
\text { purposes that are } \\
\text { intimidating or } \\
\text { threatening }\end{array}$ & 0 & 0 & 0 & 0 & 0 \\
\hline $\begin{array}{l}\text { 5. I am aware of the } \\
\text { prohibition of illegal } \\
\text { file download }\end{array}$ & 0 & 0 & 0 & 0 & 0 \\
\hline $\begin{array}{l}\text { 6. I am aware of } \\
\text { copyright issues }\end{array}$ & 0 & O & 0 & 0 & 0 \\
\hline $\begin{array}{l}\text { 7. I am aware of } \\
\text { appropriate } \\
\text { acknowledgment of } \\
\text { sources I use }\end{array}$ & 0 & 0 & 0 & 0 & 0 \\
\hline $\begin{array}{l}\text { 8. I am aware of the } \\
\text { danger of my data } \\
\text { being online }\end{array}$ & 0 & 0 & 0 & 0 & 0 \\
\hline 9. I am aware of & $\frown$ & $\frown$ & $\frown$ & $\frown$ & \\
\hline
\end{tabular}


Social Responsibility

$\begin{array}{lccccc} & \begin{array}{c}\text { Strongly } \\ \text { disagree }\end{array} & \begin{array}{c}\text { Somewhat } \\ \text { disagree }\end{array} & \begin{array}{c}\text { Neither } \\ \text { disagree } \\ \text { nor agree }\end{array} & \begin{array}{c}\text { Somewhat } \\ \text { agree }\end{array} & \begin{array}{c}\text { Strongly } \\ \text { agree }\end{array} \\ \begin{array}{l}1 . \text { I adhere to the } \\ \text { rules of discourse } \\ \text { and proper behavior } \\ \text { in social networks }\end{array} & 0 & 0 & 0 & 0 & 0 \\ \begin{array}{l}2.1 \text { make sure not to } \\ \text { reveal information } \\ \text { about organizations } \\ \text { without consent }\end{array} & 0 & 0 & 0 & 0 & 0 \\ \begin{array}{l}3 . \text { I make sure not to } \\ \text { hurt others - people } \\ \text { and organizations - } \\ \text { online }\end{array} & 0 & 0 & 0 & 0 & 0\end{array}$

Self-report of Data Quality

$\begin{array}{ccccc}\begin{array}{c}\text { Strongly } \\ \text { disagree }\end{array} & \begin{array}{c}\text { Somewhat } \\ \text { disagree }\end{array} & \begin{array}{c}\text { Neither } \\ \text { disagree } \\ \text { nor agree }\end{array} & \begin{array}{c}\text { Somewhat } \\ \text { agree }\end{array} & \begin{array}{c}\text { Strongly } \\ \text { agree }\end{array} \\ 0 & 0 & 0 & 0 & 0\end{array}$




\section{Block 3}

\section{Select one area below to demonstrate your digital literacy.}

Examples are not intended to be exhaustive. Feel free to offer a reflection and/or explanation of any evidence you believe supports earlier responses.

Email evidence to the researcher at sshannon@messiah.edu - or - use one of the dedicated links below through an application on your phone or the Outlook client on your laptop.

\section{Information Research and Retrieval}

Link to or screenshot of resource from prior research with reflection/explanation of why and where you found it.

2. Information Validation Link to or screenshot of resource with reflection/explanation of how you evaluated the reliability and credibility of the information.

3. Information Management

Provide screenshot of file structure with reflection/explanation as to how you organize your files.

4. Processing and Presentation of Information Link to or attach presentation completed in prior course work with reflection/explanation on how you processed and created the artifact.

5. Team-based Learning in Digital Environments

Reflect/explain your learning experiences in online discussions and online group projects.

6. Awareness of Digital Integrity

Provide reflection/explanation regrading active steps you take to avoid and/or proactively address ethical issues online.

7. Social Responsibility

Reflect/explain on your actions regarding your social responsibility. 
APPENDIX K 


\section{Descriptive Statistics for Page Time Submissions for Each DLD}

Closer inspection of page submission times for each DLD revealed mean scores higher than respective median scores, indicating positively skewed distributions. The skewness statistic and visual inspection of histograms and box plots for page submission times confirm a positive skew for each DLD. Descriptive statistics, histograms, and box plots of page submission times for each of the seven DLDs are presented here. All outliers and extreme values exist on the high end of page submission times, not the low end. It can be expected that students may have been distracted during the survey and come back to it at a later time to finish. These cases were not screened.

\begin{tabular}{|l|l|l|l|l|}
\hline \multicolumn{5}{|c|}{ Descriptive Statistics of Response Times (sec.) for Each DLD } \\
\hline Digital Learning Domains & M & Mdn & SD & Skewness (SE) \\
\hline $\begin{array}{l}\text { Information Research and Retrieval } \\
\text { (N=131) }\end{array}$ & 67.7 & 50.8 & 110.5 & $9.7(0.21)$ \\
\hline Information Validation (N=129) & 32.0 & 26.4 & 26.2 & $4.0(0.21)$ \\
\hline Information Management (N=129) & 14.5 & 12.0 & 9.3 & $3.1(0.21)$ \\
\hline $\begin{array}{l}\text { Processing and Presentation of } \\
\text { Information (N=129) }\end{array}$ & 44.2 & 38.8 & 33.3 & $4.3(0.21)$ \\
\hline $\begin{array}{l}\text { Team-based Learning in Digital } \\
\text { Environments (N=129) }\end{array}$ & 43.9 & 35.8 & 28.3 & $2.3(0.21)$ \\
\hline Awareness of Digital Integrity (N=128) & 292.5 & 57.8 & 2546.7 & $11.3(0.21)$ \\
\hline Social Responsibility (N=128) & 20.1 & 13.7 & 31.2 & $8.5(0.21)$ \\
\hline
\end{tabular}

Notes: $\mathrm{PS}=$ performance statement 

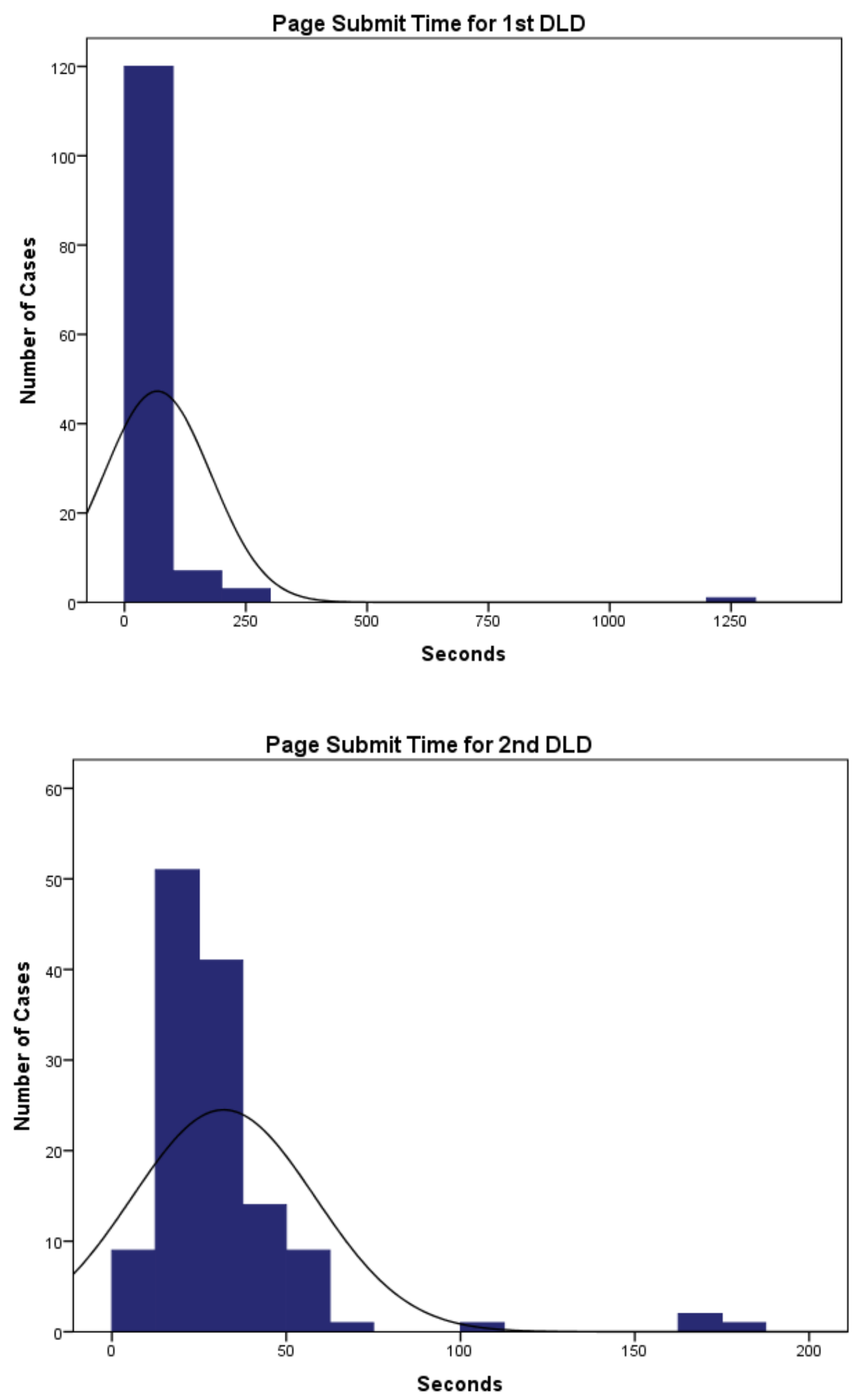

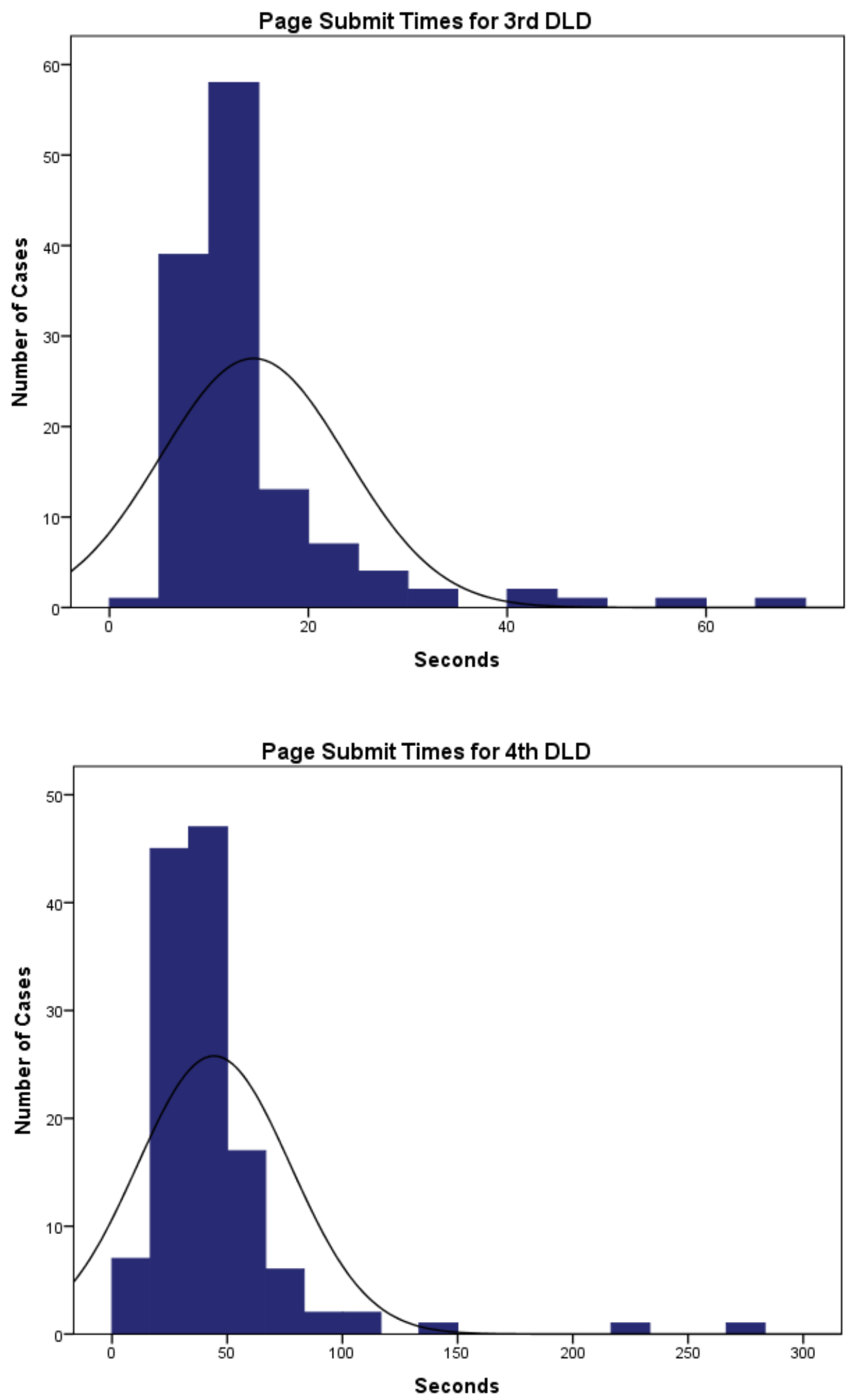

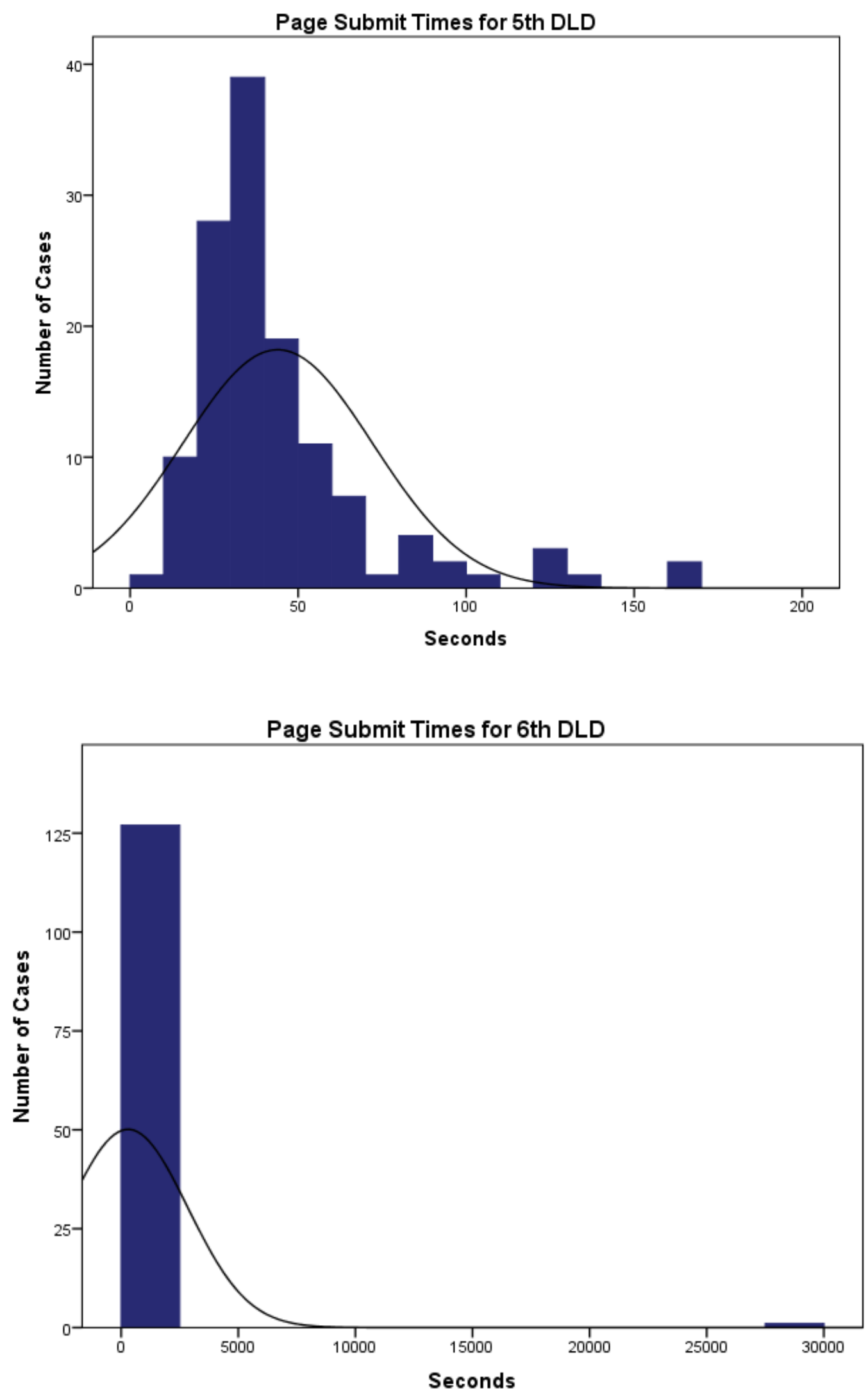
Page Submit Times for 7 th DLD

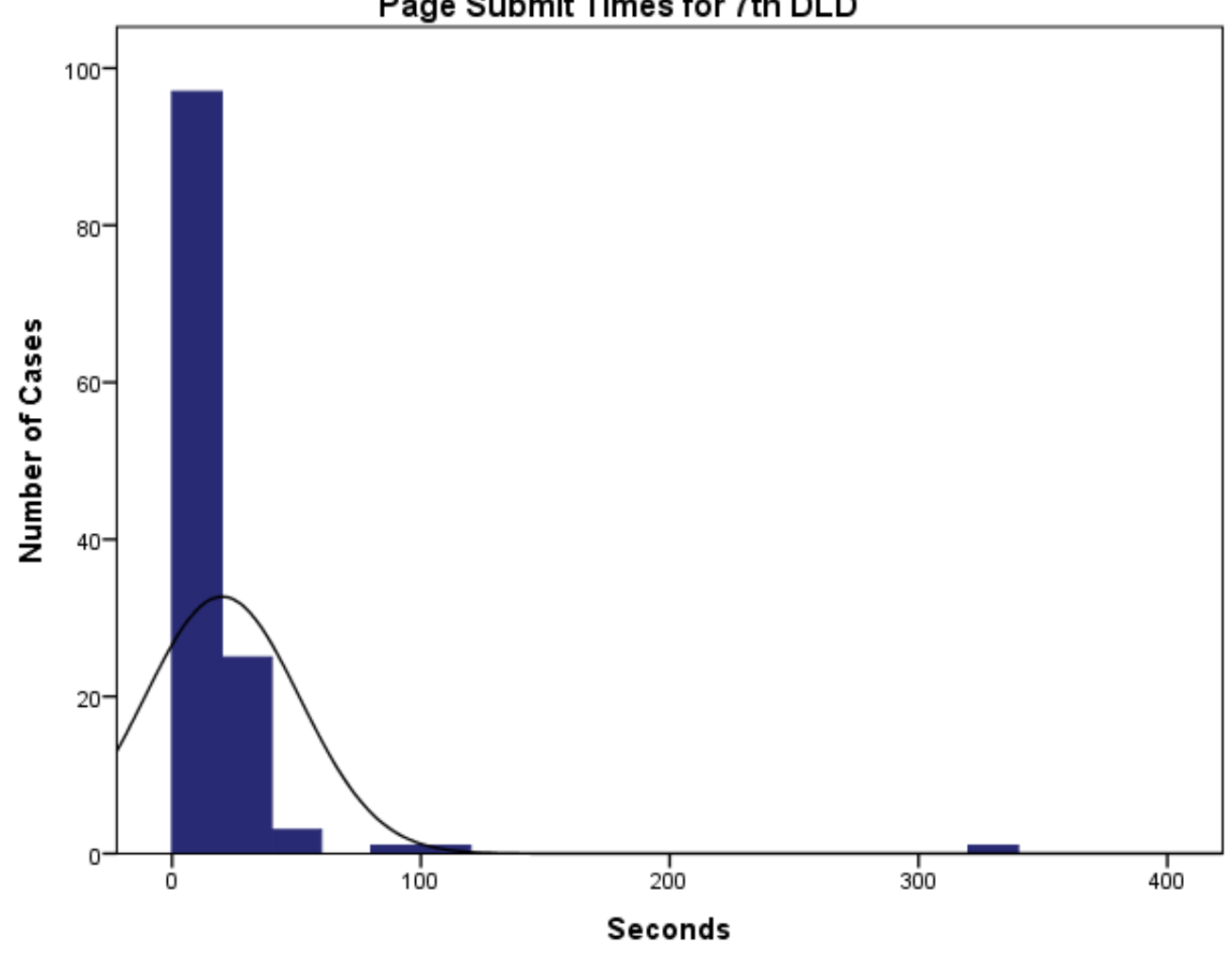


Box plots for page submission times in seconds for 7 DLDs. The most extreme value on the high end for the first, sixth, and seventh DLD were eliminated to produce a clearer presentation of results on low end.

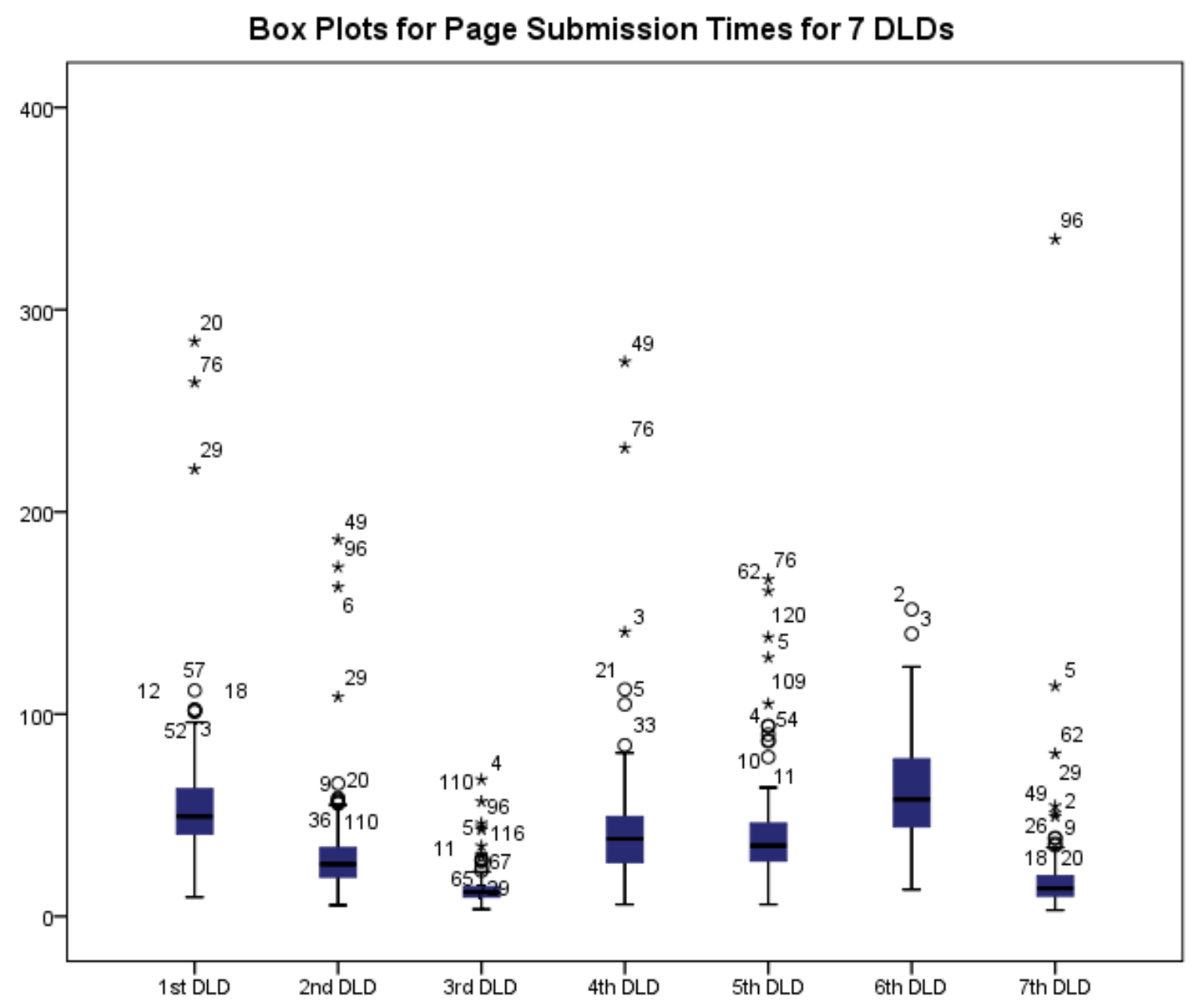


APPENDIX L 


\section{Boxplots of all Performance Statements for each DLD}

Within the boxplots displayed here, a heavily weighted black cross bar identifies the median, a blue area identifies the interquartile range, and small circles and asterisks identify outliers and extreme values respectively with corresponding case numbers. Each boxplot represents student responses to rating scale (1-5) for each performance statement within each DLD.

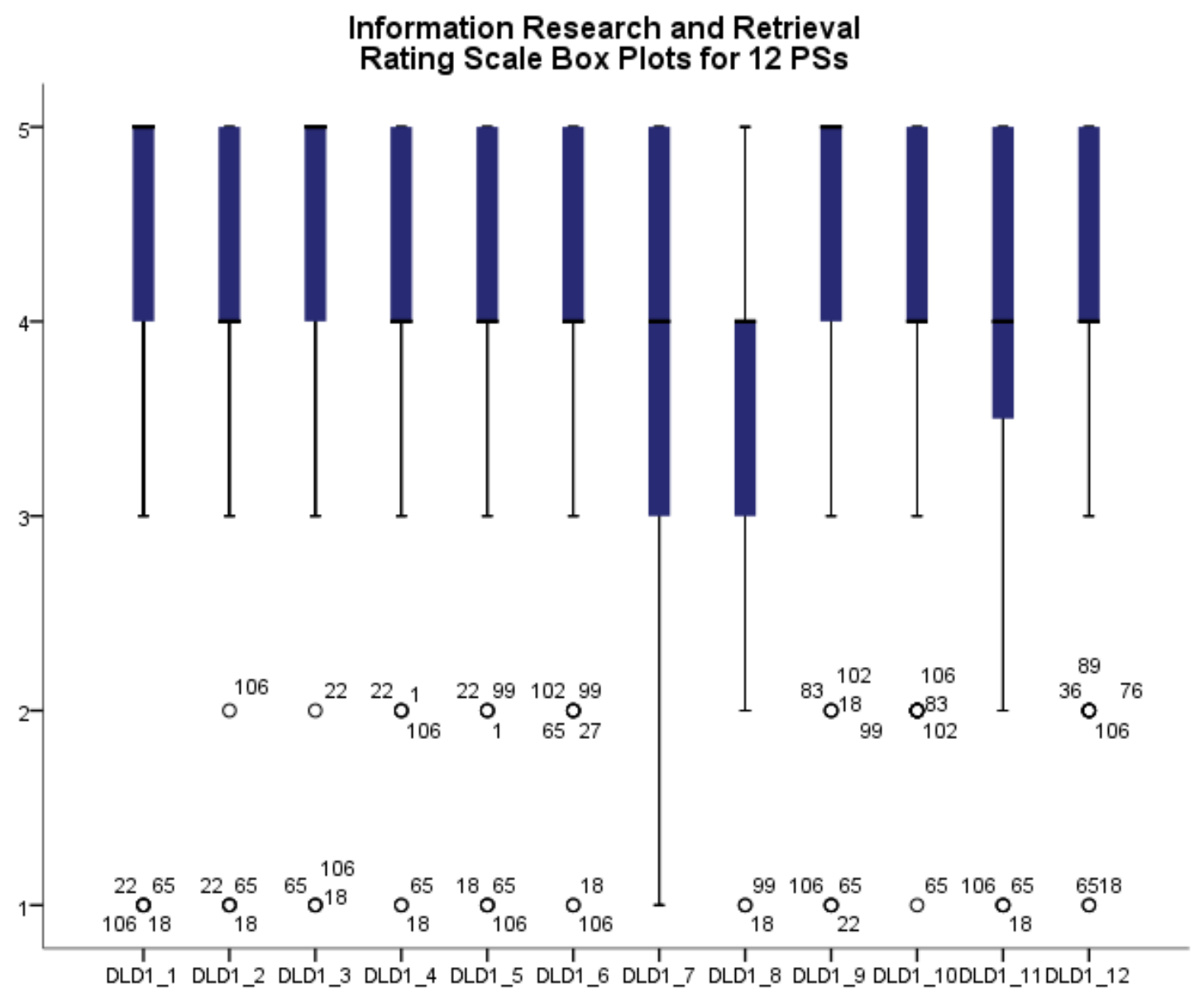


Information Validation

Rating Scale Box Plots for 5 PSs

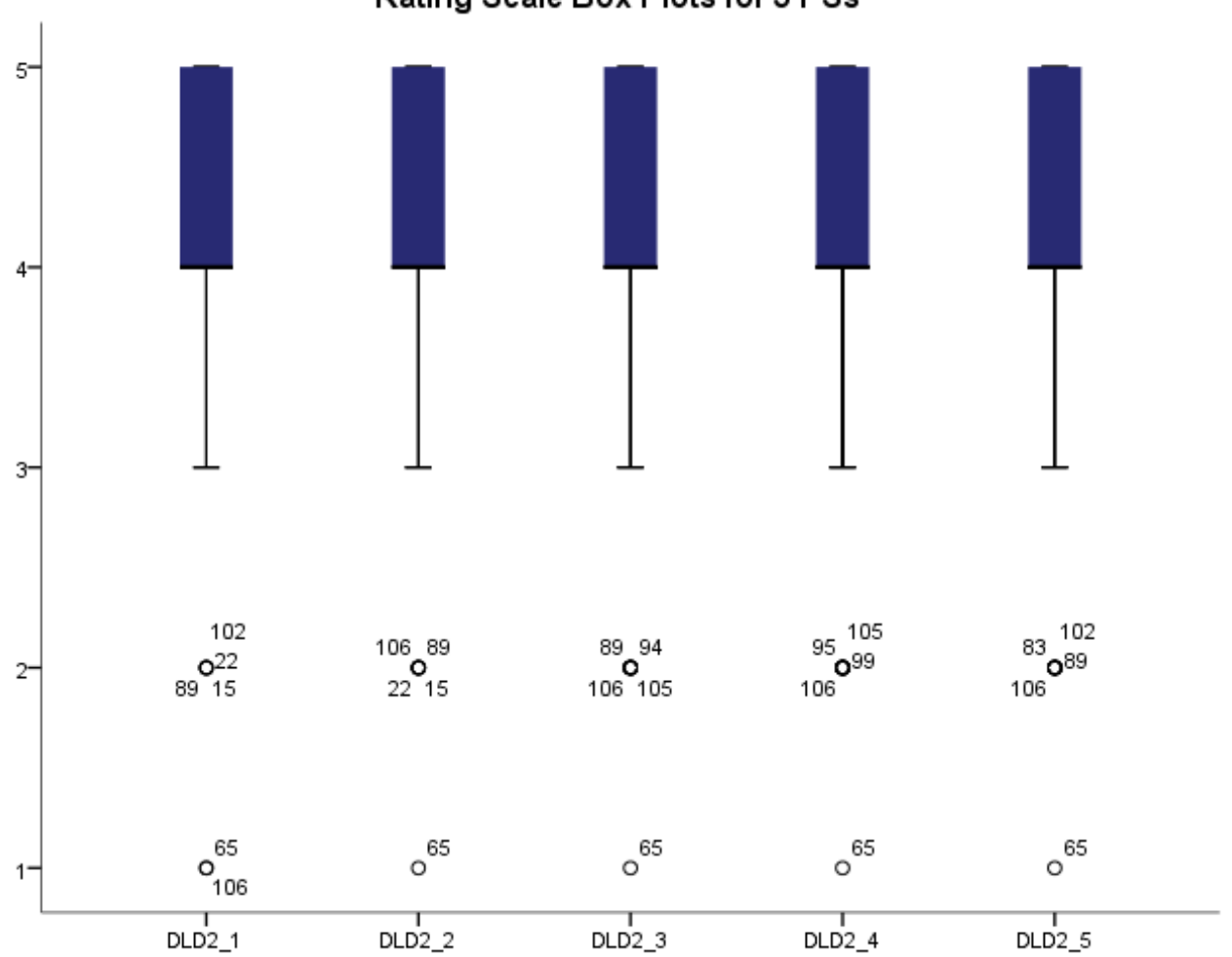

Information Management

Rating Scale Box Plots for 3 PSs

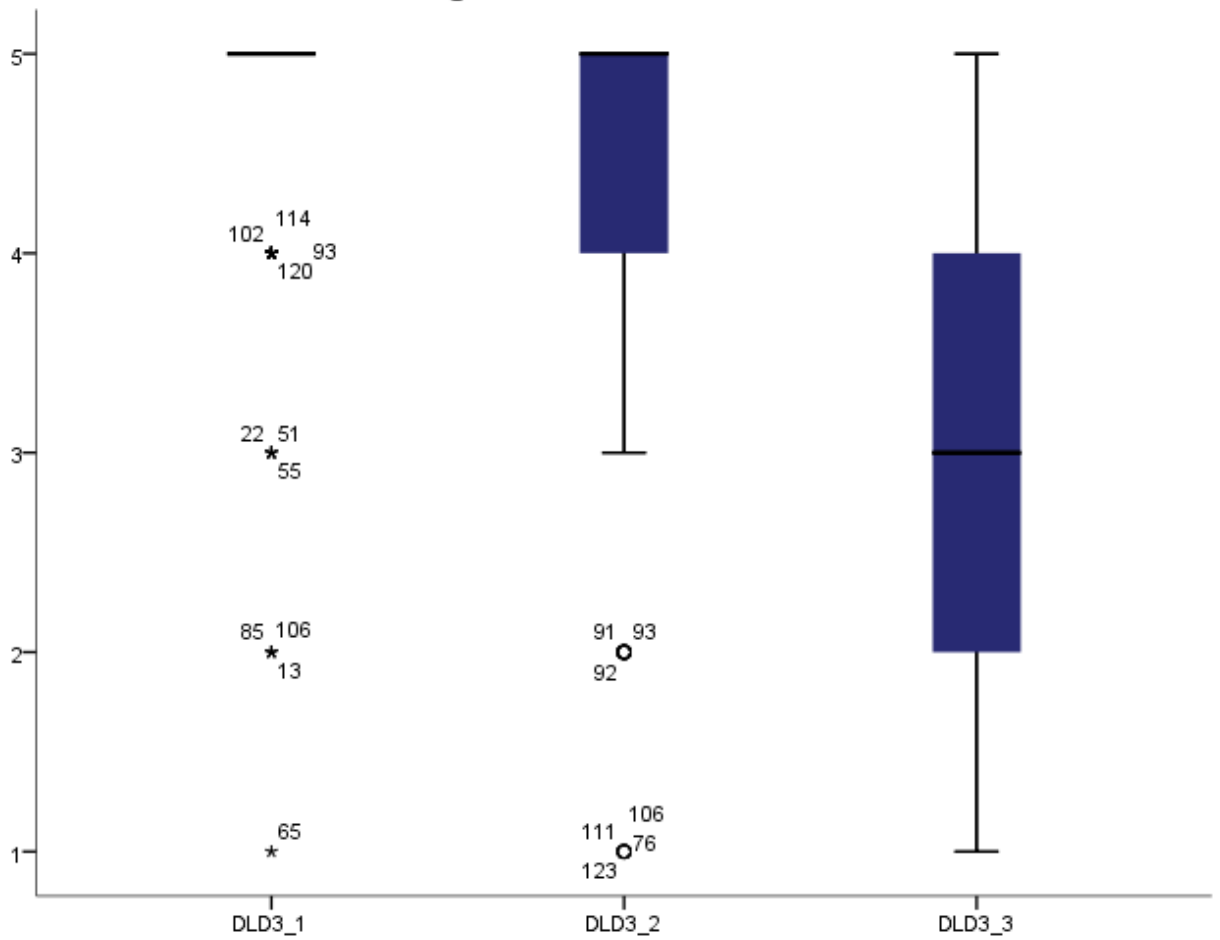


Processing and Presentation of Information Rating Scale Box Plots for 8 PSs

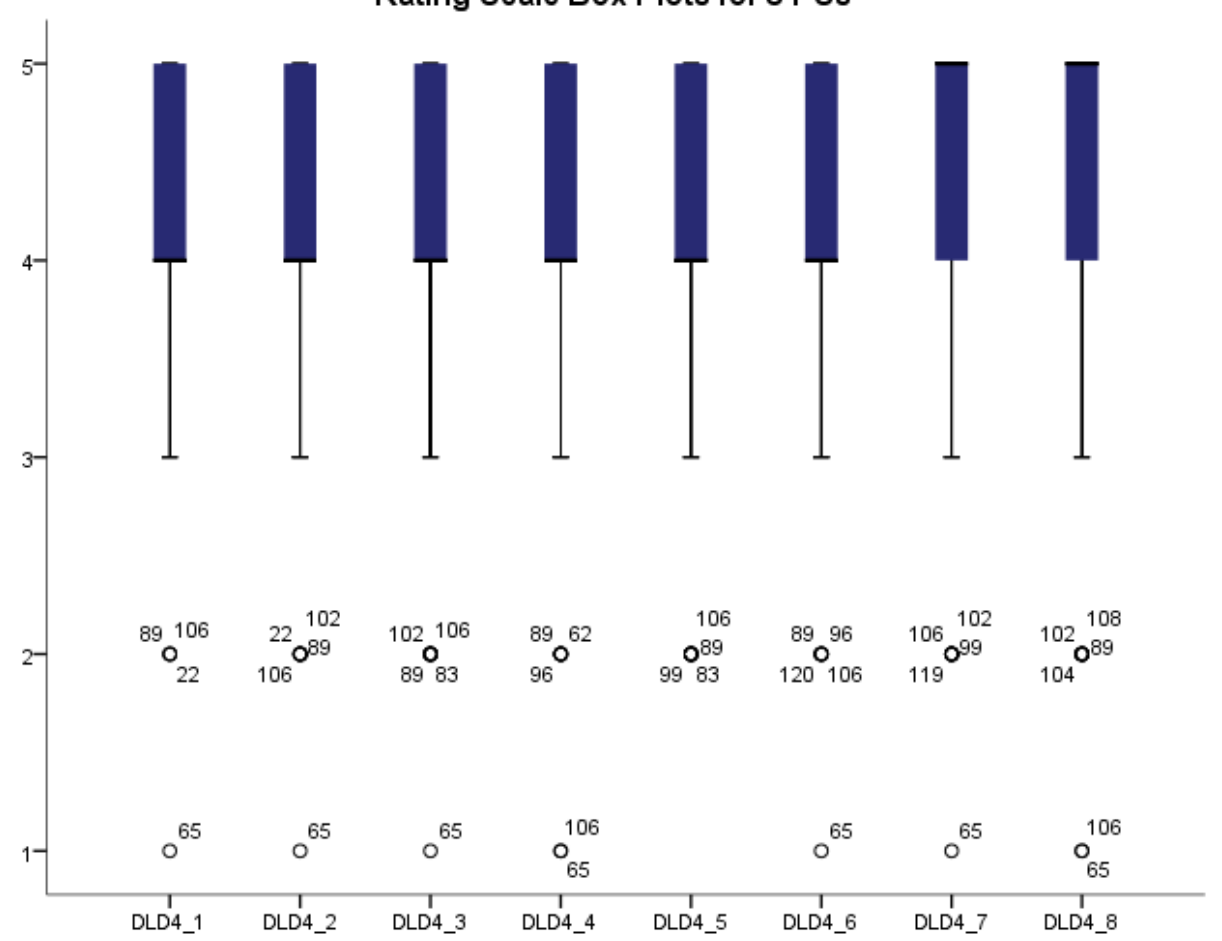

Team-based Learning in Digital Environments Rating Scale Box Plots for 8 PSs

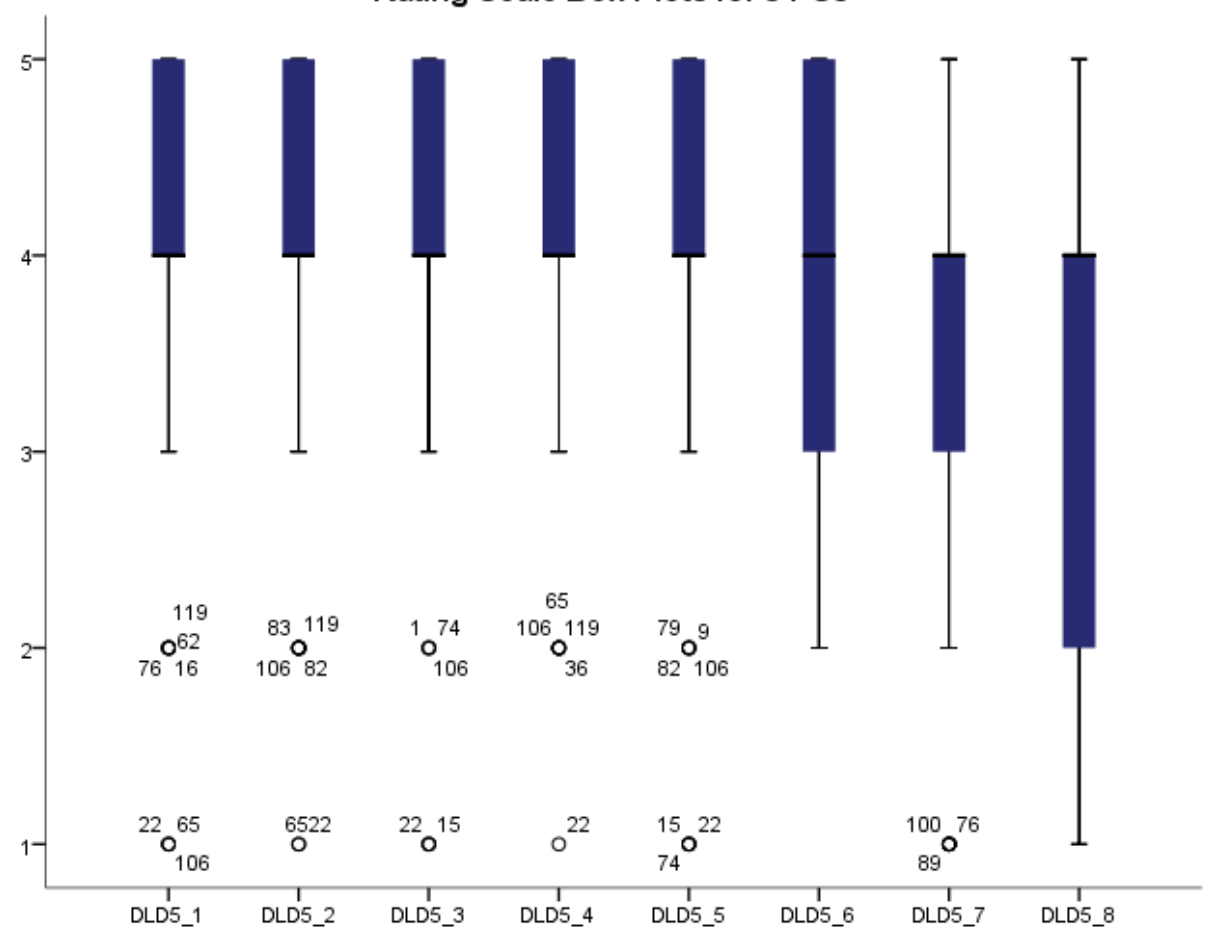




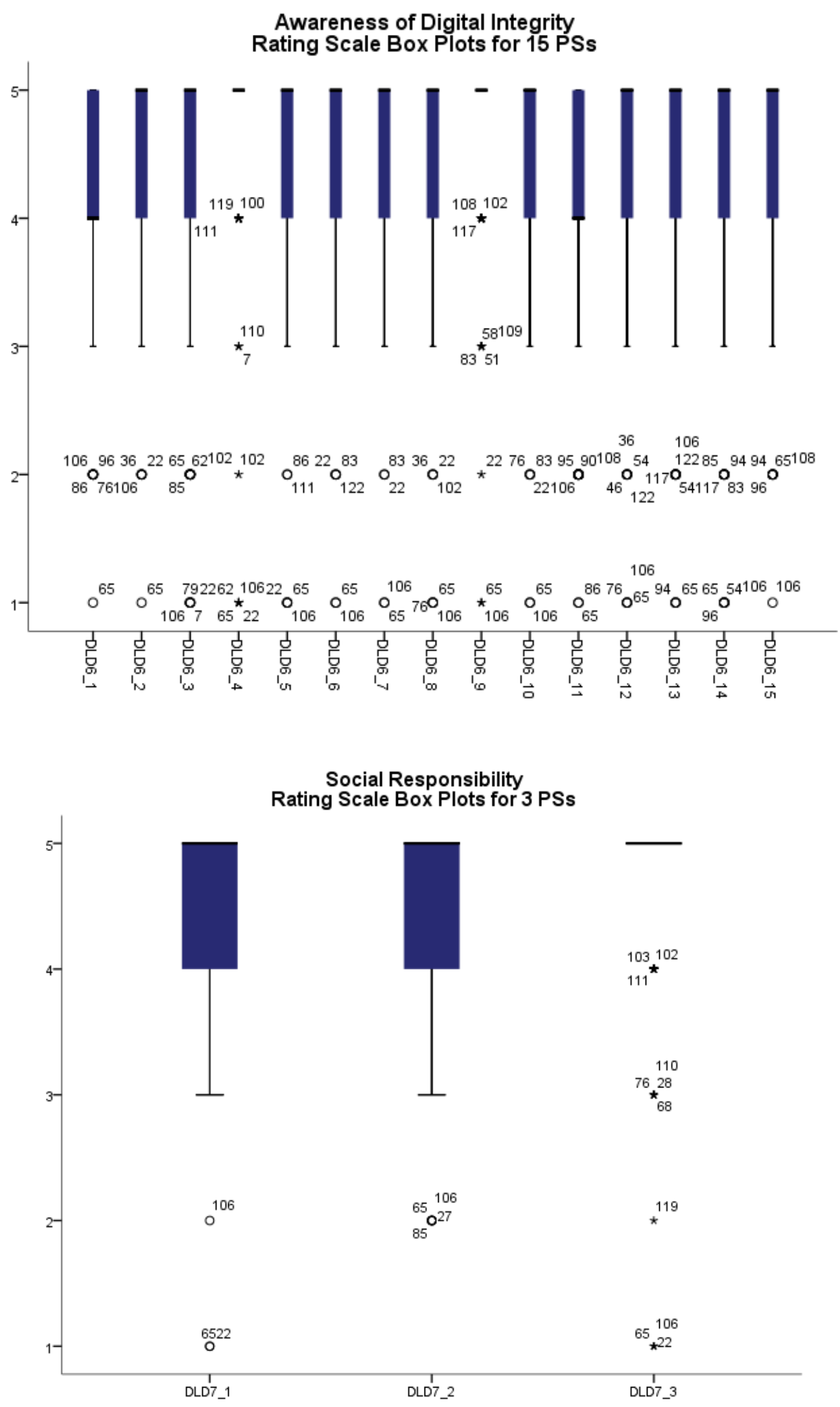

